This report has been reproduced directly from the best available copy.

Available to DOE and DOE contractors from the Office of Scientific and Technical Information, P.O. Box 62, Oak Ridge, TN 37831; prices available from (615) 576-8401, FTS $\$ 26-8401$.

Available to the public from the National Technical Information Service, U.S. Department of Commerce, 5285 Port Royal Rd., Springfield, VA 22161. 
DOE/EH--0104

DE91 006756

TECHNICAL SAFETY APPRAISAL

BROOKHAVEN NATIONAL LABORATORY

PREPARED UNDER

THE DIRECTION OF

REVIEWED BY

APPROVED BY

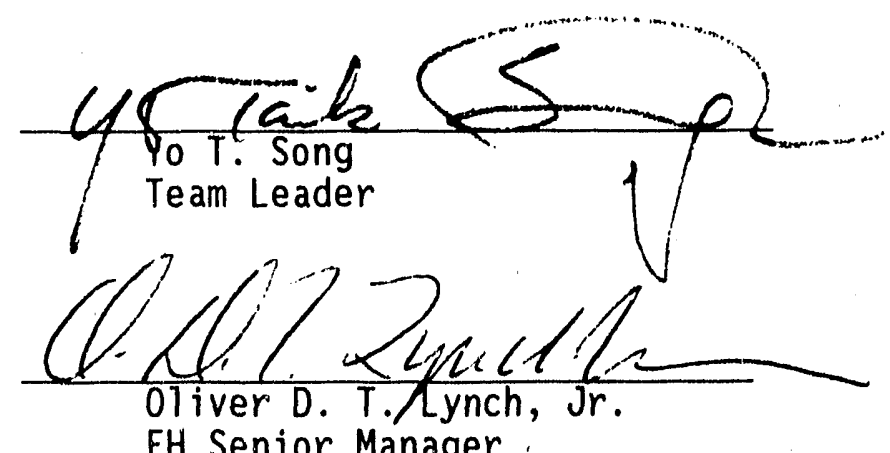

EH Senior Manager.

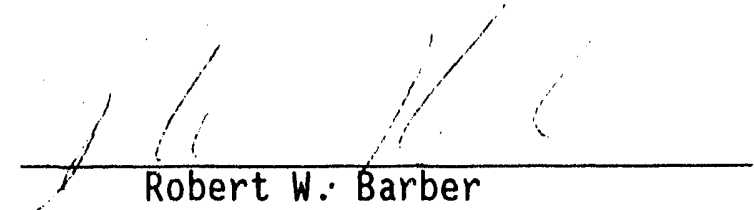

Acting Deputy Assistant Secretary Safety and Quality Assurance 


\section{U.S. Department of Energy Environment, Safety, and Health Washington, D.C. 20585}

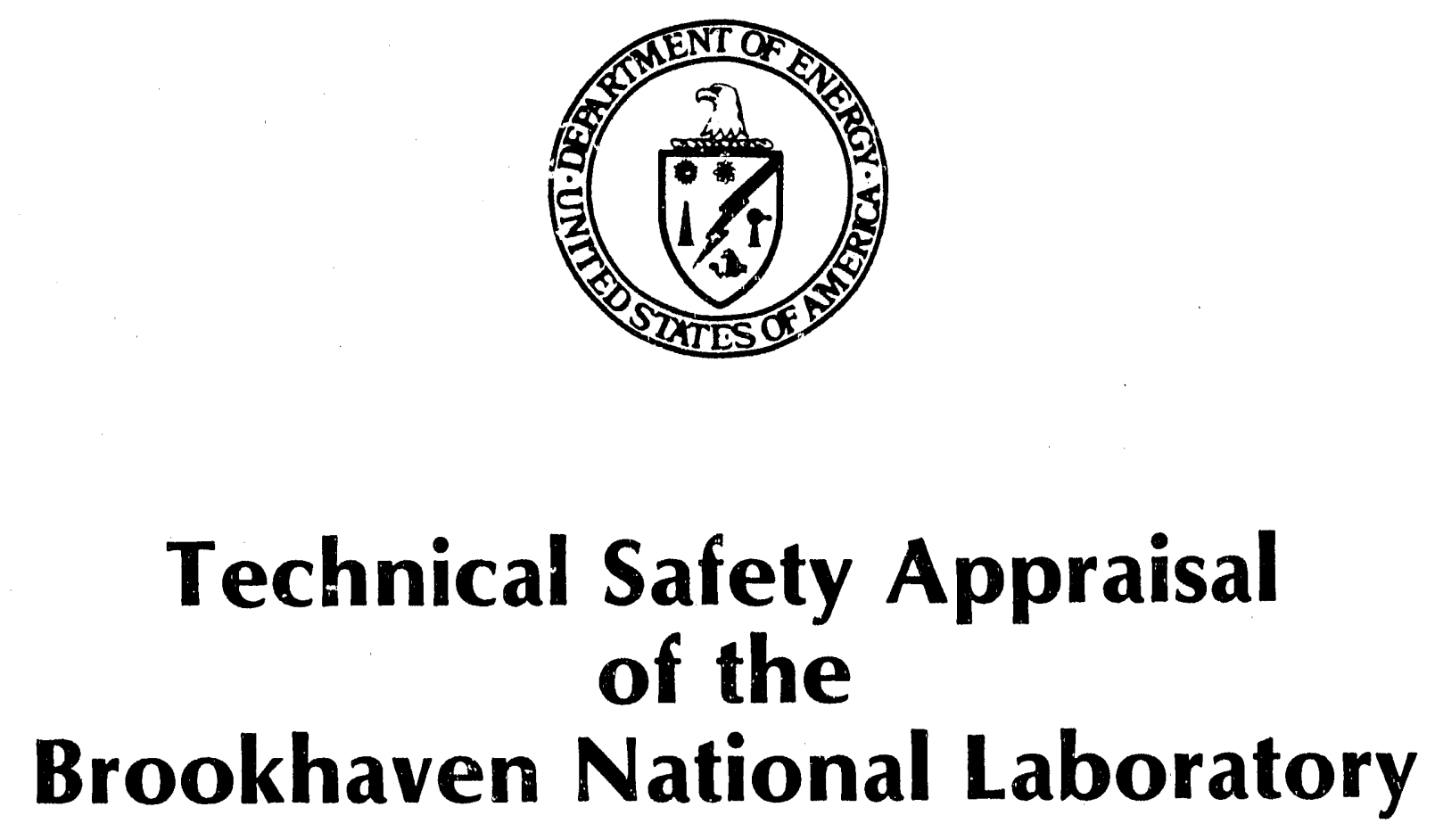

December 1990

\section{MASTER}




\section{TABLE OF CONTENTS}

I. INTRODUCTION............................ I I

II. PERFORIMANCE EVALUATION.................... II-I

III. FINDINGS AND CONCERNS $\ldots \ldots \ldots \ldots \ldots \ldots \ldots \ldots$ III -1
A. Organization and Administration............ III-2
B. Quality Verification................... III-1l
C. $\quad$ perations ............................ III -24
D. Maintenance......................... III -30
E. Training and Certification............... III -35
F. Auxiliary Systems..................... III -4 I
G. Emergency Preparedness................. III -43
H. Technical Support.................... III -47
I. Nuclear Criticality Safety............... III -53
J. Experimental Activities................. III -56
K. Site/Facility Safety Review.............. III -60
L. Radiological Protection................. III -63
M. Industrial Hygiene..................... III -70
N. Occupational Safety....................... II -74
0 . Fire Protection....................... III -77
P. Medical Services........................ III-92

IV. NOTEWORTHY PRACTICES $\ldots \ldots \ldots \ldots \ldots \ldots \ldots \ldots \ldots$ IV -1

APPENDIX A: System for Categorizing Concerns.......... A-1

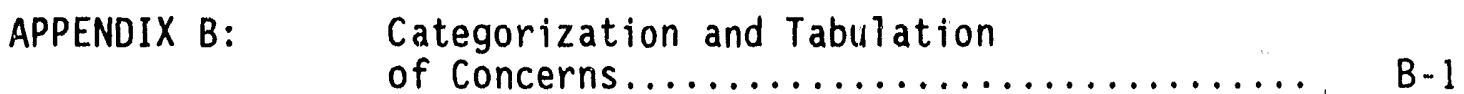

B-1: Categorization of Concerns.......... B-1-1

B-2: Tabulation of Concerns............. B-2-1

APPENDIX C: $\quad$ Team Composition and Areas of

Responsibility...................... C -1

APPENDIX D: Biographical Sketches of

Team Members.......................... D 1 


\section{ACRONYMS}

The following acronums are used throughout this report.

$\begin{array}{ll}\text { AGS } & \text { Alternating Gradient Synchrotron } \\ \text { ALARA } & \text { As Low As Reasonably Achievable } \\ \text { ANSI } & \text { American National Standards Institute } \\ \text { ATF } & \text { Accelerator Test Facility } \\ \text { BHO } & \text { Brookhaven Area Office (DOE) } \\ \text { BMRR } & \text { Brookhaven Medical Research Reactor (Also Known as MRR) } \\ \text { BNL } & \text { Brookhaven National Laboratory } \\ \text { CH } & \text { Chicago Operations Office (DOE) } \\ \text { DOE } & \text { Department of Energy } \\ \text { DQAR } & \text { Designated Qual ity Assurance Representative } \\ \text { EOF } & \text { Emergency Operations Facility } \\ \text { HFBR } & \text { High Flux Beam Reactor } \\ \text { HQDOE } & \text { Headquarters, Department of Energy } \\ \text { LINAC } & \text { Linear Accelerator (Bldg. 930) } \\ \text { MRTE } & \text { Measuring and Testing Equipment } \\ \text { NCR } & \text { Nonconformance Report } \\ \text { NSLS } & \text { National Synchrotron Light Source } \\ \text { OMC } & \text { Occupatiorial Medical Clinic } \\ \text { OSHA } & \text { Occupational Safety and Healin Administration/Act } \\ \text { OSR } & \text { Operational Safety Requirement } \\ \text { ORR } & \text { Occupancy Readiness Reviews } \\ \text { S\&EP } & \text { Safety and Environmental Protection } \\ \text { SAR } & \text { Safety Analysis Report } \\ \text { SARA } & \text { Superfund Amendments and Reauthorization Act } \\ \text { SOP } & \text { Standard Operating Procedure } \\ \text { TSA } & \text { Technical Safety Appraisal } \\ \text { TTA } & \text { Tiger Team Assessment } \\ \text { UOR } & \text { Unusual Occurrence Report }\end{array}$




\section{INTRODUCTION}

The purpose of the Technical Safety Appraisal was to assess the effectiveness of representative safety and health programs at the BNL through the evaluation of activities at selected facilities and in selected safety disciplines.

The TSA was conducted in accordance with established procedures. The following BNL safety and health program elements were reviewed as a part of this TSA: Organization and Administration, Operations, Maintenance, Training and Certification, Nuclear Criticality Safety, Auxiliary Systems, Technical Support, Site/Facility Safety Review, Emergency Preparedness, Radiological Protection, Industrial Hygiene, Occupational Safety, Fire Protection, Quality Verification, and Medical Services.

The TSA was conducted from March 26 - April 12, 1990. The evaluation was conducted by a team of experts assemblind by EH, Office of Safety Appraisals (OSA). Team members consisted of HQDOE staff, employees of DOE contractors, and outside consultants. The team was led by a Team Leader from the OSA. Guidarice and direction were provided by an EH Senior Safety Manager. Biographical sketches of each team member and their areas of responsibilities are provided in Appendices $C$ and $D$.

TSAs are operationally focused. As such, in terms of safety, health, and quality verification, tre site and selected facilities were appraised relative to operations, and the condition of equipment and facilities. This approach is based upon the assumption that the facility and its equipment have been appropriately designed, constructed, and tested, and that safety reviews or the SARs adequately evaluate the risks presented by the operation of the facility. The evaluation thus addresses whether current operations are being conducted within the operational safety procedures established for specific facilities and activities.

The BNL is a multiprogram laboratory operated by the Associated Universities, Inc., (AUI) for DOE. The missions of BNL include research in high-energy physics, nuclear physics, 1 ife sciences, nuclear medicine, materials sciences, and chemical sciences. Management of the Laboratory operations is assigned to the Brookhaven Area Office (BHO) under the Chicago Operations Office (CH). The three responsible Headquarters (HQDOE) offices include Energy Research (ER), Nuclear Energy (NE), and Environmental Restoration and Waste Management (EM).

The BNL is in the process of improving its ES\&H programs. Commitment has been clearly stated by senior management. Progress has been made as the Laboratory prepared for this assessment. However, progress is limited by an insufficient number of staff and a lack of needed expertise and rigor. Laboratory management has acknowledged the need for ES\&H expertise, both in terms of technical knowledge and regulatory requirements, and is moving ahead to obtain the needed expertise in some of the disciplines.

The Laboratory has clearly demonstrated a long-standing disciplined and technically inquisitive approach to scientific programs, including a system of checks and balances. This approach needs to be applied to the ES\&H programs and facility maintenance. This will greatly improve the Laboratory's ability to 
conduct critical self-assessment, which is a major step in developing a sound ES\&H program. Knowledge and discipline together with the availability of clear checks and balances in the Laboratory organizational structure will go a long way toward fulfilling the Department and Laboratory management's common goal of safe and environmentaliy sound operations while achieving scientific objectives.

The $\mathrm{CH}$ has taken actions to increase staffing at BHO in an effort to fulfill its line management responsibilities. However, oversight of $\mathrm{BNL}$ operations by $\mathrm{BHO}$, $\mathrm{CH}$, and $E R$ is not adequate. This inadequacy is due to a 1 ack of resources and the fractionated assignment of line-management responsibilities for ES\&H versus scientific activities. Lessons can be learned from the oversight concept and process being developed with NE for reactor operations. Also, both short-term and long-term resource requirements to address ES\&H and facility maintenance have to be clearly identified and prioritized so that funding decisions can be made at the appropriate Department management level with an understanding of the resultant benefits. 


\section{PERFORMANCE EVALUATION}

While on the threshold of a modern safety culture in some areas, there remains a deep seated and pervasive attitude at the Brookhaven National Laboratory (BNL) that safety is a necessary evil, that a rigorous approach to safety is incompatible with the research-oriented mission of the Laboratory, that safety compliance should be minimal, that good science equates to satisfactory safety performance, and that BNL's pioneering of many safety disciplines implies an unbroken lead in the community obviating a need for improvement and suppressing any urgency for necessary corrective measures. We recognize a change in attitude will take diligence at all levels, but it must occur expediently.

Laboratory-wide policies and controls were not designed to ensure a uniform and consistent safety program at BNL. Safety is considered a line responsibility at $B N L$, and safety responsibility and authority flow from the Laboratory Director down through Department and Division Heads to the working level. Direction and guidance issued from the Laboratory Director level are general in content and broad in scope, designed to give maximum latitude and responsibility to the Associate Directors and the ir subordinate Department Chairpersons. When this mid-level management passes the general directions on without further amplification or specificity, the result is a deficient safety performance on the part of the Laboratory. The absence of a followup or feedback mechanism to ensure effectiveness of the original instruction further exacerbates the failure of communications.

Strengths were noted in three areas: the Medical Services discipline, where one Noteworthy Practice was identified; the experimental activities which function well at the scientist-to-scientist level, with the actions of liaison scientists and engineers assuring that experiment and personnel relations are smoothly functional; and in the Plant Engineering Division's sitewide maintenance program.

Several improvements have taken place in other areas since the September 1989 comprehensive Technical Safety Appraisal (TSA) of the Laboratory. These improved areas include the packaging and transporting of hazardous materials, an increased emphasis on occupational safety, a decline in occupational accident rates, greater attention to the construction safety program, and a inarked improvement in the safety training program.

One Category II concern was identified during the March/April 1990 TSA addressing substantial noncompliance with DOE Orders on hazard communications to employees. other less immediately serious concerns were identified in the areas of fire protection, formality of operations, quality verification, organization and administration, technical support, and radiation protection. 
Senior management has been involved in some of the site safety activities. This involvement is noted particularly in the annual operating reviews of individual departments. Participation by the Laboratory Director; the Associate Director for Reactor, Safety and Security; and the cognizant Department Associate Director has resulted in establishing some sitewide consistencies. In fact, when a particular aspect of the safety program is approached in a comprehensive sitewide manner, success and consistency usually result. BNL's effective facility safety review system is an example of this approach, where three sitewide safety review committees are working: the Cryogenic Safety Conmittee, the Reactor Safety Committee, and the Laboratory Safety Committee.

High standards of safety are held by some individuals, but are not universally required nor exhibited, nor widely appreciated and practiced among all facility personnel. The Laboratory's personnel injury incidence (possibly because of their reporting criteria) remains the highest among DOE research establishments, although this has been declining since 1988. Competence exists in the staff of essential safety organizations. However, resources are stretched thin, especially in fire protection, where staff and funding constraints appear to account for the majority of fire protection deficiencies identified.

There is little evidence of systematic development of safety policy and procedures. Also, a lack of formality in the management of safety policy in the line organizations, and orderly systems of procedures, controls, and documentation impede its efficient administration. Procedures written and used by operating groups do not undergo formal periodic review, revision, and approval by Safety and Environmental Protection (S\&EP) personnel. In addition, S\&EP does not track for review and revision their own procedures, as required by DOE and good practice. Inadequate documentation poses an unintended, and even unanticipated, threat to safety of workers and experimenters.

Implementation of DOE Orders is inconsistent and sluggish, with major deficiencies noted in OSHA hazard communication requirements (a Category II concern) and compliance with other OSHA standards. After a slow start, the Laboratory is making progress in compliance with DOE 5480.11 training, but the external radiation dosimetry program is still not accredited through the DOE Laboratory Accreditation Program. Internal audits of the dosimetry program are lacking.

Maintenance perforined by the Plant Engineering Division is an exception to the overall lack of adequate procedures and disciplined approach to safeiy problems: activities are conducted in a safe and efficient manner, established policies are followed and consistently applied, and the Laboratory-wide computerized Job Control Accounting and Recording System will not accept a work order without properly completed health and safety data. 
Controls to verify compliance with safety procedures and requirements are not applied by either the Laboratory or BHO. Implementation of QA programs, which have been evolving since early 1985, is spotty. On the other hand the struggling QA Office is doing a creditable job of providing assistance and guidance to the BNL organizations, and is conducting independent audits, but its time and staffing resources are insufficient to provide the increased coverage needed Laboratory-wide.

A significant radiological contamination incident related to the HFBR occurred during the TSA. The ongoing investigation had not been completed prior to the end of the appraisal; however, our observations indicate BNL and CH response is appropriate.

Overall performance and documentation of technical support activities at BNL are performed in a thorough manner only at the reactor areas. Other areas exhibited inconsistencies in preparation of timely SARs, which are often completed after the fact, opening up the possibility for excessive construction costs and undesirable compromises of safety protection in the facilities. For the most part, nonreactor areas did not employ Operational Safety Requirements and did not adequately identify, document, test, and maintain safety systems and safety equipment. Also, an envelope of parameters in which experiments or classes of experiments can be safely operated has not been developed.

While BNL recognizes that it has not adequately addressed the release or handling of nonradioactive toxic materials and specific emergency scenarios in their respective facility SARs and emergency preparedness, it has not taken positive steps to address this. Likewise, required training for emergency management response personnel is not in place.

The dedicated and highly competent staff at BNL is capable of substantially improving overall safety performance. This improvement can be realized by full acceptance of safety as an equal. partner with the research mission, a sitewide approach to safety policy, procedures and training, and a positive attitude toward compliance with Federal regulations and DOE Orders. Improvement can be demonstrated through better workplace practices and documentation. 


\section{FINDINGS AND CONCERNS}

The Team activities were guided by the performance objectives and supporting criteria contained in the "Performance Objective and Criteria for Technical Safety Appraisals at Department of Energy Facilities and Sites," February 1990. The findings identified were obtained in three ways: (1) observing routine operations, and the physical condition of the site and facilities; (2) interviewing management, staff, operators, and craft personnel; and (3) reviewing policy statements, records, procedures, and other relevant documents. A concern addresses a situation that in the judgment of the Team: (1) reflected iess than full compliance with a DOE safety and health requirement or mandatory safety standard, (2) threatened to compromise safe operation, or (3) if properly addressed would substantially enhance the excellence of that particular situation even though that part of the operation was judged to have a currently acceptable margin of safety. Because of this last category for addressing the excellence of the operation, more concerns are reported than would result from a strictly compliance-oriented appraisal.

As a result of the individual findings, 69 concerns are identified in this section of the report. The findings that support each concern are listed immediately in the front of the concern. All of the concerns were judged to be Category III, except IH.6-2, which was judged to be Category II. The category rating, potential hazard, and level of noncompliance for each concern were determined by using criteria contained in Appendices A and B.

Drawing upon the extensive experience of its members, the TSA team has made an effort to identify some of the responsible factors in each statement of concern. However, they recognize that this effort is at best imperfect due to the team's relative unfamiliarity with the details of the contractors' overall operations. Therefore, the team believes that the contractors should consider the findings, and even the statements of concern, as possibly symptomatic of some set of deeper root causes and should search out and correct those root causes so that there will be reasonable assurance that improvements in the safety of the operation will be sustained.

This is the second sitewide TSA to be performed at the BNL, the first was conducted in September 1989. Because of the proximity to the first TSA, and because response to both TSAs will be through a single action plan responsive to the Tiger Team report, this second TSA is additive to the previous, and these remarks are cumulative, reflec:ing both new concerns, which have been numbered consecutively to the September 1989 effort, confirmation of the previous findings, and improvements. 


\section{A. ORGANIZATION AND ADMINISTRATION}

The review of BNL was accomplished by interviews with Associate Laboratory Directors, Department Chairpersons, Safety Coordinators, Safety Officers, and Division Heads. An extensive array of documentation was reviewed and evaluated.

The organizational structure of BNL most closely resembles that of a large research university. With this concept in mind, the direction and guidance that are issued from the Laboratory Director level are general in content and broad in scope. Laboratory-wide policies and controls are not designed to ensure a uniform and consistent safety program within the Laboratory. They are designed to give maximum latitude and responsibility to the Associate Directors, who, in turn, confer the responsibility of specificity upon the Department Chairpersons. The result is that responsibility for safety policy implementation and operation resides in the Office of each of the Department Chairpersons.

The ability of Department Chairpersons and their support staff directly determine the effectiveness of both formulation and communication of safety policies to their staff. Likewise, the effectiveness of the implementation of the safety policy and procedures rests directly on the Departmental Chairpersons.

To produce a desirable result, this type of approach to the concept of linemanagement responsibility requires a strong, independent oversight and audit function that reports to the highest levels of management and has the ability to commission outside reports on everything from facility management to economic feasibility of forms of advanced research. The Team found S\&EP functions 1 imited both by staffing, by the concept of their being required to provide service to the programmatic staff, and by the potential conflict of interest for independent safety assessments.

Further, the type of line-management approach to safety employed by BNL requires that Associate Directors be aware not only of new programs that must be funded, staffed, and supported, but that they recognize and accept responsibility for funding, staffing, and supporting the type of "housekeeping" that goes with running major experimental programs or facilities. This commitment to operations as well as to new programs become more critical as the number of experimenters or the number of auxiliary programs increases.

The Team found little evidence of systematic development of safety policy and procedures, which should include complete paper trails from the Associate Director level of any given line of management at the Laboratory to the technician or operator who ultimately reports to him. Further, the Team found a lack of formality in the management and administra:ion of safety policy in the line organizations. Failure to use orderly systems of procedures, controls, and documentation can pose an unintended, and even unanticipated, threat to safety of workers and experimenters.

The S\&EP attempts to provide what amounts to a safety and health service by stationing Safety Represeritatives at the major facilities and departments. While these programs appear to work well on a routine basis, the effectiveness of this approach has the potential of being limited since the programmatic office has the responsibility for the facility or site at which the activity takes place. In 
fact, both the authority and responsibility are inaccurately attributed to the S\&EP Division by personnel of other organizational entities.

Some line management from the Associate Director level down through the Department Chairpersons have failed to provide the charter and definitive direction for safety review committees, allowing these to be set up on an ad hoc basis. Although the committee activities considered by the Team provided general ?y appropriate reviews, the prol f feration of unchartered review committees tends to spread the responsibility to the degree that no one is acccuntable.

A similar effect of the reliance on maximum management flexibility/minimal guidance from the highest leveis of management is the spotty implementation of writing of mission and function statements, the writing of definitive job descriptions for all personnel who have safety responsibilities and authorities, and the establishment of measurable safet; goals and objectives at all levels of responsibility.

The Team found that control systems for technical support and administrative information varied greatly in their implementation. For example, some department and division QA manuals that should be signed and dated are not, and there is no assurance that outdated versions of revisions are returned to document control personnel. This causes documents, which should be meintained in a current status, to be outdated, or causes numerous different versions of the same "controlled" document to be in existence.

The Team, likewise, is concerned that under certain conditions there could be a conflict of interest among thuse who have independent safety review responsibility. More importantly, the Team is concerned that areas of safety review do not report high enough in the BNL management structure to keep upper management sufficiently informed with respect to safety activities. At a lower level, it appears that when chairpersons and members of experiment review committees consider their own experiments, they do not disqualify themselves from active participation in the re"iew. 


\section{OA.1 SITE/FACILITY ORGANIZATION}

PERFORMANCE OBJECTIVE: Management should organize and manage the site/facility's work, programs, and resources so that safety and health are an integral part of the personnel duties, and requirements are consistently implemented.

FINDINGS: - Many first-7ine supervisors and workers expressed a belief that the Safety Coordinator or the S\&EP Representative was responsible for employee safety.

- Many employees interviewed indicated that if they had a safety problem they would involve the S\&EP Representative or the Safety Coordinator before their own supervisor.

- The AGS operators on shift work reported to one supervisor for programnatic direction and to another one for line safety direction.

- The investigation committee that revieweu the radiation incident of December 18,1989, in the Accelerator Test Facility (ATF), B1dg. 820, concluded that a contributing tactor to the incident was unclear organizational lines of responsibility.

- The investigation report stated:

- "From the very first draft of the SAR, the safety responsibility was assigned through the NSLS Department." However, "Comments on the drafts went so far as to suggest a letter of agreement about the responsibilities for safety between the NSLS Chairman, the Assistant Director for Safety, and the other senior management parties whomever they are."

- $\quad$ "After the incident, the NSLS Dept. Chairman questioned whether he was the most appropriate person to sign the (Unusual Occurrence Report) UOR."

- The investigation committee report also stated: "These evening shifts consisted of personne? from several departments (Physics, Instrumentation, Light Source), with no lead person assigned."

- The investigation report further stated: "The investigation committee doesn't yet understand the organizational lines of the ATF."

CONCERN: Line safety responsibility was not clearly

(OA.1-2) understood and practiced at Brookhaven

(H2/C2) National Laboratory. (Also see Concerns OA.1-1, Appendix B; OP.1-1, AppendiX B; and OP.1-3.) 
FINDINGS: - Employees and first-line supervisors interviewed indicated that the holding of safety meetings varied from one per week in some groups to nonexistent in others.

- The quality of safety meetings voried; some were well planned with preselected safety topics and others were primarily program oriented meetings in which safety was an occasional topic.

- Workers and first-line supervisors interviewed were not aware of their department and division safety goals. (See Concerns OA.3-1, Apprndix B; OA.3-2, Appendix B; and OP.1-2, Appendix B.)

- Those interviewed indicated that the policy on attending safety meetings varied from mandatory attendance to just encouraged to attend.

CONCERN: Safety meetings are not regularly scheduled and do not fully

(OA.1-3)

$(\mathrm{H} 2 / \mathrm{C} 2)$ promote safety at Brookhaven National Laboratory. 


\section{OA.2 ADMINISTRATION}

PERFORMANCE OBJECTIVE: Administrative programs and controls should be in place to ensure policies concerning health and safety are administered through out the facility.

FINDINGS: - Many management elements that pertain to safety-related items were informally delegated by the Laboratory Director to department and division level managers, and sometimes further delegated to even lower levels of management.

- Management was using memoranda extensively to provide safety policy directives and guidance. Some organizations had compiled in excess of 175 memoranda in the past 15 months. Over 275 memoranda were considered as active instructions.

- No Laboratory-wide document contained all current BNL safety policy statements and safety directives. However, BNL was planning to issue a Laboratory and Department/Division Safety Administrative Procedural Guide. This guide will be issued over a period of time, with the binder and first entries targeted for release in May 1990 .

- The physical disposition of the policy directives and guidance memoranda mentioned above varied from retention of all memoranda to "read and dispose."

- No Laboratory-wide policies set requirements for:

- chartering and formulating department and division safety review committees;

- establishing and promulgating safety goals and objectives;

- writing mission and function statements for the various suborganizational elements of the Laboratory;

- writing job descriptions which include safety responsibilities and authorities;

- controlling important safety documents that are necessary for the safe operation of the Laboratory; and,

conducting regularly scheduled safety meetings to stimulate employees to perform their jobs safely and to strive to meet established safety goals.

CONCERN: Laboratory-wide administrative policies and controls do not ensure $(0 A .2-2)$ that all elements of an effective safety program exist within

(H2/C2) each department and division. (Also see Concern OA.2-1, Appendix B.) 
FINDINGS: - The Associate Director for Reactor, Safety and Security had a potential conflict of interest in that he had: (1) the responsibility for independent safety overview (provided by the S\&EP Division), (2) the line safety responsibility for the Reactor Div: iion, and (3) the three standing, independent laboratory safety committees reporting to him.

- The S\&EP Division also had a potential conflict of interest in its three-fold responsibility for:

- providing line safety responsibility for hazardous waste management;

- providing advice, guidance, and assistance on safety matters to other departments and divisions; and,

- providing independent safety overview of the hazardous waste management area, as well as those departments and divisions for which it provides advice and assistance.

- Some former BNL employees have been used as consultants to provide independent safety review on programs that they helped develop and implement.

- When the chairperson or members of some experiment safety review committees were respensible for an experiment that was being reviewed by their own committee, they did not always disqualify themselves from participating on the review committee.

CONCERN: A potential conflict of interest exists among those who have both (OA. 2-3) independent safety review responsibilities and line safety $(\mathrm{H} 2 / \mathrm{C2})$ responsibility or past safety responsibility for the program. 


\section{OA.3 MANAGEMENT OBJECTIVES}

PERFORMANCE OBJECTIVE: Site/facility management objectives should ensure commitment to safe operation, including enforcement of approved work practices and procedures.

FINDINGS: - The DOE TSA Team that visited BNL in September 1989 noted the following regarding the formulation and implementation of goals:

- $\quad$ The BNL environment, safety, and health goals are neither definitive nor measurable and, in many cases, lack specific departmental action plans to accomplish the Laboratory-wide goals, as well as the specific departmental goals. Safety goals were also not embraced or appreciated by all Laboratory Management." (Also see Concern OA.3-1, Appendix B.)

- Measurable goals and performance indicators are not used at many facilities to effectively improve performance and safe operation." (Also see Concern OP.1-2, Appendix B.)

- Workers and first-line supervisors interviewed were not aware of their department and division safety goals or objectives. Most of those interviewed thought that the current safety goals were one or more of the following:

- clean up their work space;

- perform their work safely;

- increase safety awareness; or,

- eliminate or reduce potential hazards.

CONCERN: Measurable and definitive goals are not being developed and $(0 A .3-2) \quad$ promulgated to all laboratory employees.

$(\mathrm{H} 2 / \mathrm{C} 2)$ 


\section{OA.7 DOCUMENT CONTROL}

PERFORMANCE OBJECTIVE: Document control systems should provide correct, readily accessible information to support site/facility operations.

FINDINGS: - The Management Information Systems Division QA Manual was not a controlled document. It included pages from other documents that were outdated and the sources of these pages were not noted. Similar problems were also noted in the QA manuals for the Medical Department and Instrumentation Division.

- The BNL Safety Manual was not strictly controlled by copy number, and there was no follow-up system to ensure that copies were kept up-to-date.

- At the Medical Department, the procedures for the radiochemistry production of strontium-90 were neither dated nor signed.

- The Report of the Investigation Committee on Radiation Incident in Building 820 at BNL, December 18,1989 concluded that the following document control issues were contributing factors and recommended that:

"Written and approved (by NSLS and S\&EP) operating procedures which clearly define interim modes of operation should be established by Facility personnel."

- "There should be some formal notification from the Assistant Director for Safety to the organization that the SAR is approved."

- The DOE TSA Team that visited BNL in September 1989 noted that:

- Management is not ensuring control of vital safety documentation and operating logs." (Also see Concern OA.7-1, Appendix B.)

- $\quad$ "BNL, in general, does not have policy and procedures establishing the requirements for facility operations logs, their content, use, and review." (Also see Concern OP.2-1, Appendix B.)

- Indexes of operating procedures, hecklists, drawings, technical manuals and other documents pertinent to the operation of the facilities do not exist or were not available at the facility, and many documents important to the safe operation of the facility were not always available at the faciijty. (Also see Concern OP.3-1, Appendix B.) 
CONCERN: The Brookhaven National Laboratory document control system does not

$(0 A .7-3)$ ensure, as required by ANSI/ASME NQA-1, that QA documents important

$(\mathrm{H} 2 / \mathrm{C2})$ to the safe operation of a facility are available when needed and controlled. 


\section{B. QUALITY VERIFICATION}

The quality verification appraisal activities at BNL were guided by seven performance objectives that focused on the development and implementation of an approved QA program. Interviews were conducted with management and QA personnel, selected documents were reviewed, and a sampling of departments and divisions were visited with selected activities observed. Those Departments and Divisions visited were: AGS, NSLS, Central Shops, BMRR, Instrumentation, Plant Engineering, Medical, Supply \& Materiels, Nuclear Energy, Contracts \& Procurement, Physics and Accelerator Development. Selected activities were observed in the following Bldgs.: $911,928,930,725,462,479,207,208,120$, $535-B, 134-C, 600,610,452,490,801,211,703,130,197-C, 830,938,355,510$, $902-\hat{A}, 935$, and 924 .

The BNL QA program has been an evolving one. A Laboratory QA policy was issued February 1, 1985. This policy, in part, states that each department, division, and project shall establish and implement QA programs that are appropriate to its activities, in terms of providing increased confidence, programmatic satisfaction, and safety. Four years later this policy was reiterated in a memorandum by the Director to $2 ? 7$ employees. Even so, four of 21 BNL organizations had yet to develop an approved QA program. Of the 17 programs in various stages of development or implementation, only the Reactor Division program was considered by BNL to be fully implemented. The Reactor Division was not reviewed during this appraisal. Seven others were actively attempting to formalize their $Q A$ activities. Each department and division had appointed a Designated Quality Assurance Representative (DQAR) to represent the organization in matters pertaining to quality and to serve as the focal point for the QA activities within the organization.

The BNL QA Manager had developed a generic Laboratory QA Manual that serves as an excellent guide in the establishment of $Q A$ programs. The manual includes necessary requirements for QA programs intended to meet NQA-1 standards, and 1 imited requirements for $Q A$ programs intended to satisfy independent scrutiny and verification of research projects. The QA Office was doing a creditable job of providing assistance and guidance to the BNL organizations and conducting independent audits. The training provided by the QA Office had increased the awareness of BNL persorinel of the need for their participation in the QA program. The staffing level of the QA Office and the time allocated by the Department and Division DQARs, however, was insufficient to provide the increased coverage needed Laboratory-wide.

A QA Steering Committee, consisting of 12 members selected from a cross-section of Laboratory management, meets quarterly and makes recommendations to the Associate Director for Management and Physical Plant concerning the development and implementation of formal $Q A$ programs throughout the Laboratory. The $Q A$ Steering Committee functions and lines of communication are not addressed in the BNL QA Manual. The QA Steering Committee had encouraged QA awareness and formalization of $Q A$ activities through recommended initiatives from each of the Laboratory departments and divisions.

The QA program had received additional emphasis in recent years as a result of both internal and external reviews. Current Laboratory action plans address 
those findings. Observations made during this appraisal confirmed that all milestones had not been met. Concerns have been noted for six of the seven appraisal performance objectives. No potential concern is noted for tre performance objective for receiving and pre-installation inspections. The BMRR facility and storage areas were reviewed, and documentation was fou d to be complete and adequate.

Provisions were established for the rontrol of purchased material, equipment, and services. The Division of Contracts and Procurement was in the process of developing a basis for evaluation of supplier performance. One of the data bases will contain information on nonconforming material supplied by that supplier. However, most users/requisitioners have yet to complete nonconformance reports required to provide feedback to the Division of Contracts and Procurement.

BNL policy for a documented procedure to be established, implemented, and maintained by each department and division for the calibration and control of measuring and test equipment, and associated standards, was appraised in detail. All aspects of the Laboratory operations and activities (i.e., operations, research, maintenance, etc.) were affected by the lack of implementation of a calibration program. The need for a calibiration program that is accepted by all users of measuring and test instruments is evidenced by the number of findings.

The Labcratory Director has made it clear that safety and quality are line responsibilities. In carrying out this responsibility, each department and division is to verify the adequacy and effectiveness of its quality program by planned audits. Immediate corrective action is to be taken when deficiencies that will adversely affect quality, reliability, or safety are discovered. The independent verifications (by both the QA Office and the DQARs) of quality attainment within the departments, divisions, and projects were not adequate to enable BNL management to review and evaluate implementation of QA programs as required by Laboratory policy and DOE $5700.6 \mathrm{~B}$.

The $\mathrm{CH}$ had not conducted timely quality verification audits as required by $D O E$ $5700.6 \mathrm{~B}$. 


\section{QV.1 QUALITY PROGRAMS}

PERFORMANCE OBJECTIVE: Administrative programs and controls should be in place to ensure policies concerning quality are administered for each facility throughout the site.

FINDINGS: - The BNL QA Policy was issued February 1, 1985, by the Laboratory Director. This policy, in part, stated that each department shall establish and implement QA programs that are appropriate to its activities, in terms of providing increased confidence, programmatic satisfaction, and safety. Four years later, this policy was reiterated in an April 3, 1989, memorandum by the Director to all employees.

- Full implementation of the departments and divisions QA programs was paced by the preparation, review, approval, and issuance of the supporting procedures. The BNL QA Manual provides guidance procedures to the departments, divisions, and projects for development of QA programs based upon $\mathrm{CH}$ 5700.6 and ANSI/ASME NQA-1. Seventeen of the 21 departments and divisions identified by BNL as needing to develop programs had formalized them in varying degrees ranging from preliminary issues to forma 1 release and distribution.

- The BNL status report for October 1, 1989, through December 31 , 1989, revealed that the departments and divisions had a widely varying rate of progress in developing and implementing their QA programs.

CONCERN: See Concern QV.1-1, Appendix B.

FINDINGS: - The QA Steering Committee and its functions were not addressed in the BNL QA Manual. This Committee had been in existence since 1984. The charter was in the form of a "charge" to the committee and was found on page 29 of the BNL Committee Handbook. The document was revised January 1990 to update the term of membership of committee members.

- It was unclear how the important discussions and recommendations of the Committee are forwarded to the Directorate as a whole. The meeting frequency of the $Q A$ Steering Committee was quarterly, or at the request of the chairperson. Meeting minutes were published and distributed to the committee members. The last meeting was held February 9, 1990. The QA Steering Committee was charged with making recommendations to the Associate Director for Management and Physical Plant concerning the development and implementation of formal QA programs throughout the Laboratory. The recommendations were documented in the meeting minutes and distributed to committee members. There was no specific distribution to the Director's Office, al though three members are Associate Directors. 
CONCERN:

(QV.1-3)

$(\mathrm{H} 2 / \mathrm{C} 2)$

FINDINGS: - The QA Office had not performed all of the audits scheduled

The Quality Assurance Steering Committee functions and lines of of communication are not addressed in the Brookhaven National Quality Assurance Manual. for the past 3 years. Some of the departments and divisions had been audited more than once, whereas about half of the 21 departments or divisions had not been formally audited.

- $\quad$ QA audits are required by DOE $5700.6 \mathrm{~B}$ to be performed as a primary activity by any organization that implements $Q A$ criteria or requirements. The BNL Laboratory Director's policy states that it is the responsibility of the BNL QA Manager, or his delegates, to periodically audit BNL Departments to ensure compliance with their procedures.

- The QA Office did not have an adequate audit tracking system regarding audit responses, follow up, and closeout.

- The BNL QA Manual assigns responsibility to department and division management to roview and evaluate the implementation of their QA programs to make certain that they are being carried out in a timely and effective manner.

- The DQAR is assigned the responsibility in the BNL QA Manual to audit the implementation of the $Q A \operatorname{program}(s)$ and procedures, to make certain that they are being followed in a timely and consistent manner, and to report status and problems to the Department or Division Head. Also, the DQARs are to prepare status reports for the Laboratory QA Manager. Some departments and divisions, for example the Division of Contracts \& Procurement, had chosen to give this auditing assignment to other than the DQAR.

- Some of the DQARs had performed interna? audits, whereas the majority had not. Many of the departments and divisions (14 of 21) had completed the preparation of their 1990 and 1991 internal QA audit schedules, and others were preparing theirs.

CONCERN: Quality assurance audits at Brookhaven National Laboratory

(QV.1-4) conducted by both the Quality Assurance Office and

$(\mathrm{H} 2 / \mathrm{C2})$ Designated Quality Assurance Representatives do not cover al1 departments and divisions as required by Laboratory policy. (Also see Concern QV.1-2, Appendix B.)

FINDINGS: - The BNL QA Office was staffed with three full-time professional QA personnel - one of whom was the QA Manager.

- The BNL QA Manager was responsible for the development of a generic Laboratory QA program and procedures for providing professional $Q A$ assistance and guidance to the $B N L$ departments, divisions, and projects and periodically auditing 
to ensure compliance with procedures.

- $\quad$ Each department and division had appointed a DQAR to represent the organization in matters pertaining to quality and tc serve as focal points for the QA activities. Most of these DQARs had other primary duties, thus the time spent on quality matters was only minimal in those cases.

CONCERN: See Concerns QV.1-1, Appendix B, and QV.1-4.

FINDINGS: - CH had not performed a formal QA appraisal in the last 4 years. The workshop held in 1987 does not qualify as an appraisal.

- The CH QA appraisal scheduled for 1988 was canceled due to participation by $\mathrm{CH}$ in the TSA conducted in 1987.

CONCERN: The Chicago Operations Office had not conducted timely quality

(QV.1-5) verification audits as required by DOE $5700.6 \mathrm{~B}$.

( $\mathrm{H} 2 / \mathrm{C2})$ 


\section{QV.2 PROCUREMENT AND SUPPLIER CONTROL}

PERFORMANCE OBJECTIVES: Provisions should be established for the control of purchased material, equipment, and services; for selection and control of suppliers; and for assessing the adequacy of procurement activities.

FINDiNGS: - The Division of Contracts and Procurement was in the process of developing a basis to evaluate supplier performance. One of the data bases will contain information on nonconforming material supplied by that supplier.

- The Inventory Procurement Accounts Payable system presently listed shipping memorandum numbers for material that was returned to the supplier. This is only a small percentage of the nonconformances associated with purchased material. The system did not capture information on nonconforming materiai that was reworked or dispositioned "use-as-is."

- Mnst users/requisitioners had not completed the nonconforming report portion of Form BQF-003, "Inspection/Test Record Form" and provided feedback to the Division of Contracts and Procurement. A formal commitment had been made by the Laboratory for full implementation by June 30, 1990.

CONCERN: Brookhaven National Laboratory does not currently have a system

(QV.2-1) in place for the evaluation and control of suppliers based on

$(\mathrm{H} 2 / \mathrm{C2})$ their past performance. 


\section{QV.4 CALIBRATION PROGRAN}

PERFORMANCE OBJECTIVE: Provisions should be made to ensure that tools, gages, instruments, and other measuring and testing devices are properly identified, controlled, calibrated, and adjusted at specified inter als.

FINDINGS: - Policy, as expressed in the BNL QA Manual, requires a documented procedure to be estabiished, implemented, and maintained by each department and division for the calibration and control of measuring and test equipment (M\&TE), and associated stindards.

- Not all departments, divisions, and projects had such a program. The milestone was to have all procedures documented by March 31, 1990.

- Some departments and divisions had established a calibration program, but implementation had not taken place. Listings of equipment requiring periodic calibration were not readily available for most departments and divisions. The Laboratorywide milestone was to have listings of safety MT\&E prepared by May 31, 1990, with calibration to be completed by March 31, 1991.

- The NSLS was in the process of documenting (QAP-901) and implementing à system for calibrating and maintaining MT\&E used for activities affecting the safety of its work. The NSLS Control Room had three oscilloscopes used for beam control, of which the recalibration for two (LINAC, VUV \& $X$ ray beams) had exceeded the dates for recalibration as noted by the calibration labels affixed by the service company that last repaired the scopes.

- The Central Shops had recently (March 31, 1990) documented its calibration system in SOP 3.8.0, "Control of Measuring and Test Equipment." The Central Shops had also specified calibration frequencies for specific MT\&E. However, the calibration prograin had not been fully implemented. A number of micrometers and calipers used for final acceptance inspection were being used even though the recalibration date had been exceeded. Also, some of the inspection M\&TE had not been put in the calibration system.

- Calibration of electrical instruments for use by the AGS technicians was performed by Instrument Repair and Calibration Section (B1dg. 923) of the Experimental Planning and Support Division of AGS. This instrument laboratory maintains electrical standards which are transfer standards. The transfer standards were calibrated by the BNL primary standaras at the Standards Laboratory in the Instrumentation Division. A digital voltmeter that had not been formally calibrated and labeled was used to calibrate some user 
instruments. Also at the AGS:

- Instruments submitted by users were not always calibrated; some were just checked to reference points. Results of check or calibration were indicated on tape strips by notation, i.e., "Cal 3-23-90." Other information, such as calibration due date and the calibrating laboratory, was not indicated.

- The calibration log book was maintained in an informal manner, and in many cases traceability information for the instrument was not documented.

The vacuum leak standards in use in the Magnet Division, Accelerator Development Department (B1dg. 902), were not maintained in a manner that provides traceability to the primary standard. Also at Bldg. 902:

- Vacuum leak standards were not assigned unique identifier numbers.

- Leak standards were reworked and tested with incomplete documentation of hielium gas specification/grade and log book information.

- A BNL uniquely modified vacuum leak standard of highprecision measuring capability had no part number or serial number assigned, and it was used as a transfer standard.

- Vacuum leak standards did not always display unique identification and calibration labeis that indicate complete calibration status.

- In the Magnet Division coil winding operation (BIdg. 924), and assembly, welding, and testing operations (BIdg. 902), some inspection and setup gages were not included in a calibration recall program. Also in Bldgs. 902 and 924:

- Some dimensional gage blocks and gaging shims were not assigned unique identification numbers.

- A special gage master (identified as "DSS") was observed to be deformed, which makes questionable its use and reliability as a reference standard.

- Calibration frequency intervals to verify continuing accuracy of gages had not been established.

Calibration data and calibration certificates normally were not requested for gages manufactured by Central Shops. 
CONCERN: See Concerns QV.4-1, Appendix B, and MA.5-2. 


\section{QV.5 IDENTIFICATION AND CONTROL OF HARDWARE/MATERIALS}

PERFORMANCE OBJECTIVE: Provisions should be established to identify and control the use or disposition of hardware, materials, paris, and components as well as to ensure that incorrect/defective items are not used.

FINDINGS: - None of the DQARs inierviewed produced a current listing of all personnel designated by the Department or Division Head to review and approve use-as-is or repair disposition for items that had been assigried to QA Classification Category A-1 or A2. Such listings are required by the BNL QA Manual, Part II, Section 800, BNL-QAG-801, "Nonconforming Material Contro1," which also states that material designated as nonconforming will be reviewed and dispositioned by authorized personnel, who will also attempt to establish the root cause and prescribe corrective action.

- The BNL QA Office did not receive copies of Nonconformance Reports (NCRs) from the various departments and divisions.

- Individual departments and divisions had insufficient numbers of NCRs to track, analyze, and trend.

- Most department and division users/ requisitioners had not completed the NCR portion of Form BQF-003, "Inspection/Test Record" and had not provided a copy to Contracts and Procurement. (See Concern QV.2-1.)

CONCERN:

(QV.5-2) $(\mathrm{H} 2 / \mathrm{C} 2)$

FINDINGS:
A formal system for the disposition of nonconforming materials has not been implemented by all Brookhaven National Laboratory departments and divisions.

Spare parts and an only spare assembly tachometer generator, (QA Category A-2) for the AGS were maintained in locked steel cabinets at the Motor Generator Power Supply Area. This tachometer generator at AGS was observed to be stored under conditions that allowed paint spillage on it.

- The tachometer was subsequently cleaned without review, approval, and documentation.

- Category A-2 spare parts (electrical brushes) observed in the AGS storage area were not tagged to indicate inspection status or category classification (Quality Level).

- Spare Radiation Averager circuit boards (Category A-2) for the Neutral Beam Test Facility were observed to be stored on an office shelf in Bldg. 830. These items were not tagged for identification of $Q A$ Caterory or inspection status.

- Persons intervie'sed indicated that storage of spare parts in offices by the user was a commun practice. 
CONCERN: Identification, control, and storage of safety-related hardware (QV.5-3) and materials are not being performed in accordance with

$(\mathrm{H} 2 / \mathrm{C2}) \quad$ ANSI/ASME NQA-1 requirements. 


\section{QV.6 INSPECTIONS}

PERFORMANCE OBJECTIVE: Prerequisites should be pruvided in written inspection procedures with provisions for documenting and evaluating inspection results.

FINDINGS: - No record of inspection or calibration was available at the Magnet Division or Central Shops on master gage (Drawing No. 25-704.05-3) date marked "10-13-88."

- Magnet Division master gage, Drawing No. 25.545.11-2 was inspected rather than calibrated by Central Shops. Variables data were not requested or reported.

- Requisitioners of shops fabricated items requesting inspection by the Central Shops Quality Control Section are under the perception that all dimensions on all parts are inspected 100 percent. Discussions with DQARs at NSLS and Physics confirmed this understanding. The Central Shops SOP 3.0.0, "Quality Control Section Responsibilities," paragraph 3.0.6.2 "Full Inspection," indicate that "100 percent" inspections are not always performed.

CONCERN: Personnel requesting inspections and tests do not always provide (QV.6-1) acceptance instructions or procedures describing the effort to $\left(\mathrm{H} 2 / \mathrm{CL}_{2}\right)$ be performed and the criteria for acceptance, as required by ANSI/ASME NQA-1. 


\section{QV.7 CONTROL OF SPECIAL PROCESSES}

PERFORMANCE OBJECTIVE: Provisions should be established to ensure the acceptability of special processes such as welding, heat treating, nondestructive testing, and chemical cleaning, and that special processes are performed by qualified personnel using qualified procedures and equipment.

FINDINGS: - Welding procedures developed by users and instructions provided in Central Shops SOPs did not provide specific instructions on the control of weld rod material.

- At the Welding Station for the Bldg. 902 Magnet Assembly Area, some stainless steel welding rods were observed to be without identification flags. They were mixed with flagged rods in the weld rod storage cabinet. The multiple types and sizes of welding rods in use at this welding station increase the need for positive controls.

- Requirements for welding rod suppliers to identify welding rod by markings or color codes on each rod or flagging each welding rod were not indicated in procedures.

CONCERN: Material identification requirements are not adequately provided (QV.7-1) in welding rod control procedures and practices. 


\section{OPERATIONS}

The review of the BNL safety program in the area of facility operations was performed by reviewing the BNL Safety Manual, SARs, operating procedures (where they existed), operating logs, formal audits and appraisals, and other Laboratory documents. In addition, interviews were conducted with Safety officers, the S\&EP Division Head, operations persinnel and their management, including Department Chairpersons and the Associate Director for Reactor, Safety and Security. General inspections of facilities were conducted in Bldgs. 725A, 930, 901, 491, $938,939,535,911,928,906,701,820$ and 528.

Unless otherwise noted, the findings and concerns in operations do not include reactors. However, the BMRR was inspected, the operating logs were reviewed, and the Reactor Supervisor (Group Leader) was interviewed. No potential concerns were found. The HFBR is still shut down. Line management, Safety Officers, and facility operations personnel had a good attitude toward improving the safety of their operations. Interviews with supervisors or operators at facilities visited led to the conclusion that, in general, operators and supervisors were knowledgeable of their facilities, including the operators in the central control room. However, qualifications of supervisors and operators couli not be verified because of insufficient records of training, testing, and on-the-job performance in specific areas of assigned responsibilities.

Department Chairpersons and Division Heads, as a general practice, pass the numerous memoranda issued by the Laboratory Director's office down to lower levels in the organization, without formal amplification or other guidance. Considering the lack of overall policies, guidelines, and procedures, operations personnel at some facilities have developed practices that are good. For example, the operations staff of the AGS distributes copies of shift logs to key personnel daily and makes them available in the control room area conference room for interested parties to read. They also developed a control room log system that provides a history of operations that is informaiive, includes off-normal conditions, and is traceable chronologically. The operations staff of other facilities has generally not been as perceptive.

Most of the findings leading to concerns resulted from lack of policy and guidelines from Department Chairpersons and Division Heads who have been delegated responsibility to "develop prograns specific to their needs. "This may be the root cause of most deficiencies, such as, lack of organization charts down to lower levels of operations, lack of job and functional descriptions of each person and organizational unit, lack of clarity of responsibility and authority within operations organizations, and lack of clear understanding of responsibilities and authorities of organizations interfacing with operations. Departmental policies and guidelines have not been isued, by Department Chairpersons and Division Heads, such that all elements of a good safety program are implemented.

Some action was initiated by the Directors' Office prior to this visit to correct deficiencies in specific areas of safety. If these deficiencies still exist, they are included in this report. Several committees have been formed to ajdress the issues and recommend corrective action. Schedules have been set for completion of each of these efforts. Areas being examined by BNL include 
preparation, control, content, and use of operating procedures; guidelines on SAR preparation; organization charts; tracking recommendations for improving safety; and conduct of operations. Efforts already implemented by line management have not resulted in correction of the total problem. For example, the directive issued on requirements for organization charts was not followed-up with formal guidance by the Department Chairpersons and Division Heads. This resulted in unclear charts being distributed for AGS operations and operaticnal personnel interaction with other organizations. Success of the program will depend upon appropriate implementation of the guidelines by the Department Chairpersons and Division Heads. 


\section{OP.1 ORGANIZATION AND ADMINISTRATION}

PERFORMANCE OBJECTIVE: Operations organization and administration should ensure effective implementation and control of operations activities.

FINDINGS: - In operations in AGS, documentation of the organizational structure and the interface with other organizations was not clearly defined.

- Operations personnel in AGS did not always understand their interface with experimenters and Safety officers and the parent organization of the experimenters.

- In the Chemistry Department and AGS, responsibilities and authorities of management, supervisory, and professional positions were not well-defined. In most cases, formal, approved job des criptions did not exist. The advertisement used to fill a vacant position which emphasizes qualification rather than job description was generally accepted to be the job description.

CONCERN: Operations personnel do not clearly understand their authority and (OP.1-3) $(\mathrm{H} 2 / \mathrm{C} 2)$ responsibility. (Also see Concern OA.1-2.)

FINDINGS: - The organization chart for operations at the AGS distributed by memorandum on March 20, 1990, was not signed as required by Laboratory policy (Memorandum from H. C. Grahn, February 16, 1990).

- Formal instructions from Department and Division Heads typically did not exist and typically did not require operation organization charts, showing operations line of authority and interrelationship of other organizations that may affect safety, to be reviewed and concurred in by all affected organizations before they are approved.

- The operation organization structure at lower livels was developed into chart form without the benefit of guidance in format and use of solid versus thin or dotted lines. This practice does not provide clarity with respect to lines of authority, and some charts implied lines of authority that were not factual.

CONCERN: Formal policy and guidelines from Department Chairpersons and (OP.1-4) Division Heads do not exist for development, review, approval, $(\mathrm{H} 3 / \mathrm{C} 2)$ and issuance of organization charts. (ATso see Concern OA.1.?.)

FINDINGS: - The Associate Director for Safety issues memoranda to Department Chairpersons and Division Heads ident ifying safety problems and issues. Department Chairpersons and Division Heads, in turn, usually pass these same memoranda to lower 
levels, rather than developing a policy or providing specific instructions related to the need.

- Operations personnel expressed concern that they may not be following the latest requirements because it is cumbersome to check so many references.

- A11 Department Chairpersons and Division Heads had been assigned responsibility "to develop programs and a department/division policies and procedures manual specific to their needs." Informal programs have been established; however, few policy and procedures manuals have been published.

CONCERN: Department Chairpersons and Division Heads are not effectively (OP.1-5) formulating and issuing policy for their organizations which is (H2/C2) specific for their needs.

FINDINGS: - The suggestive "should" rather than the directive "shall" has extended to the operations level.

- Action words used in policy and guidance documents, such as may, should, will, must and shall, were not defined in BNL policy or safety documents. ANSI standards normally define shall, should, and may. Nonuniformity in the use of the words "should" and "shall" has an adverse impact on safety and reliable operation.

- Operations-level personnel expressed concern with the use of "should" as a means of emphasizing responsibility because this word implies authority to vary from the BNL Safety Manual.

CONCERN: Use of the suggestive "should" in policy and guidance documents

(OP.1-6) results in accountability for safety-related responsibilities

$(\mathrm{H} 2 / \mathrm{C2})$ not being clearly established. 


\section{OP.2 CONDUCT OF OPERATIONS}

PERFORMANCE OBJECTIVE: Operational activities should be conducted in a manner that achieves safe and reliable operation.

FINDINGS: - At facilities visited except AGS and NSLS, Departrent Chairpersons and Division Heads had not provided formal policie's and guidelines concerning the conduct of facility operations. (For all smaller facilities reviewed, including the two cyclotrons in the Chemistry Department, the Radiation Effects Facility and t.le Neutral Beam Test Facility, all the below-listed findings apply. For larger facilities, such as the AGS, NSLS, and Tandem Van de Graaff, most of the belowlisted findings apply).

- Written requirements or guidance did not exist for types, completeness, style, or format for operational records.

- Operating procedures, safety documents, and check lists did not generally exist. Neither operating procedures nor check sheets were routinely used at small facilities.

- At the smaller facilities, operating logs were not adequate to allow reconstruction of events during the past snift(s).

- Written facility policies and procedures, requiring supervisors and managers to monitor operations to identify and correct problems, did not exist.

- Where procedures existed, provisions were not made to periodically assure the procedures were adequate for the intended task, including shift turnover.

- Formal procedures did not exist to ensure that equipment status changes were appropriately documented and communicated to appropriate shift personnel in a timely manner.

- Management guidelines did not exist for deviating from procedures during an emergency.

- Documents, drawings, and other operator references were not authorized and properly controlled.

- Written procedures existed for bypassing radiation safety systems, but did not exist for other equipment and systems.

- Written requirements did not exist requiring maintenance of operating records that contiin data for evaluating unusual occurrences and trends that could lead to procedure and equipment changes.

CONCERN: See Concerns OP.1-5; OP.2-1, Appendix B; and OP.3-1, Appendix B. 


\section{OP.4 :ACILITY STATUS CONTROLS}

PERFORMANCE OBJECTIVE: Operations personnel should know the status of the systems and equipment under their control, and should know the effect of nonoperational systems and equipment on continued operations. They should ensure that systems and equipment are controlled in a manner that supports safe and reliable operation.

FINDINGS: - There were no Laboratory-wide formal safety requirements for local identification of safety system components. The AGS began identifying safety system components in response to recommendations in UOR 87-13: AGS Radiation Safety System Fault.

- Requirements did not exist for acknowledging awareness of changes to systems or procedures by individuals or groups who might be affected by such changes. A recent change had been made at the Neutral Beam Test Facility without all affected individuals or groups having been informed.

CONCERN: A configuration control system did not exist requiring

(OP.4-1) identification of safety-related components in the field

$(\mathrm{H} 2 / \mathrm{C} 2)$ and requiring formal review and approval before changes are made that may affect safe operation. 


\section{MAINTENANCE}

During the course of this appraisal, all Performance objectives in the Maintenance area were addressed. Interviews were conducted with personnel from the Reactor Division, Safety and Environmental Protection Division, Plant Engineering Division, Central Shops Division, NSLS Department, and AGS Department. Interviews included managers, supervisors, and technicians. The following buildings were visited; 535, 913, 488, 931B, 462, 170, 930, 490, 725, $134,933,901$, and 459 .

Maintenance activities that are performed by the Plant Engineering Division through the "Intra Laburatory Request" system are conducted in a safe and efficient manner. Policies contained in the BNL Safety Manual are followed and consistently applied by the Plant Engineering Division. The "Intra Laboratory Request" contains a section that requires the requester to specify the applicability of health and safety considerations. The Laboratory-wide computerized work control system, Job Control Accounting and Recording System, will not accept the work order unless the health and safety block has been completed. It is not clear that the health and safety section is always filled out by qualified personnel. Plant Engineering is developing maintenance procedures for activities they consider necessary. A review of completed procedures indicates that they are of high quality.

Maintenance activities conducted by programmatic device organizations are less formal than those conducted by Plant Engineering, and improvements are needed to upgrade them to current good practice levels. A steering committee has been formed to address the operation and maintenance of programmatic equipment. 


\section{MA.1 ORGANIZATION AND ADMINISTRATION}

PERFORMAKCE OBJECTIVE: Maintenance organization and administration should ensure effective implementation and control of maintenance activities.

FINDINGS: - Within the AGS, numerous groups were responsible for maintenance activities.

- Many maintenance activities and associated health and safety practices were informally implemented and were not consistent within the AGS Department. Individual organizations within the Department had developed independent systems for implementation of maintenance activities and health and safety practices.

- Th? various AGS groups conducted maintenance activities with different practices and procedures, both formal and informal.

- BNL policies for health and safety were applied inconsistently among the various AGS groups which had maintenance responsibilities. The "Safety Instruction Form" from the BNL Safety Manual was not always used.

CONCERN: Formal or uniform maintenance programs are not consistentiy

(MA. l-3) implemented at the Alternating Gradient Synchrotron Facility.

$(\mathrm{H} 2 / \mathrm{C2})$ 


\section{MA.2 CONDUCT OF MAINTENANCE}

PERFORMANCE OBJECTIVE: Maintenance shouid be conducted in a safe and effective manner to support each facility condition and operation on the site.

FINDINGS: - Work orders or work requests were not uniformly prepared or used in the NSLS and AGS Departments.

- Maintenance activities were often conducted with only oral instructions, and there was no record of actual work performed, post-maintenance testing, or certification of satisfactory completion.

- Within the AGS and NSLS Departments, it was not clear who had specific authority to initiate maintenance activities.

CONCERN: Documentation of maintenance activities for programmatic equipment (MA.2-2) is incomplete, and procedures for work control are not sufficient $(\mathrm{H} 2 / \mathrm{C} 2)$ to ensure safe and efficient maintenance. 


\section{MA.5 CORRECTIVE MAINTENANCE}

PERFORMANCE OBJECTIVE: The material condition of components and equipment should be maintained to support safe and effective operation of all facilities on the site.

FINDINGS: - A classification of operational control instrumentation that requires calibration did not exist for the AGS or NSLS.

- Procedures were not in place for calibrations that wi?l provide reproducible data and acceptance criteria.

- All control room instrumentation was not calibrated or was being used when indicated calibration dates had been exceeded.

- Tolerances for normal operation of control instrumentation had not been established to alert operators of drifting or failed signals.

CONCERN: A calibration and testing program which identifies instrumentation (MA.5-2) requiring periodic calibration and/or testing is not in place.

(H2/C2) (Also see Concern QV.4-1, Appendix B.) 


\section{MA.8 PROCEDURES AND DOCUMENTATION}

PERFORMANCE OBJECTIVE: Maintenance procedures and related documents should provide appropriate directions and guidance for work and should be used to ensure that maintenance is performed safely and effectively.

FINDINGS: - With the exception of the Plant Engineering Department, maintenance procedures and records were not developed or maintained in a uniform manner.

- A BNL procedure development policy was not consistently implemented for maintenance procedure development at the department level.

- Maintenance procedures ranged from excellent to nonexistent from department to department and within individual departments.

- Many existing procedures were informal, not adequately reviewed and approved, and lacked validation.

- Procedure compliance requirements were not clearly stated or were not enforced at the facility level.

- Policies and practices were often issued by memorandum.

- "Intra Laboratory Requests" and safety instructions were not always filled out or were filled out improperly; namely, without sufficient information for maintenance personnel in regard to specific health and safety concerns.

CONCERN: Maintenance procedures and documentation of maintenance activities

(MA.8-2) for programmatic equipment frequently do not enable maintenance

(H2/C2) to be carried out in a controlled and safe manner. (Also see Concerns RP.3-5 and RP.3-7.) 


\section{E. TRAINING AND CERTIFICATION}

This appraisal included interviews with training personnel in the Safety and Environmental Protection, Reactor, Plant Engineering, and Safeguards and Security Divisions as well as in the AGS, NSLS, Medical, and Nuclear Energy Departments. Documentation of training $\mathrm{plans}$ and procedures, classroom lesson plans, on-thejob training, examinations, and personnel training records was reviewed and evaluated.

There is considerable evidence of a commitment at BNL to bring training and certification programs into compliance with DOE requirements and good practice standards. There are also indications that some groups are moving slowly in their training program improvements. A task force on training has been formed to determine the Laboratory-wide status of and needs for training and documentation. The task force is gathering information from the many divisions and departments and plans to make recommendations and issue guidance later this year. It is clear that initial training content, certification, and documentation will receive adequate attention, but it is not clear that regularly scheduled retraining and certification will receive similar attention.

The Training Group in the S\&EP Division is responsible for general safety training Laboratory-wide; e.g., radiation protection, industrial safety, industrial hygiene, respirator training, and hazardous material handling. The group is diligently upgrading courses; preparing lesson plans; and drafting procedures for classroom training, on-the-job training, examinations, and the maintenance of training records. Their training facilities are minimal for effective group instruction. Except for one small, dedicated S\&EP training room and a dedicated conference room, classes are generally given in other conference rooms around the Laboratory.

Laboratory-wide safety training has been particularly active in recent months. Department and division supervisors have received special training to the new requirements of DOE 5480.11. The radiation worker training course has been revised to reflect the new requirements, and all radiation workers are receiving this training as quickly as possible. As required, an introductory right-to-know course has been given to almost everyone in the Laboratory. A survey is under way to determine the chemicals used in various laboratory areas to allow for specific hazards training. S\&EP safety representatives at the various Laboratory departments and divisions receive special training in health physics, industrial hygiene, and industrial safety. Because of incomplete documentation, however, it cannot be verified that health physics technician training meets DOE Orders requirements.

Many other divisions at BNL have programmatic safety-related training responsibilities. The Reactor Division has documented training programs for operators and maintenance personnel of both the HFBR and the BMRR. The division is now conducting the initial self-evaluation of current training programs relative to the new accreditation requirements in DOE 5480.18. Reactor operators and supervisors as well as fissile material handlers in the Isotopes and Special Materials Group are trained annually in criticality safety principles and control procedures, as required by DOE Orders. The Security Division has an effective performance-based training program. Plant Engineering has significantly 
strengthened its training programs with specific course requirements, lesson plans, and training records. However, not all of their important safety-related training courses have certification exam requirements. Accelerator facilities do not have a documented, performance-based training program for initial and ongoing operator and maintenance personnel qualification and certification.

Both the AGS and the NSLS have recently prepared guidelines for the conduct of operations which spell out training requirements. On-the-job training using a checklist is becoming more formal. Facility-specific, safety-related training requirements generally have increased. Laboratory-wide safety training and certification requirements for employee and visitor users of high-radiation facilities, however, need additional attention. 


\section{TC.I ORGANIZATION AND ADMINISTRATION}

PERFORMANCE OBJECTIVE: The training organization and administration should ensure effective implementation and control of training activities.

FINDINGS: - With the exception of the Reactor Division, Plant Engineering, and the Security Group, performance-based job task analysis for operations had not been performed. Lesson plans were not formalized. Qualification and certification records were inadequate.

- The AGS Operator Training Program was comprised of informal or-the-job training without a checklist. Documented evaluations of performance were not required; qualification was certified by the assistant head of operations.

- NSLS operators received an introductory training lecture and viewed training video tapes. On-the-job training was a scheduled activity, but a check list had not been developed. Documented evaluation of performance was not used for certification.

- In Plant Engineering, certification testing in important safety-related courses, e.g., that for training of crane operators and riggers, had not been implemented.

- Individual training records at operating facilities were not kept uniformly Laboratory wide. The content of the training records varied from good at the Reactor Division and Plant Engineering to unavailable in several departments.

CONCERN: See Concerns TC.1-1, Appendix B, and TC.1-2, Appendix B. 


\section{TC.4 GENERAL EMPLOYEE/PERSONNEL PROTECTION TRAINING}

PERFORMANCE OBJECTIVE: General employee and personnel protection training programs should ensure that site/facility personnel, subcontractors, and visitors have an understanding of their responsibilities and expected safe work practices and have the knowledge and practical abilities necessary to effectively implement personnel protection practices associated with their work.

FINDINGS: - DOE 5480.11 requires radiation worker training every 2 years. BNL had upgraded its training course to meet the DOE requirement. Al1 new employees who were occupational workers rereived training to the new course content. However, all existing occupational workers were not trained to the new requirements by January 1, 1990.

- BNL had requested an extension of time to meet the requirement for all radiation workers, but no formal response had been received from $H Q D O E$.

- Onty one single exam was used to certify radiation worker training. A passing grade requirement had not been establi shed.

CONCERN: Al1 radiation workers at Brookhaven National Laboratory have not (TC.4-1) been trained and certified to meet the requirements of

$(\mathrm{H} 2 / \mathrm{Cl}) \quad$ DOE 5480.11 .

FINDINGS: - Employee and visitor users at the NSLS view an 11-minute safety orientation videotape and then sign a certification form. The videotape content was to be expanded to about 30 minutes to provide additional coverage of radiation safety. Exams were not required for certification.

- By June 1990 access to the AGS ring, LINAC area, or primary beam lines will be permitted only for personnel who have received $A A 256$ Key training and Lock out/Tag out training. Exams were not to be required for certification.

- Radiation worker training ( $f i l m$-badge course) was required to obtain a radiation worker film badge. A passing grade for certification wis not required on the exam. This training course was available each Monday for employee and visitor users. Until the training is completed, users are issued a red film badge, which requires escort in radiation areas.

CONCERN: Safety training and certification requirements for employee and (TC.4-2) visitor users are not in compliance with DOE 5480.11 at many $(\mathrm{H} 2 / \mathrm{Cl}) \quad$ Brookhaven National Laboratory facilities. 


\section{TC.5 MAINTENANCE PERSONNEL}

PERFORMANCE OBJECTIVE: The maintenance personnel training qual ification programs should develop and improve the knowledge and skills necessary to perform assigned job functions.

FINDINGS: - At the AGS, a maintenance manual was used as a guide for on-the-job training. Certification evaluations were not used, and no formal documentation of training was maintained.

- At the NSLS, maintenance was performed by equipment operators. There was no formal documentation of training, and qualification evaluations were not required.

- Maintenance training at the BMRR was carried out according to a check list. Certification exams were not required.

- In Plant Engineering, lesson plans had been developed for maintenance training. However, formal exams were not required to qualify maintenance personnel.

CONCERN: At most Brookhaven National Laboratory facilities, there is no (TC.5-1) maintenance training and qualification program to ensure safe $(\mathrm{H} 2 / \mathrm{C} 2)$ and effective maintenance activities. (A) so see Concern TC.3-1, Appendix B.) 


\section{TC.9 RADIOLOGICAL PROTECTION PERSONNEL}

PERFORMANCE OBJECTIVE: The radiological protection personnet training and qualification program should develop and improve the knowiedge and skills necessary to perform assigned job functions.

FINDINGS: - Health physics technicians received 3 months of training, which included both classroom instruction and applications; however, detailed lesson plans and records of certification exams were not readily available.

- In 1988 a 5-day (40 hours) commercial health physics course was given on site to technicians, but exam records were not readily available.

- A self-paced computer-based health physics package was available for generic training. The package had a single comprehension test in each section, and test scores were recorded in the computer memory.

- Training records of health physics technicians were not available to verify certified training every 2 years.

- The Building Safety Services Group Leader stated that all health physics technicians would be certified under the accredited program required by DOE 5480.18; however, that program plan does not require submittal until November 1990.

CONCERN: Documentation of the health physics training program required to (TC.9-1) verify that technicians receive certified training in compliance $(\mathrm{H} 2 / \mathrm{Cl})$ with DOE 5480.11 is ircomplete and not readily available. 


\section{F. AUXILIARY SYSTEMS}

During the course of this appraisal, all Performance Objectives except Storage and Handling of Fissile Material were addressed. This area was covered under Nuclear Criticality Safety. Interviews were conducted with personnel from the Reactor Division, S\&EP Division, Plant Engineering Division, Central Shops Division, NSLS Department, and AGS Department. Interviews included Managers, Supervisors, and Technicians. The following buildings were visited: 535, 913, $488,931 \mathrm{~B}, 462,170,930,490,725,134,933,901$, and 459.

In general, the auxiliary systems at BNL were reliable. Technical Specifications and SAR requirements were being met at the BMRR and NSLS Facilities. Radioactive and nonradioactive waste volumes were relatively small. Waste minimization had been emphasized since 1987, and efforts to reduce storage and accumulation of hazardous materials continue to receive BNL upper management attention.

Engineered safety features and safety systems at the BMRR were maintained, and surveillance was being performed in accordance with approved procedures, and the requirements for testing were being met. Cleanup systems were being maintained at the required purity for circulating coolant and associated equipment. 


\section{AX.5 VENTILATION SYSTEMS}

PERFORMANCE OBJECTIVE: Ventilation systems should reliably direct all airborne effluents from contaminated zones or potentially contaminated zones through cleanup systems to ensure that the effluent reaching the environment is below the maximum permissible concentration and is ALAR,.

FINDINGS: - Pressure drop instrumentation was not installed on all highefficiency particulate air filters to detect incipient clogging of filters and system failures. An example was the Machine Shop "hot" area.

CONCERN: High-efficiency particulate air filters without pressure drop (AX.5-1) instrumentation cannot be monitored for cloyging or penetration $(\mathrm{H} 2 / \mathrm{C} 2)$ on a continuous basis. 


\section{G. EMERGENCY PREPAREDHESS}

The emergency preparedness evaluation used as a basis the seven performance objectives 1 isted under that heading in the DOE TSA document. These objectives covered organization and administration, emergency plan and implementing procedures, training, drills and exercises, facilities and equipment, assessment and notification, and personnel protection. The sites visited to perform this assessment included the S\&EP Office Building Annex (B1dg. 129), the Emergency Operations Facility (EOF) (Bldg. 50), the Occupational Medical Clinic (Bldg. 490), the Calibration Facility (Bldg. 348), the Atmospheric Sciences Facility (B1dg. 51) and the Hazardous Waste Facility (B1dg. 445).

An extensively revised and upgraded BNL Emergency P1 an is currently under review. The two reactor emergency plans were last revised in 1988 and al so need to be formally reviewed and updated to correct identified deficiencies. Implementation procedures, which may be required during an emergency, are in place but not specifically referenced in the appropriate plans for easy retrieval. These plans have not adequately addressed the release of non-radioactive toxic materials and specific emergency scenarios identified in their respective facility SARs. The problem is recognized and in the process of solution.

Emergency response personnel have been identified and appear competent and experienced in their own special fields. However, a required training program for coordinating the response of these individuals and to address other training needs is not in place.

A modified BNL sitewide emergency exercise, held in September 1989, failed to demonstrate proper coordination and appropriate actions by all individuals or organizations. One follow up integrated exercise has since been conducted. others are planned but have not been scheduled. However, more frequent drills are held by elements of the emergency response organizations. These have been useful in providing some measure of the required training verification.

Deficiencies in the current EOF Building design and equipment were noted and are acknowledged by Laboratory management. An alternate EOF Building has been selected but not equipped.

Equipment available to handle credible accident scenarios involving radioactive materials is adequate. For accidents involving nonradioactive toxic materials, the equipment required has not been identified and dedicated or made easily retrievable in the case of an emergency.

Deficiencies in the testing of radiation monitoring instrumentation to satisfy required performance standards were identified. 


\section{EP.2 EMERGENCY PLAN AND IMPLEMENTING PROCEDURES}

PERT URMANCE OBJECTIVE: The emergency $p l a n$, the emergency $p l a n$ implementing procedures, and their supporting documentation should provide for effective response to operational emergencies.

FINDINGS: - The BNL Emergency Plan did not fully address the consequences of, and the response to, an emergency involving the uncontrolled release of toxic, nonradioactive materials as required by SARA Title III, 1986.

- The HFBR and BMRR Emergency Plans did not specify the postulated accident scenarios whi h would trigger the responses associated with the emergen, / action levels defined by DOE. (The HFBR Emergency PIan has since been revised to correct this deficiency and has been approved.)

- The last documented revisions of the HFBR and BMRR Emergency Plans were in 1988. These plans, and others dated before 1989 , had not undergone an annual review.

CONCERN: See Concerns EP.1-1, Appendix B; EP.2-1, Appendix B; and EP.6-1, Appendix B. 


\section{EP.3 EMERGENCY RESPONSE TRAINING}

PERFORMANCE OBJECTIVE: Emergency response training should develop and maintain the knowledge and skills for emergency personnel to respoind to and control an emergency effectively.

FINDINGS: - On-site personnel who have to manage protective actions in the event of emergency had been identified. However, the training program required for these individuals was not in place.

- An emergency exercise held in September 1989 identified certain weaknesses. One table-top drill and one integrated exercise have since been held. Others are planned but have not been scheduled.

CONCERN: See Concern EP.3-1, Appendix B. 


\section{EP.5 EMERGENCY FACILITIES, EQUIPMENT, AND RESOURCES}

PERFORMANCE OBJECTIVE: Emergency facilities, equipment, and resources should adequately support site/facility emergency operations.

FINDINGS: - Potential exposures of occupants of the present EOF Building resulting from a release of toxic or radioactive materials under unfavorable meteorological conditions had not been evaluated.

- The EOF Building did not have sufficient equipment to ensure that its occupants were not unknowingly or unnecessarily exposed to toxic or radioactive materials in the event of a release of such materials.

- The EOF Building ventilation system intake was not filtered to prevent exposure to its occupants resulting from airborne toxic or radioactive particulates.

- An alternate EOF building had been designated in the event that the rimary EOF was not habitable. However, it was not equipped or ready for use.

CONCERN: See Concern En.5-1, Appendix B.

FINDINGS: - The emergency response radiation monitoring equipment had not been tested to demonstrate conformance with the specifications listed in ANSI N320-1979.

- A lack of equipment and facilities prevented compliance with sections of this standard.

- The test results for identical instrument models tested at other laboratories or DOE facilities had not be in employed as a means of meeting the ANSI requirements.

- A waiver for exemption from certain requirements of the ANSI standard had not been requested from DOE.

CONCERN: The radiation monitoring equipment designated for use during an

(EP.5-2) emergency response does not meet all of the requirements of

$(\mathrm{H} 2 / \mathrm{Cl}) \quad$ ANSI N320-1979. 


\section{H. TECHNICAL SUPPORT}

Six of the eight performance objectives in this functional area were addressed in this appraisal. Environmental Impact was not addressed as it was addressed in detail by the Environmental Subteam. Criticality Safety was covered in a separate functional area by the S\&H Subteam (see Section 4.5.9). This appraisal included visits to the NSLS, the AGS, the BMRR, the Tandem and Small Van de Graaff Accelerators, the Relativistic Heavy Ion Collider construction site, two Cyclotrons, the Inhalation Toxicology Facility, and the Positron Beam Facility. Discussions were held with representatives of the Plant Engineering Division, the S\&EP Division, the Reactor Division, the Chemistry Department, the Medical Department, the NSLS Department, the AGS Department, and the Department of Applied Science. These activities involved visits to Bldgs. 134, 179, 480, 490, $491,535,555,725,901,901-A$, and 912 .

Overall performance and documentation of technical support activities at BNL are performed in a thorough manner only at the reactor areas. Other areas exhibiled inconsistencies in preparation of timely SARs and other documents. For the most part, nonreactor areas did not employ Operational Safety Requirements (OSRs) and did not adequately identify, document, test, and maintain safety systems and safety equipment.

A wide variety of organizations provide technical support at BNL. The Plant Engineering Division provides design and construction management for capital improvement projects and is well-organized to provide this support in an effective manner. Technical support for on-going operational activities is largely provided by groups with in the various operating departments.

OSRs are employed for reactor operations but not for most other activities at BNL. A new Occupational Health and Safety Guide entitled, "Safety Analysis Reports," was in draft form at the time of this appraisal. This document, as drafted, will require generation of OSRs from each SAR as well as a 1 ist of safety systems and devices. If fully implemented, this could lead to alleviation of three of the concerns expressed in this appraisal.

Reactor engineering was appraised only for the BMRR, since the HFBR was out of service at the time of this appraisal. These activities were adequately documented and were in conformance with DOE Orders.

Facility modifications are generally conducted in conformance with DOE Orders. However, frequently these modifications are undertaken and sometimes completed before the SAR is completed and approved. This practice could lead to excessive construction costs as well as to undesirable compromises of safety protection in the facilities, and a concern is expressed in this area.

Occupancy Readiness Reviews (ORRs) are conducted near the completion of each construction project. Often, these are conducted in two stages, one to allow beneficial occupancy to permit setting up equipment for testing purposes within the new facility, and a second which leads to the status of "occupancy readiness." Documentation is not always clear as to which of these reviews is being performed. The emphasis of both types of ORR is on the construction performed and the inclusion of adequate safety features. Few, if any, of the 
documented findings, following conduct of recent ORRs, relate to operational activities to be conducted in the facility or to adequacy of training or procedures for the conduct of these activities. A concern is expressed in this area.

Packaging and Transportation of Hazardous and Radioactive Materials was undergoing significant upgrade at the time of this appraisal. A new policy statement on this subject was issued by the Laboratory Director on March 23, 1990. These activities will culminate with preparation of a packaging and transportation manual by 0ctober 1, 1990. In view of this changing situation and the satisfactory progress being made, this performance objective was not assessed in detail during this appraisal. 


\section{TS.2 PROCEDURES AND DOCUMENTS}

PERFORMANCE OBJECTIVE: Technical support procedures and documents should provide appropriate direction, allow for adequate record generation and maintenance for important activities, and should be properly and effectively used to support safe operation of all facilities on the site.

FINDINGS: - Over 20 nonreactor SARs were reviewed; operational safety requirements or limits were identified only for the one concerning the Live Fire Range.

CONCERN: Operational safety limitations are not identified for most

(TS.2-3) nonreactor facilities. (Also see Concern EA.4-1.)

(H2/C2)

FINDINGS: - None of the over 20 nonreactor SARs reviewed identified safety systems or devices along with requisite testing and maintenance requirements.

- None of the Safety Coordinators interviewed in nonreactor organizations were aware of any other documented identification of safety systems or devices, or of any documented requirements for testing and maintenance of such devices.

CONCERN: In nonreactor areas, safety systems and devices are not fully

(TS.2-4) identified, and special testing or maintenance requirements

$(\mathrm{H} 2 / \mathrm{C2})$ are not stipulated for such equipment. 


\section{TS.3 FACILITY MODIFICATIONS}

PERFORMANCE OBJECTIVE: Technical support services required by each facility on the site to execute modifications should be carried out in accordance with sound engineering principles that should assure proper design, review, control, implementation, and documentation in a timely manner.

FINDINGS: - An ORR was performed for beneficial occupancy of the Positron Beam Facility in B1dg. 480 on December 5 , 1989, but the SAR had not yet been issued. The ORR memorandum, in fact, suggested two additional items for incorporation in the SAR.

- An ORR for beneficial occupancy of the Inhalation Toxicology Facility was performed on February 6, 1990, but the SAR had not yet been submitted to the Laboratory Safety Committee for approval.

- An ORR for beneficial occupancy of the Accelerator Test Facility was performed on April 20, 1989; the SAR was later recommended for approval on September 27, 1989.

CONCERN: Safety Analysis Reports are not prepared before completion of (TS.3-2) a facility design or of a facility modification.

$(\mathrm{H} 2 / \mathrm{C} 2)$

FINDINGS: - BNL performs ORRs in connection with construction of new facilities in accordance with BNL Occupational Health and Safety Guide No. 1.3.2. These reviews cover primarily the facilities and equipment that were part of the construction project and seldom include activities to be performed in the facility.

- Review of the memoranda concerning ORRs performed during the preceding 6 months showed no instance of a finding relative to the experiments, procedures, training, or activities to be performed in the new facility.

- Neither the ORR for beneficial occupancy performed on April 20, 1989, nor the final ORR performed on March 23, 1990, for the Accelerator Test Facility in Bldg. 820, contained any finding relative to the experimental activities to be performed in the new facility.

- An UOR (UOR-89-28) was issued for a radiation incident occurring at the Accelerator Test Facility in Bldg. 820 on December 18, 1989. The report of the incident investigating committee stated that the lack of a complete safety review of the experimental setup and planned interim operations was a major factor causing this incident. 
CONCERN: Brookhaven National Laboratory Occupancy Readiness Reviews (TS.3-3) do not satisfy the requirements for the more conventional (H2/C2) Operational Readiness Reviews. 


\section{TS.4 EQUIPMENT PERFORMANCE TESTING AND MONITORING}

PERFORMANCE OBJECTIVE: Effective equipment performance testing and monitoring should be performed by technical support groups to ensure that equipment and system performance is within established safety parameters and limits.

FINDINGS: - No formal system has been established for performance testing and monitoring of all safety-related equipment outside of the reactor areas.

- Through interviews it was found that some equipment is run as needed and only repaired or replaced when it fails.

CONCERN: No formal sitewide system has been established for performance (TS.4-3) testing and monitoring of equipment within established safety (H2/C2) parameters and limits. (Also see Concern TS.4-1, Appendix B.) 


\section{NUCLEAR CRITICALITY SAFETY}

This appraisal included discussions with the Criticality officer, HFBR Plant Manager, Reactor Training and Procedures Manager, and Isotopes and Special Materials Group Leader. Documentation of nuclear criticality safety training, procedures, analyses, and audit reports was reviewed and evaluated. Fissile storage areas were visited at the HFBR, Bldg. 750, and Hazardous Waste Facilities, Bidg. 446.

Policy for the nuclear criticality safety program at BNL is defined and documented in the BNL Safety Manual. Although nuclear criticality safety is a line responsibility delegated by the Laboratory Director to the various departments and divisions, a Criticality officer is appointed to advise upper management on the safe handling of fissile materials. The responsibilities of the Criticality officer are clearly defined. A concern about the degree to which the Criticality officer is independent of operations has been expressed.

Although analyses required to ensure criticality safety are the responsibility of operations within specific departments and divisions, they are reviewed and approved by the criticality Officer and the Reactor Safety Committee. Conservative sitewide nuclear criticality safety mass limits are spelled out in the BNL Safety Manual. Greater mass limits for specific applications have been adequately supported by documented analyses.

Other than reactor fuel for the HFBR and the BMRR, only small quaritities of fissile materials are used at BNL. This greatly reduces the risk of a criticality accident. Written procedures, which include conservative limits and administrative controls to ensure the safety of operations, cover the movement of both fresh and spent fuel for the reactors. Fuel is moved and placed in storage by trained fissile material handlers. Fuel is stored safely in approved facilities; however, more attention could be given to the good practice of eliminating combustible materials in the storage areas. Storage areas are appropriately posted, but more attention could be given to the uniform quality of the signs. Nuclear criticality safety practices are audited annually for compliance with regulations and good standards.

The HFBR does not have a criticality alarm system or nuclear accident dosimeters as required by DOE Orders. However, an alarm system has been ordered and is scheduled to be installed and operational in 1991. Appropriate emergency procedures and exercises remain to be addressed. 


\section{CS.1 ORGANIZATION AND ADMINISTRATION}

PERFORMANCE OBJECTIVE: All operations with fissionable material should be conducted to provide effective nuclear criticality control during all activities.

FINDINGS: - According to the BNL Safety Manual, the safe use of fissionable material is a line responsibility. Nevertheless, the Associate Director for Safety had appointed a Criticality Officer to advise him and the Reactor Safety Committee on matters related to criticality safety.

- Although the Criticality Officer was in the Reactor Analysis Division, for criticality safety he reported to the Associate Director of Reactor, Safety and Security. The Reactur Operaitions group al so reported through the Reactor Division to the Associate Director of Reactor, Safety and Security.

- The Reactor Safety Committee also reported to the Associate Director of Reactor, Safety and Security.

CONCERN: The criticality safety program is not independent of operations (CS.1-1) in compliance with ANS 8.1-1983 as required by DOE Orders.

(H2/C1) (A1so see Concern OA.2-3.) 


\section{CS.5 CRITICALITY ALARM SYSTEM AND ENERGENCY PROCEDURES}

PERFORMANCE OBJECTIVE: All reasonable steps should be taken to mitigate the consequences of a nuclear criticality accident.

FINDINGS: - The June 1987 TSA of the HFBR expressed a concern that the criticality alarm system did not meet all the requirements of DOE 5480.6. (DOE 5480.6 implements the requirements of DOE 5480.5.)

- As a response to that concern, BNL presented an analysis to verify that safe mass requirements, even with double contingency, can be achieved with administrative procedures requiring that only five fresh fuel elements be handled at a time outside of the fuel shipping container.

- DOE 5480.5 requires that a criticality alarm system be installed in all locations where the quantity of fissionable materials exceeds specified limits, regardless of administrative procedures.

- BNL intends to install and put into operation a criticality alarm system at the HFBR by January 31, 1991.

- At the HFBR fissile fuel storage areas, nuclear accident dosimeters were not used as required by DOE 5480.11, and criticality emergency exercises and drills were not conducted.

CONCERN: A criticality alarm system, nuclear accident dosimeters, and (CS.5-1) emergency procedures and drills have not been implemented to $(\mathrm{H} 2 / \mathrm{Cl})$ cover the fissile fuel storage areas at the High Flux Beam Reactor in compliance with DOE 5480.5 . 


\section{J. EXPERIMENTAL ACTIVITIES}

The experimental facilities at the BNL consist of four major user-based facilities and their ancillaries. There are also numerous smaller, programoriented experimental facilities.

The four major experimental facilities include: the AGS, the NSLS, the Tandem Van de Graaff, and the HFBR. This assessment covered all of the major facilities, except the HFBR, and many of the smaller facilities.

In terms of numbers of users/experimenters, the largest facility is the NSLS. This facility has over 2000 general users consisting of BNL scientific and technical staff, and scientists and engineers from various sectors of industry, from the university community, and from the international high-energy and nuclear physics community.

The second largest facility, in terms of numbers of users/experimenters, is the AGS. Of the approximately 650 users, the BNL staff comprise 15 to 20 percent with the renainder coming from university, industry, and international scientific sources.

The Tandem Van de Graaff Generator is the third major experimental facility at BNL. The user/experimenter community at this facility numbers about 100 . Most of these users are from Federal Government Departments other than the DOE, as well as contractors.

In general, the Team found that experimental activities functioned well at the scientist-to-scientist level. The organizational units responsible for the experimental facilities have instituted User. Programs by which a staff member from the facility becomes the liaison scientist, and thereby, the official spokesman for the experiment. The liaison scientist shepherds the experiment through the required safety and experiment review committees and through staff review. A liaison engineer also serves as the experiment fabrication/construction interface with the BNL technicians and craftsmen to ensure that the experiment is constructed as approved. This utilization of "liaisons" ensures that experiment and scientist-to-scientist relations remain smoothly functional during both preoperational activities and during experiment operations.

Although this program of experiment development and implementation is one of the more formally defined at BNL, there are still portions for which adequate planning and implementation are suspect, as evidenced by documentation and procedures.

In summary, there are two branches of these overall experimental programs: experiment conception and implementation and experiments/facilities operation. Although experiment conception and implementation appears to work well on the liaison scientist and liaison engineer concepts, the Team had two significant 
concerns. The first concern arises in the safety review and subsequent operation of the experiments/facilities because the safety review committees charters lack sufficient detail to fully define the mission and authority of the committee. This can lead to incomplete safety review, unsafe operations, and failure to complete necessary information.

Secondly, an envelope of parameters in which the experiments or classes of experiments can be operated safely has $n r t$ been developed and formalized at the various departments and divisions. 


\section{EA.2 EXPERIMENTAL ACTIVITIES}

PERFORMANCE OBJECTIVE: All proposed experiments should be approved by an independent Safety Review Committee before they are performed.

FINDINGS: - Charters for department and division experiment safety review committees were primarily memoranda appointing the team leader and members. Some general guidelines regarding authority and responsibility were usually included.

- Of the charters for the department and division experiment safety review committees reviewed by the TSA Team, none included all of the elements of a good committee charter; i.e., length of appointment of members, quorum required to act, meeting frequency, multi-discipline revinw capabilities, group interaction during reviews, reporting level, and complete scope of authority and responsibility.

- The committee which reviewed the radiation incident that occurred on December 18, 1989, in the Accelerator Test Facility (ATF), Bldg. 820, concluded that the lack of a complete safety review of the experimental setup and planned interim operations were major factors in the incident.

CONCERN: The charters for the department and division experiment safety

(EA.2-1) review committees did not fully define the body, scope, and

$(\mathrm{H} 3 / \mathrm{C} 2)$ and authority of the committee. 


\section{EA.4 OPERATION OF EXPERIMENTS}

PERFORMANCE OBJECTIVE: Experiments performed in any facility on the site shouid not present undue risk or significantly increase the risk previously evaluated for the facility or the site.

FINDINGS: - Experiments performed at BNL have been reviewed by an experiment safety review committee. However, it was not always clear what degree of change in the experiment prompts additional review by the experiment safety review committee.

- Some of the larger experiments had an SAR that defined the boundaries of safe operation; however, for smaller or shorter term experiments, this safe envelope of operation was not always defined.

- There was no Laboratory-wide policy or guidance regarding the development of boundaries of safe operation for experiments.

CONCERN: The boundaries of safe operation were not developed for each

(EA.4-1) experiment or class of experiments at the various departments

$(\mathrm{H} 2 / \mathrm{Cl})$ and divisions at the Brookhaven National Laboratory, as required by DOE 5481.1B. (A1 so see Concern TS.2-3.) 


\section{K. SITE/FACILITY SAFETY REVIEW}

All six performance objectives for facility safety review were addressed during this appraisal. Interviews were held with the chairmen of each of the three sitewide safety review committees as well as with the chairmen of two NSLS safety review committees and the AGS radiation safety committee. Interviews were also conducted with Safety Coordinators in the NSLS, Chemistry, Medical, and Applied Science Departments as well as persons responsible for safety reviews in the S\&EP Department. An interview was also conducted with the Associate Director for Reactor, Safety and Security regarding the triennial appraisal program. These activities involved visits to Bldgs. $51,134,179,197,460,490,535,555,703$, 725,902 , and 912 .

BNL has an effective facility safety review system which meets most aspects of DOE Orders regarding such reviews. However, iwo concerns are expressed regarding lack of compliance with specific DOE Orders requirements.

BNL has three sitewide safety review committees. All three are chartered in the BNL Safety Manual and report to the Associate Director for Reactor, Safety and Security. These are the Cryogenic Safety Committee, the Reactor Safety Committee, and the Lavoratory Safeiy Committee. The first two committees cover reviews in their respective technical specialty areas, while the third covers all other reviews. Appropriate topics are reviewed by each committee, and each is staffed by members having the capability for multidisciplinary reviews with indepth technical competence. Adequate written minutes are maintained by each committee.

In addition, many of the departments have their own safety committee for review of topics prior to submittal to the sitewide committees and for review of other topics not required to be submitted to those committees. For example, the NSLS Department has two such committees, one to review use of beam lines by experimenters and one to review other department activities. The department committees all perform useful functions, but the quality of the charters, reviews, and minutes varies by department. For some, the documentation is in need of review and upgrade.

A comprehensive annual operating review of each BNL Department having more than office-type functions is performed, and a third of the departments having merely office-type functions are included each year. In Fiscal Year 1990, a total of 19 such reviews are scheduled. Each review lasts about 1 week, and closeout sessions are attended by the Laboratory Director; the Associate Director for Reactor, Safety and Security; and the cognizant department Associate Director. This is a commendable practice. A concern is expressed regarding the scope of these reviews noi being in strict compliance with DOE Orders.

A triennial appraisal of the BNL safety review system lias not been performed, and a concern is expressed about this deficiency. However, BNL is making plans to undertake such reviews in 1991, and preliminary plans should provide effective triennial reviews when they are implemented.

Operating experiences at BNL are evaluated and appropriate actions are taken to improve safety and reliability. 


\section{FR.4 ANNUAL FACILITY SAFETY REVIEW}

PERFORMANCE OBJECTIVE: An annual operating review of the facility should be performed by a committee appointed by top contractor management.

FINDINLS: - Annual safety reviews are performed for each department having experimental, operational, or other physical activities. For departments having only office-type functions such reviews are performed every 3 years. Review teams are appointed by the Associate Director for Reactor, Safety and Security.

- These review teams did not specifically review the safety aspects of procedures and some other operational activities.

CONCERN: Periodic facility safety reviews do not include a safety review (FR.4-1) of all procedures and operational activities as required by $(\mathrm{H} 2 / \mathrm{Cl})$ DOE 5482.1B. 


\section{FR.5 TRIENNIAL APPRAISAL OF SITE/FACILITY SAFETY REVIEW SYSTEM}

PERFORMANCE OBJECTIVE: A triennial appraisal of the safety review system should be performed by contractor management.

FINDINGS: - Except for reactors, BNL had not been performing a triennial appraisal of the safety review system as required by DOE $5482.1 B$, although planning had started so that a program can be implemented beginning in 1991 .

CONCERN: Brookhaven National Laboratory does not perform a triennial

(FR.5-1) appraisal of the safety review system. (Also see Concern SR.7-1, $(\mathrm{H} 2 / \mathrm{Cl})$ Appendix B.) 


\section{RADIOLOGICAL PROTECTION}

The Radiological Protection Program at BNL was reviewed in the context of the performance cbjectives listed in the DOE guide for TSAs. The buildings and facilities visited during the course of this appraisal included the S\&EP Division complex (which houses the whole body counting facility, the bioassay laboratory, and the dosimetry records: Bldgs. 535, 535A, and 129), the Calibration Facility (Bidg. 348), the Hazardous Waste Management Facility (B1dg. 445), NSLS (B1dg. 725), the Accelerator Department (BIdg. 911), AGS (BIdg. 913), the AGS LINAC (BIdg. 930), the Brookhaven LINAC Isotope Production Facility (BIdg. 931B), the Medical Hot Laboratory (B1dg. 801), the Tandem Van de Graaff (B1dg. 44), the Medical Research Department (B1dg. 490), the Occupational Medicine Clinic (B1dg. 490), and the Biology Department (BIdg. 463).

The S\&EP Division is organized and managed by well-qualified professionals. They understand their responsibilities and strive to inaintain a safe and efficient program.

The internal audit program (Tier II) operated by S\&EP for radiation safety meets the requirements of DOE 5480.11 , but often the resultant report 1acks depth and the wording of the recommendations lacks strength. The incident investigation program is well administered, and improvements are under way to increase trending analyses to identify root causes.

Radiological protection procedures written and used by operating groups do not undergo formal periodic review, revision, and approval by S\&EP personnel. Similarly, all procedures written by S\&EP for their own personnel are not properly tracked for periodic review and revision as required by DOE and by good practice. The Radiation Work Permit system is weak and does not fully satisfy ALARA concerns.

Posting of controlled and radiation zones was generally good with minor exceptions, which are being corrected. Access into building laboratory areas lacks proper controls.

The external radiation dosimetry program is operated by an outside vendor not currently accredited through the Department of Energy Laboratory Accreditation Program. The vendor is attempting to correct the deficiencies and BNL and DOE are closely monitoring its progress.

Internal dosimetry performed on-site consists mainly of urinalysis for tritium and the use of the whole body counter for internal gamma emitters. Most other bioassay samples go to an outside laboratory. There is an S\&EP Division QA check of the whole body counter operation but no independent audit. Similarly, there has been no independent audit of the bioassay program. The program otherwise meets the requirements of DOE 5480.11 .

The radiation monitoring instruments are adequate in quantity and quality and are calibrated at regular intervals although the interval for some portable instruments ( 1 year) is excessive. Some deficiencies in the calibration facility capabilities were noted. A related problem is the failure to properly check instruments in the field between calibrations. 
Contamination control was lacking in the areas where isotopes are routinely handled but is being strengthened. Training, a major factor in contamination control, has improved but needs reinforcement and documentation.

A draft ALARA document, currently under review, lacks sufficient emphasis on environmental releases and contamination control. Moreover, implementation procedures, necessary to bring the individual department ALARA programs into compliance with DOE requirements, have not been developed. 


\section{RP.3 RADIOLOGICAL PROTECTION PROCEDURES AND POSTING}

PERFORMANCE OBJECTIVE: Radiation protection procedures for the control and use of radioactive materials and radiation generating devices should provide for safe operations and for clearly identified areas of potential consequences.

FINDINGS: - Radiological safety procedures, developed by the AGS, NSLS, and Medical Departments to provide guidance in the safe conduct of their operations, were often in the form of memoranda.

- Many of these procedures did not undergo formal review, either initially or periodically, for possible needed changes or additions.

- There was no tracking scheme to ensure that the required reviews and revisions occur.

- A written procedure used in Bldg. 801 had no listed responsible author, organization, or date.

CONCERN: Many radiation protection procedures developed and used by (RP.3-5) operations personnel are outdated or do not apply accepted (H2/C2) good practices. (Also see Concern MA.8-2.)

FINDINGS: - S\&EP Division requires documented reviews of their procedures every 3 years.

- A procedure developed by S\&EP (BSS-2, "Landfill Monitor Procedure") was 5 years old and had no signatures.

- Instructions, developed by S\&EP for their use at the Hazardous Waste Management Facility, were outdated and unsigned procedures issued in 1986 (e.g., HWM-001,-010,-015...).

CONCERN: Procedures issued by S\&EP are not being effectively tracked for (RP.3-6) review, revision, and approval.

$(\mathrm{H} 2 / \mathrm{C} 2)$

FINDINGS: - The Radiation Work Permit form did not contain all the elements necessary to be considered to safely perform a job that may involve radiation exposure, a release of radioactive material, or spread of radioactive contamination.

- A Safety Instruction form existed that provides additional information that should be part of the Radiation Work Permit for many anticipated procedures.

- The Radiation Work Permit system did not ensure ALARA considerations prior to all jobs including those involving modest exposure rates. 
CONCERN: The existing Radiation Work Permit form lacks information required (RP.3-7) to ensure work is performed safely and does not ensure "as low as (H2/C1) reasonably achievable."

FINDINGS: - A child was discovered playing in a laboratory in the Physics Building over a weekend. At least one adult was present. The laboratory was not a radiologically controlled area.

- There were no signs at the entrances of some radiologically controlled rooms or laboratories at the Medical Department clearly restricting entry only to authorized personnel.

- There were no signs at the entrances to many. laboratory buildings, where radiation sources or radioactive materials are used, directing visitors to a receptionist or central office and prohibiting unlimited access to laboratory areas.

CONCERN: Brookhaven National Laboratory does not have an effective program to (RP.3-8) control access to radiological areas.

$(\mathrm{H} 2 / \mathrm{C} 3)$ 


\section{RP.7 INTERNAL RADIATION DOSIMETRY}

PERFORNANCE OBJECTIVE: The internal radiation dosimetry program should ensure that personnel radiation exposures are accurately determined and recorded.

FINDINGS: - The S\&EP bioassay program had not recently undergone an internal audit.

- The S\&EP whole body counter program had not undergone an internal audit, although it had undergone an internal $Q A$ review.

CONCERN: The Safety and Environmental Protection Division internal

(RP.7-1) Division internal dosimetry program has not undergone an internal $(\mathrm{H} 2 / \mathrm{Cl})$ audit as required by DOE 5482.1B. 


\section{RP.8 FIXED AND PORTABLE INSTRUMENTATION}

PERFORMANCE OBJECTIVE: Personnel dosimetry and radiological protection instrumentation used to obtain measurements of radioactivity should be calibrated, used, and maintained so that results are accurately determined.

FINDINGS: - The strongest cesium source available at the calibration facility was not adequate to allow calibration, in conformance with ANSI N323 requirements, of all high-range gamma instruments in use at the laboratory.

- Calibration of the neutron instruments to the accuracy required by the ANSI standards was not possible because of the lack of accuracy of the BNL neutron calibration source.

- Equipment did not exist to test instrument response for temperature, humidity, and energy dependence as required by ANSI N323.

- Many instruments were not checked for their over-range response as required by ANSI standards because of the lack of calibration sources of sufficient strength.

- Many radiation monitoring instruments, fixed and portable, were not source-checked properly in the field to verify that they were maintaining calibration during the period between their annual calibrations.

- Portable radiation monitoring instruments are calibrated annually. ANSI 323 recommends more frequent calibration for instruments subjected to hard usage.

CONCERN: See Concern RP.8-1, Appendix B. 


\section{RP. 11 ALARA PROGRAM}

PERFORMANCE OBJECTIVE: A formally structured, auditable program should be in place with established milestones to ensure that exposures are maintained ALARA.

FINDINGS: - A Laboratory ALARA program did not exist. However, there was a draft ALARA Program Guideline Document which was nearing the final review and approval stage. This guide will be incorporated into the BNL Safety Manual. The guide is intended to provide guidance to help operating groups in developing their own Al ARA program.

- The draft ALARA Program Guideline was based on personnel dose levels. Reducing environmental releases and contamination levels was given little emphasis.

- Existing ALARA programs at the individual facilities were difficult to audit and did not adequately address contamination control, environmental releases, and reasonable efforts to reduce even low exposures.

- There were no ALARA implementation procedures in he areas of auditing, trending, and training.

CONCERN: See Concern RP.11-1, Appendix B. 


\section{INDUSTRIAL HYGIENE}

The emphasis of this evaluation was on the Industrial Hygiene Program. In addition to the offices and laboratory of the Industrial Hygiene group (BIdg. 535), field surveys or interviews were made at the NSLS (BIdg. 725), the Chemistry Building, (BIdg. 555), and the Occupational Medical Clinic (BIdg. 490).

Contacts were with operating, supervisory and senior management professional staff. Industrial hygiene program requirements have expanded in recent years, as new standards have been adopted and previous standards broadened or reinterpreted. Important examples are hazard communication, hearing conservation, and respiratory protection.

No deficiencies were noted in hearing conservation. However, the hazard communication and respiratory protection programs were not in line with requirements. Since deficiencies have been noted previously, and are addressed in action plans, status will be summarized in this overview, and concerns will be expressed only where implementation schedules are not being met, or are overly generous in the amount of time allowed.

Hazard communication is the area with the greatest amount of work remaining. The BNL decision to operate under the laboratory provisions of the standard has delayed the effective date of training requirements. The OSHA Final Rule for Occupational Exposures to Hazardous Chemicals in Laboratories, effective May 1, 1990, requires more training than the Laboratory provisions of the Hazard Communication standard. This OSHA policy change adds to the scope of the BNL compliance effort. The compliance dates in BNL action plans called for "generic" training to be completed by the end of June 1990 and more detailed training to be completed by December 1990. Although the Laboratory expresses confidence that those target dates will be met, plans are lacking in specific commitments of time and personnel necessary to comply.

The existence of Laboratory programs which predate the standards and the longstanding issue regarding the regulatory approaches to laboratories appear to have contributed to a lack of urgency. As a result, specific compliance plans, with firm commitments of time and resources, have yet to be developed.

Upgrading the respiratory protection program is also necessary. The Laboratory is proceeding to provide annual training for users of negative-pressure respirators to include quantitative fit testing. Supervisory training is also in progress.

Communication between Industrial Hygiene and the Occupational Medical Clinic was explored, and no major failings were perceived. A potential need for more systematic communication is recognized.

Sampling priorities, protocols, and reports have been documented in an Industrial Hygiene Policies and Procedures Manual, which appears fundamentally sound. 
Laser inspections and procedures have been improved and appear to comply with ANSI Z136.1.

Overal1, increased attention to the selection of priorities and the establishment of schedules with specific commitments of time and resources seems in order. 


\section{IH.4 SURVEILLANCE OF HEALTH CONCERNS}

PERFORMANCE OBJECTIVE: Appropriate surveillance of activities should be conducted to measure industrial hygiene performance and ensure the continual effectiveness of controls.

FINDINGS: - The Permissible Exposure Limits are usually expressed as 8hour time-weighted averages, but often are based upon chronic effects based upon exposure over a working lifetime.

- BNL Industrial Hygiene had recognized the long-term nature of exposure estimates which would be of most use to allied health professions (e.g., Medical, Epidemiology). For some exposures, data were developed to integrate total exposure (e.g., noise, asbestos). This practice had not been extended to apply to other hazards encountered in the work environment.

CONCERN: Industrial hygierie data are not developed to allow long-term (IH.4-1) exposure estimates for many substances.

$(\mathrm{H} 2 / \mathrm{C} 2)$ 


\section{IH. 6 PERSONNEL COMMUNICATION PROGRAM}

PERFORMAMCE OBJECTIYE: Site/facility ersonnel should be adequately informed of chemical and biological stresses that may be encountered in their work environment.

FINDINGS: - Hazard communication training was incomplete.

- The amount of specific training requires had been expanded by the puhlication of OSHA 29 CFR 1910.1450.

- Plans to accomplish hazard communication training commitments lacked specifics.

Realistic dates for compliance with the training requirements for hazard communication had not been established.

CONCERN: Brookhaven National Laboratory is nut in compliance with

(IH.6-2) 29 CFR 1910.1200 and unlikely to comply with deadlines (H2/C1) established in 29 CFR 1910.1450. 


\section{‥ OCCUPATIONAL SAFETY}

The emphasi is of this evaluation was on the program for Occupational Safety. In addition to the offices of the Occupational Safety Group (B1dg. 535), field surveys or interviews were conducted at the Biology Building (Bldg. 463), the Chemistry. Building (Bldg. 555), the Plant Engineering Offices (B ${ }^{2} \mathrm{dg}, 134$ ), and the Waste Water Treatment Planc. Contacts were with line and stafi management professionals, and a few nonsupervisory personnel. Inadequacies identified previously, and included in action plans, are addressed in this overview.

Accideni rates have substantially exceeded average for the DOE-regulated community. Analysis of accident factors, using data provided by Investigated Incident Reports, UORs, Recordable and Lost Workday accidents, have been previously found inconsistent and/or poorly documented. Root cause analysis and tracking of remedial actions have al so been found inadequate. Current Laboratory action plans address these previously expressed findings. The monthly Occupational Health Review meeting group has formed a subcommittee to assist in accident/incident reduction planning and programming. Documents describing increased emphasis on occupational safety have been distributed and were available. A "Team Safety" program rewards and recosnizes operating units for achieving periods of 8-12 weeks without a lost workday injury. Accident record trends show a conitinuing decrease starting in 1988. While accident rates continue to exceed $D O E$ averages, the positive trend and the increased management emphasis are believed related.

Construction safety has been a source of major concern in recent years. A double-fatality accident in 1986, involving construction activity, was the only instance in which a BNL employee has been fatally injured. However, independent evaluations of the Laboratory ES:H program have identified significant risks on construction projecis, including a condition during a September 1989 TSA which required an order to stop work.

The construction safety program has received substantial emphasis in the last few years. Plant Engineering has developed a program stressing contractor safety requirements at the pre-bid, award, and project implementation stages. Additional staffing has been provided. This system establishes and communicates requirements and verifies conformance of contractors, at each stage of the project. It incorporates applicable standards and is in line with recommendations of the insurance industry for effective loss control on major construction projects.

Protective equipment requirements and usage, lock out/tag out, and interlock maintenance hà'e been the subject of critical comments in previous evaluations. Letters indicating management attention to these concerns have been distributed. 


\section{OS.3 MANAGEMENT OF SAFETY CONCERNS}

PERFORMANCE OBJECTIVES: Physical and/or other environmental stresses arising in the work place should be identified, evaluated, and controlled.

FINDINGS: - The Biology Department, Bldg. 463, contained a pottery shed adjacent to an office area. Pesticides were stored and mixed in the shed. Food and beverages were consumed in the office area.

- Doors between the shed and the office area were noted in an open position.

- While there is a sink in the shed, there is another within the office area, and coffee cups were hanging on a pegboard over the office-area sink.

- There were no requirements for door closure or signs to remind employees of the need to wash hands in the shed after working there.

- After the team expressed its concern, the Biology Department immediately installed signs requiring the door to remain closed at all times.

CONCERN: All pasticide hazards arising in the work place are not identified (OS.3-1) and controlled.

$(\mathrm{H} 2 / \mathrm{C} 2)$ 


\section{S.5 COMPLIANCE WITH OCCUPATIONAL SAFETY STANDARDS}

PERFORMANCE OBJECTIVE: Work places should be free of uncontrolled physical safety concerns and be in compliance with DOE-prescribed occupational safety standards.

FINDINGS: - Two catch basins at the waste water treatment plant can receive and hold water in depths of 7 feet or more.

- The polymeric material which forms the sides and bottom of the basin can itself be slippery. Algae and other growth can further contribute to slip hazards.

- Two incidents of an employee slipping into the basin were reported to the TSA team.

- There were no provisions for emergency egress or rescue from the catch basin.

CONCERN: Egress or rescue capability is not provided for the catch basins (OS.5-3) as required by the Occupational Safety and Health Act, $(\mathrm{Hl} / \mathrm{Cl})$ Section 5(a)(1). 


\section{FIRE PROTECTION}

During this TSA, procedures relating to fire protection equipment testing and inspection were reviewed. Fire protection inspection and test procedures were reviewed on a selected basis. (See Appendix C for details.) Proposed and existing budget items for fire-protection related improvements were appraised. Interviews were held with the fire protection engineer, deputy manager of facilities maintenance, safety coordinators of the selected buildings, and Fire Rescue Brigade shift captain. The AGS (BIdgs. 912, 918, 922 \& 923 with associated mobile trailer and modular units), Chemistry (Bldg. 555), Physics (BIdgs. 510 and 515), NSLS (BIdg. 725), Accelerator Development Dept. (B1dgs. 901 and 905), Medical Research Center (Bldg. 490), Biology (Bldg. 463), Tandem Van de Graaff (Bldg. 902), Central Shop (Bldg. 462), Water Treatment (Bldg. 624), Steam Plant (Bldg. 610) were physically surveyed. Other buildings noted in this report were observed by the September TSA Team fire protection engineers. Related findings and concerns from that appraisal were discussed with the BNL fire protection engineers.

BNL does not presently meet all DOE standards and NFPA codes pertaining to its facilities. While identification of major hazards and physical protection improvement measures have been documented by BNI, limited funding has delayed implementation of many of the original 171 recommendations from the 1974 Factory Mutual Engineering Association Report.

A detailed analysis of fire protection risks has not been updated since the 1984 Professional Loss Control Report. Without this total analysis of the facility, including life safety, a consolidated long-range improvement $\mathrm{plan}$ cannot be implemented. It is recognized that BNL is over 40 years old with buildings dating back to the 1940s. However, without a plan assessing the missior requirements and actual serviceable life of the plant, BNL cannot reach the Improved Risk Criteria. The key to this plan will be reasonable and sustained funding for upgrades, based upon existing and proposed studies conducted by BNL.

The fire protection urganizational structure is well defined and understood. However, some procedures need to be updated to refer to field forms and frequencies of activities now employed by the staff. Some of the functions of a fire protection engineer, such as facility appraisals and risk analyses, cannot be routinely performed due to a lack of adequate staffing. Long-term funding limitations have resulted in fire protection improvement items from key independent studies, dating from 1974, not being corrected in a timely manner. $\mathrm{CH}$ has not conducted a formal Industrial Safety and Fire Protection Appraisal since 1987 (an appraisal was made in 1988, but no formal report was developed).

Many buildings at the Laboratory do not meet NFPA 101, "Life Safety Code." A Survey Plan of Action was developed by BNL in April 1989. Personnel exposure to toxic gases from hazardous materials areas can occur during a fire evacuation due to unrated doors and enclosures to the rooms adjacent to egress hallways (e.g., Reactant Storage at Medical Research Center and Hazardous Waste Storage area of Biology). Inadequate horizontal and vertical subdivision is provided in some major buildings to ensure safe evacuation. 
A quantitative analysis of risk has not been formally documented to ensure that an off-site release of toxic materials will not occur under a Maximum Credible Fire Loss at the AGS. An SAR is being developed.

The fire loss of a transformer in the substation areas adjoining the AGS may involve adjacent transformers, cable trays, or building structures due to inadequate separations. Thi's condition could lead to a protracted outage for operations while await the installation of replacement equipment.

Formal analysis of Marinulin credible Fire Loss has not been provided in key facilities. Cooling tower exposures to the Chemistry and Physics Buildings, unprotected cable trays in the AGS and NSLS, and areas shielded from sprinkler protection at the NSLS and AGS are of principle concern. The large undivided spaces of the AGS and NSLS pose a value subject to loss greater than 25 million.

The Fire Department appears to be well trained and prepares detailed pre-fire plans for response.

Flammable liquid quantities in laboratory areas are generally larger than encountered in general industry practice for similar occupancies. Combustible storage in ventilation areas and utility corridors pose a potential for smoke spread throughout building areas. Combustible materials and evidence of smoking were encountered within cable trays areas. Portable trailers adjacent to the AGS pose an exposure to tl e exterior tiers of cable trays and the AGS building wall. Extensive roof leakage was noted throughout the Laboratory, posing a large-scale damage potential to important equipment and experiments.

Limited fire protection staff and funding constraints appear to account for the majority of issues covered in this appraisal. An effort has been made by BNL and S\&EP to identify and prioritize these issues as they are encountered.

A positive program involves the installation of Emergency Information signs at each laboratory, instrument shop, and chemical storage area. The signs have card slots identifying emergency contacts, department responsible for the room, radiation hazards, toxic hazards, flammable liquids (over 1 gallon in quantity), and utilities present in the room. Instructions for completing the cards are on the sign. Periodically, the cards must be reviewed and updated. This practice provides easily accessible information to the emergency responder, as well as raising the awareness of the occupants to the potential hazards in their areas.

Automatic sprinkler riser control valves are both monitored by the proprietary alarm system for tampering and locked in the fully open position with nonbreakable shackle locks and chains. This good practice, together with regularly recorded inspections of the valve, ensures that water supplies to sprinkler protection are not inadvertently shut-off by unauthorized personnel. This maximizes the effectiveness of both the electronic supervision and deterrence of the locks. 


\section{FP.1 ORGANIZATION AND ADMINISTRATION}

PERFORMANCE OBJECTIVE: Fire Protection organization and administration should ensure the effective implementation and control of fire protection equipment and activities.

FINDINGS: - BNL has provided an additional fire protection engineer; however, a further increase in staff is needed to meet the DOE Fire Protection Resource Manual requirement.

- There were no documented job qualification requirements for fire protection engineers.

CONCERN: See Concern FP.1-1, Appendix B.

FINDINGS: - Approximately $\$ 3$ milition (M) was provided for improvenents in fire protection (primarily for the on-site fire alarm system) in FY 1989 and an additional \$1.7M was provided in FY 1990. The majority of recommendations have not been completed.

CONCERN: See Concern FP.1-2, Appendix B.

FINDINGS: - Formal Annual Industrial Safety and Fire Protection Appraisal had not been conducted by $\mathrm{CH}$ since 1987 .

CONCERA: The Chicago Operations Office has not conducted Fire Protection (FP.1-3) Appraisals of Brookhaven National Laboratory facilities at the (H2/C1) frequency required by DOE 5480.7.

FINDINGS: - A pre-printed inspection form was being used during fire protection water supply valve inspections but was not required by the test procedure.

- A written protocol, stipulating flow sites and gauge locations for annual loop and source tests, was not provided in the water testing procedures, but an informal draft had been developed and was sometimes used.

- Consistent fire water supply test locations were not being used, thereby, making it difficult to "trend" historical test data. A decline in water supplies to an area or steady increases in pipe friction loss may not be identified in a timaly manner.

CONCERN: All requirements for testing frequency and documentation for

(FP.1-4) fire protection equipment are not clearly identified in

(H2/C2) Brookhaven National Laboratory fire protection procedures. 


\section{FP.2 LIFE PROTECTION}

PERFORMANCE OBJECTIVE: All facilities on site should provide adequate life safety provisions against the effects of fire.

FINDINGS: - A complete life safety appraisal of all Laboratory buildings has not been made.

- In 1976, Gage-Babcock Associates conducted a Life Safety study of 15 facilities at BNL. Thirty percent of the recommendations were implemented.

- Since considerable changes in occupancy and code requirements had occurred, BNL developed a Survey Plan of Action on April 27, 1989. This survey had not been conducted.

- Dead-end corridors with inadequate warning signs were encountered in the AGS, Chemistry, and Biology complexes.

- Travel distances within AGS complex beam hall exceed NFPA 101$1988,5-6.2$ and needs analys is in NSLS.

- The doors to the Reactant Storage Rooms in the Medical Research Center (e.g., Room 9-283) were blocked open and communicated with the hallway.

- The waste pickup area, Room 121A, of the Biology Building, had both flammable and mixed waste. The room had unsealed wall penetrations and unprotected doorways. In these areas, toxic products of combustion would spread easily to the surrounding operations making life safety evacuation difficult. This would increase chemical contamination within the facilities or result in a release of contamination outside of the buildings.

CONCERN: See Concern FP.2-1, Appendix B. 


\section{FP.4 IMPAIRMENT OF OPERATIONS}

PERFORMANCE OBJECTIVE: The site should not be vulnerable to being shut down for an unacceptable period as the result of a credible fire.

FINDINGS: - The transformer yard at the southwest end and the substation at the north end of B1dg. 912 were located within 10 feet of the corrugated steel frame exterior walls of the AGS. The individual transformers were in close proximity to one another. Neither individual dikes, division walls, nor fire protection were provided to control the spread of burning oil or shrapnel. The fire loss or explosion of one transformer may involve adjoining units, cable trays, or the AGS building walls.

CONCERN: The transformer yard arrangement does not meet the criteria of (FP.4-2) Factory Mutual Data Sheet 5-4, Table III for equipment and $(\mathrm{H} 2 / \mathrm{C} 2)$ building separation. 


\section{FP.5 PROPERTY PROTECTION}

PERFORMANCE OBJECTIVE: A maximum credible fire, as defined in DOE 5480.7, Section 6.f, should not result in an unacceptable property loss.

FINDIMGS: - Specific Fire Hazard Analyses had not been performed on routine basis to identify those areas where a fire could have a significant programmatic impact that could shut down the operation or facility for a period greater than 6 months for all areas. The impact of a fire on operations could not be determined because of the lack of fire risk analysis or fire hazards analysis reports.

CONCERN: See Concern FP.5-1, Appendix B.

FINDINGS: - The wood frame and combustible fill cooling tower atop the Chemistry Building is nonsprinklered and is adjacent to the metal frame mechanical penthouse.

- The wood frame and combustible fill cooling tower atop the Physics Building was no longer in use and is nonsprinkler protected.

CONCERN: A fire involving either the Chemistry or Physics complex cooling (FP.5-2) towers may result in direct damage to the buildings in excess of $(\mathrm{H} 2 / \mathrm{C2})$ the "improved risk" criteria of DOE 5480.7 .

FINDINGS: - In the NSLS, Room 1-110, ventilation equipment and duct work near the ceiling posed an obstruction to the sprinkler above.

- Automatic fire protection was not provided within the hutches along the beam lines of the NSLS, resulting in obstructed areas from roof sprinklers, above.

- A 10-foot $\times 10$-foot Hypolon hood had been erected over the Laser Electron Gamma Source which obstructs ceiling sprinklers from this equipment. Obstructed areas of otherwise adequately sprinkler protected buildings can allow fires to grow in intensity and spread products of combustion to surrounding areas.

- An undocumented decision was made not to provide automatic sprinkler protection at the roof level of the AGS Complex based upon the height of the building ( 80 feet) and relative insensitivity of the heads to a fire at the floor. This has resulted in an implied occupancy standard.

- A combustible storage area existed below the open metal grating of the power supply transformers in B1dg. 912 at Column A-2, and automatic sprinkler protection was not provided. 
- Many small carpenter and maintenance areas; a welding area; and enclosed mezzanine, control room, office, and restroom areas are nonsprinkler protected in the AGS.

- Hypolon shrouds were installed around accelerator targets at AGS and NSLS. Line-type heat detection was provided; however, ribbon cable, power supplies, and hydrogen gas contributed to a fuel loading that had the potential for a sustained fire.

- An extensive network of cable chases and tunnels, as well as the beam enclosures (tunnels) themselves, had limited access to fire protection and a heavy coricentration of combustible plastic insulated signal and power cables in AGS.

- While the overall beam-1ine complex was non-combustible, the sensitivity of equipment to smoke damage and the values of equipment in combustible, nonsprinklered areas may result in a fire loss in excess of the "improved risk" criteria outlined in DOE 5480.7 .

- The portable laminar air units, used for maintenance of light beam equipment at the NSIS complex measure 5 feet by 7 feet and were constructed of $\mathrm{pl}$ istic sheeting and particle board on a steel frame form and were an obstruction to the sprinkler protection above. A fire originating inside a portable laminar air unit during service may result in direct loss and programmatic impact in excess of improved risk criteria from DOE 5480.7 .

CONCERN: Combustible areas obstructed from sprinklers at the National

(FP.5-3) Synchrotron Light Source and small combustible operations of the

$(\mathrm{H} 2 / \mathrm{C} 2)$ Alternating Gradient Synchrotron are not protected in accordance witi: ractory Mutual Data Sheet 2-8 for Highly Protected Risks.

FINDINGS: - Fire protection is not provided for the computer in Room 2-198 of the Physics complex.

- The Digital Equipment Corporation Vax 11/750 in Room 2-208 of the Physics Complex did not have automatic fire protection.

- The computer tape storage in Room 2-211 of the Physics complex may represent vital data acquired through a long or difficult research process (actual status unknown). This area did not presently have automatic fire protection.

- The computer lape storage in the second and third floor corridor of the Physics complex contains data of likely importance to experimental programs or research. This area did not presently have automatic fire protection.

- While automatic sprinkler protection had been provided for the basement tape storage vaults of the Physics complex, a 
critical records review had not been conducted to determine the need for further off-site duplicate storage (NFPA 232).

- In the Biology complex, the STEM I and II Rooms were protected by only Halon 1301 automatic fire suppression.

- The computer room used for processing experimental data in the Chemistry coinplex was not equipped with automatic fire protection.

- Combustible paper storage was present within the open area of the computer room of the Chemistry Complex in excess of daily use.

- Openings in the walls (including a non-rated glass-windowed door) for the Chemistry computer would allow smoke to reach this area from the surrounding nonsprinklered operations.

- In the computer rooms surveyed, floor-puller apparatus were unavailable for access to the raised floor. In the event of fire, these apparatus would be important to gain access to the raised floor.

- No formal study of critical or vital records has been made for this media.

- The raised floor in Experiment 814 Counting House was imbalanced and causes the tape drives to sway. Damage may result to the tape drive units or data, due to foot traffic in the Counting House.

CONCERN: Automatic Fire protection of critical records, off-site vital records (FP.5-4) storage, and the arrangement of equipment are not consistently $(\mathrm{H} 2 / \mathrm{Cl})$ provided for electronic data and computer apparatus as required by DOE 5480.7 and mandatory standards.

FINDINGS: - Roof leaks were noted in the AGS, Accelerator Development Department, Biology, Chemistry, and Physics Buildings.

- \$10M magnet in operation at the AGS had a shroud in place to prevent damage from roof leaks.

- The roof of the B1dg. 814, Counting House, was actively leaking during the survey.

- Tall grasses and two trees (approximately 12 feet high) were growing from the roof of the Physics building.

CONCERM: The maintenance of roof decks is inadequate to prevent damage (FP.5-5) to critical equipment and experiments and weakening to windstorm $(\mathrm{H} 2 / \mathrm{C} 1)$ damage per DOE 5480.7 . 
FINDINGS: - Plastic-insulated cabies in trays represent a significant combustible loading which can produce both dense, corrosive smoke and signal and power system damage. While testing by BNL and by Fermi laboratories concluded that little or no hazard was posed by such cables, loss experience throughout industry, as well as extensive full-scale testing by Factory Mutual Research Corporation, has shown otherwise.

- Multitiered cable trays extended throughout the AGS and Tandem Van de Graaff Accelerator complexes. The trays had multiple layers of plastic-covered cables 8 inches apart. Vermiculitefilled plastic bags used for fire stopping are not listed or approved material and did not cover the entire width of the trays.

- Cables below the raised floor in the Upper Terminal Room of the AGS (BIdg. 911) were not protected by automatic sprinklers despite their heavy concentration.

- There were cables in moderate groupings both above and below the NSLS LINAC. Despite the presence of heat detectors in the LINAC, there was no fire protection for this concentration of combustible cables.

- While automatic sprinklers were provided in the cable tunnel adjacent to the Terminal Room of the AGS, cables in lower trays were shielded from the heads at the ceiling. (See Concern FP. 5-3.)

CONCERN: Cable tray arrangements do not meet the criteria of Factory Mutual (FP.5-6) Data Sheet 5-31, and the impact of a fire involving this material $(\mathrm{H} 2 / \mathrm{C2})$ has not been recently analyzed.

FINDINGS: - Vertical subdivision was not adequately provided within the utility corridors of the Chemistry and Physics Buildings by providing smoke-tight, fire resistive seals around pipe, cable, and duct openings.

- Rated fire walls were not provided between the maintenance areas and the beam line of the NSLS despite an equipment value of nearly $\$ 30 M$.

- Walls were not fire rated assembiies between the Instrument Shop and storage areas adjoining the NSLS beam lines.

- The AGS Experimental Floor (B1dg. 912) was a largely open area without fire walls for beam line subdivision or separation from adjoining office and equipment areas. 
- The Accelerator Development Department complex lacked fire walls between building sections and exposed high-valued equipment to smoke damage during fire suppression activities. The lack of fire walls during times of impairment to sprinkler protection may subject the entire facility to a fire.

CONCERN: The lack of fire walls, smoke barriers, or sealed vertical cut-offs (FP.5-7) poses a loss potential in excess of the improved risk criteria of $(\mathrm{H} 2 / \mathrm{C} 2) \quad$ DOE 5480.7 .

FINDINGS: - In at least 18 buildings at BNL, the Maximum credible Fire Loss appears to exceed $\$ 1 M$ because of the lack of instailed automatic fire protection systems (mainly fire sprinkler systems). Examples include Bldgs. 50, 179, 422, 477, 480, $510,526,555,801,815,820,901,902,905,912,918,929$, and 930 .

- Formal Maximum Credible Loss Analyses had not been performed for all major buildings to determine the doliar loss potential.

- The east experimental area rectifier trailers, Experiment 778 Trailer, Bldg. 912, and wood frame roof over the Beam Line "C" had been provided with exterior urethane foam insulation. These structures are adjacent to the main AGS Beam Line Building and below 10 levels of exterior mounted cable trays. A fire involving low-valued structures adjacent to Bldg. 912 may cause major damage to the building and important cables in excess of DOE 5480.7, DOE/EV-0043, and goud practice for Highly Protected Risks.

CONCERN: Brookhaven National Laboratory has not determined through formal and (FP.5-8) regularly scheduled analyses that a maximum credible fire will not $(\mathrm{H} 2 / \mathrm{Cl})$ that a maximum credible fire will not result in an unacceptable property 10ss, as required by DOE 5480.7 . 


\section{FP.7 PROGRAM IMPLEMENTATION}

PERFORMANCE OBJECTIVE: A fire protection engineering program should be in place to effectively provide and maintain an "improved risk" level of fire protection.

FINDINGS: - Experiment 719 Counting House, BIdg. 912 in the AGS Beam Line complex was provided with an automatic Halon 1301 fire suppression system. However, the cable penetrations in this module were not sealed.

- The lower terminal room in the AGS complex did not have a gastight barrier established for cables penetrating the wall to the control room. Some Halon protected areas of the Alternating Gradient Synchrotron are not sealed to maintain extinguishing agent concentration, per NFPA-12A.

CONCERN: See Concern FP.7-1, Appendix B.

FINDINGS: - Standpipe cabinets in the NSLS, Physics, and AGS complexes had solid metal or partial glass and metal doors which were not labeled and were painted the same colors as the surrounding walls. Standpipe locations were not readily discernable from surrounding walls and would be difficult to identify in an emergency.

- Fire Extinguisher locations were not visible from both sides of the corridors in the Chemistry, Biology, and Physics complexes.

- A study and purchase of additional Class $A$ extinguishers were being conducted.

CONCERN: See Concern FP.7-2, Appendix B.

FINDINGS: - The laboratory flammable liquids storage and use practices generally meet NFPA 45. However, quantities up to 15 gallons of Class I flammables (not including other Class II and III flammable quantities) were observed on open laboratory benches or in hoods in excess of good practice. The overal1 level of flammable liquids is not governed by an ALARA policy for the Laboratory. Flammable liquids used or stored in laboratories are not controlled in their use and storage in accordance with good practice.

- When stored with in the rooms, flammable 1 iquids in the Medical Research Center, Biology, and Chemistry laboratories, were placed either in the laboratory hoods or in single thickness metal or wood cabinets lacking a known fire resistance or means of spill contioinment. 
- Many of the laboratory hoods throughout BNL had electrical receptacles within the work space. The hoods can be used for handling and dispensing flammable liquids and gases (both heated and unheated). A flammable vapor or liquid splash environment is possible. Many laboratory hoods built before 1981 did not have electrical receptacles that meet hazard classification criteria of NFPA 45 Section 6-9.4. for exi ting (not labeled) or new installations (not outside of ventilation).

- The four hoods for perchloric acid in the Chemistry Building did not have automatic sprinkler protection. The perchloric acid hoods did meet fire protection requirements per NFPA 45 Section 6-12.7. However, in industry, these hoods are provided with automatic sprinkler protection as well.

CONCERH: See Concern FP.7-4, Appendix B.

FINDINGS: - An independent consultant was reviewing the existing doors and walls to identify fire separations.

- Unsealed penetrations containing pipes, cable trays, and conduit extended through floors and walls in the AGS and NSLS complexes.

CONCERN: See Concern FP.7-6, Appendix B.

FINDINGS: - Expanded plastic insulation on ductwork was noted in Bldgs. $197,477,510$ (basement), 555, 815, 902, 905, 911, and 930 .

- Testing by Factory Mutual Research Corporation has shown that sprinkler protection alone cannot protect this material and that a fire resistive thermal barrier over the surface is needed.

CONCERN: See Concern FP.7-7, Appendix B.

FINDINGS: - Hood frame combustible trailers located adjacent to the corrugated metal on the steel frame exterior wall of Bldg. 943 were in poor physical condition.

- The close proximity of these comblistible structures makes them a major fire exposure to a significant operating building with inadequate separation, per DOE/EV-0043, "Standard on Fire Protection for Portabie Structures."

CONCERN: See Concern FP.7-9, Appendix B. 
FINDINGS: - Compressed gas cylinders were stored directly against the fence of the transformer yard at the southeast corner of Bldg. 912 arid within 10 feet of transformers. Compressed gas cylinders in the above area pose an undue exposure to transformers adjacent to B1dg. 912, per Factory Mutual Loss Prevention Data Sheet 5-4, Table III.

- Acetylene and oxygen cylinders stored along the transformer yard ferice at the southeast corner of Bldg. 912 were less than 5 feet apart. The cylinder storage arrangement provided inadequate separation to prevent the co-mingling of flammable gases and oxygen, per NFPA 51.

- There was no guard rail around the compressed gas cylinder storage at the transformer yard along the southeast corner of Bldg. 912 to prevent mechanical damage from traffic in the area. There was inadequate guarding for the cylinder storage, per the Compressed Gas Cylinder Association guidelines.

CONCERN: Precautions for the storage and use of compressed gas cylinders are (FP.7-10) not in accordarce with improved risk practices.

$(\mathrm{H} 2 / \mathrm{C} 1)$

FINDINGS: - Stock was stored up to the ceiling in such areas as the Block 12 corridor of the Medical Research Center and in laboratories of the Biology Building (including Room B-229). In these automatic sprinkier protected buildings, the stock height was closer than the 18 inches minimum clearance from the sprinkler deflector specified by NFPA 13.

- Autumatic sprinkler riser control valves in NSLS and AGS were located in the center of the building accessible only from the inside. In a fire, when the system is out of service for repair, access to return the system to operation at the interior riser valves will be difficult by the responder.

CONCERN: (FP. 7-11) $(\mathrm{H} 2 / \mathrm{C} 2)$

FINDINGS:

CONCERN: (FP. 7-12) $(\mathrm{H} 2 / \mathrm{Cl})$
Automatic sprinkler systems at Brookhaven National Laboratory are not always arranged and maintained according to improved risk as according to improved risk as outlined in the NFPA Fire Protection Handbook.

- There was no diking to contain hydraulic fluid (mineral oil) from the elevator equipment rooms of the Chemistry, Physics, or AGS complexes. Burning oil may spread to surrounding areas, increasing damage to important equipment.

There is no diking around elevator hydraulic tanks and pumps per NFPA 30 Section 2-4.1.1 which can allow burning oil to spread to surrounding equipment. 
FINDINGS: - Extensive use of portable electric cords was noted in the NSLS, Accelerator Development Department, and AGS complexes instrument maintenance facilities. Many of these units were fed from ceiling receptacles with no strain relief and each served multiple appliances.

- Fiberglass insulation had been installed directly on top of the suspended mineral tile ceiling and lighting of the B-Wing, B1dg. 902. A overheating condition may develop at the light fixtures resulting in gradual deterioration of the wiring insulation or fire. This modification measure may exceed the lighting fixture manufacturer's instructions, U.L. listing criteria, or NFPA 70 requirements for air circulation.

- The Helium circulation pumps and associated equipment in the Axion Area of the Accelerator Development Department produced water condensate at start-up which drips on to equipment below, posing a potential of electrical short circuit and fire.

- Electrical directories in the circuit panel boxes of the AGS were not up-to-date in accordance with 29 CFR 1910 and NFPA 70 requirements for circuit identification.

- Evidence of vermin (e.g., raccoons, rats, and mice) entering building electrical areas from the outside through openings in exterior walls for the passage of cable trays had been established. Vermin may cause major damage to electrical equipment by shorts or fire.

- The outer insulating jacket of cables in the floor tray of Bldg. 912, adjacent to column A-2, were cracked.

- Review of cables in several other trays in B1dg. 912 showed cross-sectional crushing, bulging of the outer jacket, and chafing.

- Branches from surrounding bushes adjacent to the southeast corner of Bldg. 912 extended into the exterior cable trays.

CONCERN: Cable and wiring circuits are not fully maintained in accordance (FP.7-13) with NFPA 70 "National Electric Code".

FINDINGS: - Combustible records were stored in the vicinity of cooling fan ducts in the first and second floor mechanical rooms of the Chemistry complex.

- Combustible boxes, wood cabinets, and flammable gases were stored on each floor of the utility corridor extending directly from the first floor to the third floor of the Chemistry complex. A fire within the combustible or flammable 
storage may allow the smoke to be spread to surrounding areas by ventilation ductwork or natural "flue effect," exposing personnel to toxic fumes and gases and extending damage to adjacent rooms.

- Combustible urethane foam insulation overspray from surrounding trailer module roofs has accumulated in adjacent cable trays around the exterior of the AGS. Combustible debris and urethane overspray may become ignit:d and damage important cables in the trays.

- The AGS Beam Line complex was a largely nonsprinklered structure. However, combustible wood materials were used in the construction of catwalks and maintenance cribs, and combustible wood crates were stored atop beam line tunnels. The use of combustible materials for construction of "incidental" facilities posed an unnecessary fire and smoke damage exposure to important programmatic equipment which can easily be substituted with noncombustible materials.

CONCERN: The presence of combustibles in critical equipment or otherwise

(FP. 7-14) $(\mathrm{H} 2 / \mathrm{C} 2)$

FINDINGS:

CONCERN: (FP.7-15) $(\mathrm{H} 2 / \mathrm{C} 2)$

FINDINGS : unprotected areas, such as at the Alternating Gradient Synchrotron, poses an avoidable fire risk.

Evidence of tobacco smoking was observed in and around transformers, throughout cable trays, in and around operating oil filled pumps of the AGS Beam Line complex (BIdg. 912).

Tobacco smoking is an ignition source to transient combustibles in the Alternating Gradient Synchrotron, a largely unprotected and important facility.

There were four 0il-cooled transformers (250 gallon capacity each) located along the AGS beam separator line.

- The terminal cables were supported by 2 -inch $\times 4$-inch boards, held in place by the weight of each cable.

- The majority of bolts for the transformer lids were missing.

- Heavy oil deposits were across the top of each transformer.

- The transformers lacked either an automatic fire suppression system or vault enclosure.

CONCERN: Maintenance, cable support, and fire protection for the (FP.7-16) transformers near the beam separator line of the Alternating (H2/C2) Gradient Synchrotron are not in accordance with the manufacturer's instructions or Factory Mutual Data Sheet 5-4. 


\section{P. MEDICAL SERVICES}

This appraisal addressed all five performance objectives applicable to medical services provided by the Occupational Medical Clinic (OMC). During the course of this appraisal the following locations on- and off-site were visited: University Hospital, Health Science Center; State University of New York at Stony Brook, Occupational Health Program, Department of Preventive Medicine, Radiology, Nuclear Medicine Services and the Radiation Safety Facility; Berkner Hall (Bldg. 488); Medical Research Center (Bldg. 490); Occupational Medicine Clinic (a wing of B1dg. 490); Biology (B1dg. 463); NSLS (B1dg. 725); Sewage Treatment Facility (B1dg. 575); Steam Plant (B1dg. 610); Safety Division (B1dg. 525-129); Compton House (B1dg. 170); Police Headquarters (B1dg. 50); Firehouse (Fire Department) (B1dg. 599); Administration Data Processing (Bidg. 459); and Administration (Bldg. 460).

BNL has a clearly defined and well-structured occupational medicine program which is adequately staffed and directed by an experienced and competent Medical Director. The Medical Director has been on the job less than a year but with the active support of top management has made and continues to make great improvements in the program.

The last medical audit of this site by HQDOE, was in March 1987 . No written report of this audit has been received by $B N L$. This HQDOE Medical Appraisal is being done concurrently with the TTA. Past appraisals were inadequate in relation to the Medical Clinic activities.

There is an open line of communication between the Medical Director and top management of both $\mathrm{BNL}$ and $\mathrm{BHO}$ and excellent personal relations exist. Services to protect personnel from site hazards are made available to all employees and users by Occupational Medicine, Industrial Hygiene, Health Physics, and Safety. Medical examinations, screening, and testing are adequate for preemployment, periodic, and termination observations. In addition, there are 27 protocols for Medical Surveillance Examinations mandatorily imposed on those employees subjected to special occupational hazards, such as asbestos, etc.

Treatment is adequate for both simple occupational and non-occupational injuries and illnesses. More serious conditions are referred to local hospitals, specialists, or the patient's private physician. This system reduces BNL health care costs, reduces time away from employment, and aids employee morale. The Clinic Staff is well trained and maintains proficiency by annual continuing education required to maintain their state licenses. Two of the four physicians are Board Certified Specialists in Occupational Medicine. Several were "Qcleared" even though only a few sites at BNL are so restricted.

Even though policies, procedures, and practices of the OMC have not had the scrutiny given to Industrial Hygiene, Health Physics and Safety, OMC procedures are well documented, adhere to BNL and DOE Directives, and are kept current in manuals in OMC. An on-site first-level life support ( $A B C$ ) equipped ambulance staffed by EMTs is available 24 hours a day at the Firehouse as is an Emergency Truck. Relations between OMC and the Fire Rescue Brigade are excellent. When OMC is not operational, the Fire Rescue Brigade is trained and responsible for triage and transport of medical emergencies. Two helicopters are on call for 
special emergencies. Depending upon the requirements of the incident, transport time is from 5 to 20 minutes to various hospitals, including State University of New York at Stony Brook Medical Center, where the Medical Director is on the Faculty of Occupational Medicine and a member of the Radiation Safety Committee of the Medical Center.

The OMC Program meets or exceeds the provisions of DOE 5480.8, "Contractor Occupational Medical Program." Therefore, no recommendations are in order; however, some concerns are noted. First, injury incidence at BNL is too high. This places demands on the OMC staff's time which could be used on preventive work. Second, more of the OMC staff's time should be devoted to observation of work sites to further develop preventive programs. Third, no formal program exists to periodically review and audit OMC policies, procedures and practices. Fourth, the Health Awareness and Wellness Program is not being fully implemented in view of the Health Promotion Staff Specialist vacancy.

Noteworthy practices included facilities, trained staff, and protocol for handling radiation contaminated persons. Provisions exist for handling contaminated persons, as do protocols for medical surveillance of special hazards in the work place. Placing the Medical Director on the new four-man Task Force on Safety and Environmental Protection and on the Occupational Health Review Committee is to be commended. The OMC Form provided for supervisors to forward employee occupational information to physicians prior to physical examinations is particularly beneficial in a Laboratory operation with few routine activities. 


\section{MS.2 PROCEDURES AND DOCUMENTATION}

PERFORMANCE OBJECTIVE: Procedures and documentation should provide appropriate direction, record generation, and support of the medical services for the facility and site.

FINDINGS: - A formal program to systemically track the correction of identified deficiencies and deviations from prescribed practices did not exist in OMC.

CONCERN: A formal tracking program does not exist in the occupational (MS.2-1) Medical Clinic.

$(\mathrm{H} 2 / \mathrm{C} 2)$ 


\section{MS.4 REVIEW AND AUDIT}

PERFORMANCE OBJECTIVE: Policies, procedures, and practices for medical services should be reviewed and audited periodically to ensure continued effectiveness of the medical services.

FINDINGS: - Periodic audits or appraisals of OMC have not been conducted.

- OMC was appraised by an outside expert in Occupational Medicine in March 1987. However, the results of that audit were los $\downarrow$ in $H Q D O E$, and a written final report was not received by BNL or OMC.

- Formal self-assessments on an annual basis, as an integral part of the formal annual self-assessments of Health Physics, Industrial Hygiene and Safety, are the minimum audit/appraisal required for progressive occupational medical programs; they are also not performed.

CONCERN: Policies, procedures, and practices of the Occupational Medical

(MS.4-1) Medical Clinic are not periodically reviewed and audited as $(\mathrm{H} 2 / \mathrm{C2})$ required by good practices. 


\section{MS.5 PERSONNEL COMMUNICATION PROGRAM}

PERFORMANCE OBJECTIVE: Site/facility personnel should be adequately informed of the medical hazards that may be encountered and of the medical services that are available.

FINDINGS: - The OMC has prepared a well-developed, comprehensive Health Awareness and Wellness Program for BNL. However, this program was not fully implemented.

- This highly important preventive medicine program of the OMC cannot be implemented or function effectively without the aggressive leadership of the Health Promotion Staff specialist. This position was vacant.

CONCERN: The Health Awareness and Wellness Program is not fully implemented

(MS.5-1)

$(\mathrm{H} 2 / \mathrm{C} 3)$

not fully implemented for Brookhaven National Laboratory by the Laboratory by the Occupational Medical Clinic. 


\section{NOTEWORTHY PRACTICES}

Noteworthy Practices are exceptional ways of accomplishing a Performance Objective or some aspect of it. Other DOE facilities are encouraged to adopt these practices when they are applicable to their operation. One Noteworthy Practice was found in OMC during this audit. This is described in this section. 


\section{MS.1 ORGANIZATION AND ADMINISTRATION}

PERFORMANCE OBJECTIVE: Site and Facility organization and administration should ensure effective implementation and control of the Medical Services program.

NOTEMORTHY PRACTICE: Aside from having excellent protocols (27) for jobs with unusual hazards necessitating special medical examinations and surveillance, OMC physicians obtain additional updated information about job hazards from the employee's supervisor. Prior to conducting a pre-employment, periodic, return to work, or rehire physical examination, OMC sends form OMC 8/83; Rev. 4/85 (see Section IV, IH.1, Appendix B, for a sample of the form) to the employee's supervisor. who fills it out and returns it prior to the examination.

This provides the Occupational Physician with current, detailed information on job hazards and working conditions which aids the physician in proper, safe, and healthful job placement. This practice is particularly helpful in any organization having wide diversity in operations - such as BNL. The use of this attached form in Occupational Safety has been recognized as a noteworthy practice in previous BNL TSA. 


\section{APPENDIX A \\ System for Categorizing ioncerns}

Each concern contained in this report has been characterized using the following three sets of criteria:

A. CATEGORY I: Addresses a situation for which a "clear and present" danger exists to workers or members of the public. A concern in this category is to be immediately corveyed to the managers of the facility for action. If a clear and present danger exits, the Assistant Secretary for Environment, Safety, and Health, or nis designee, is informed immediately so that consideration may be given to exercising the Secretary's facility shutdown authority or directirig other immediate mitigation measures.

CATEGORY II: Addresses a significant risk or substantial noncompliance with DOE Orders (but does not involve a situation for which a clear and present dange exists to workers or members of the public). A concern in this category is to be conveyed to the manager of the facility no later than the appraisal close-out meeting for immediate attention. Category II concerns rave a significance and urgency such that the necessary field response should not be delayed until the preparation of a final report or the routine development of an action plan. Again, consideration should be given to whether compensatory measures, mitigation, or facility shutdown are warranted under the circumstances.

CATEGORY III: Addresses significant noncompliance with DOE birders, or the need for improvement in the margin of safety, but is not of sufficient urgency to require immediate attention.

B. HAZARD LEVEL 1. Has the potential for causing a severe occupational injury, illness, fatality, or loss of the facility.

HAZARD LEVEL 2. Has the potential for causing minor occupational injury or illness, major property damage, or has the potential for resulting in, or contributing to, unnecessary exposure to radiation or toxic substances.

HAZARD LEVEL 3. Has little potential for threatering safety, health, or property. 
c. COMPLIANCE LEVEL 1. Does not comply with DOE Orders, prescribed folicies or standards, or documenced accepteú practices. The latter is professional judgment based on the acceptance and applicability of national consensus standards not prescribed by DOE requirements.

COMPLIANCE LEVEL 2. Does not comply with DOE references, standards, guidance, or with good practice (as derived from industry experience, but not based on national consensus standards).

COMPLIANCE LEVEL 3. Has lictle or no compliance consideratiors; these concerns are based on professional judgment in pursuit of excellence in design or practice (i.e., these are improvement for their own sake-not deficiency driven). 


\section{APPENDIX B \\ Categorization and Tabulation of Concerns}

Using the criteria in Appendix A "System for Categorizing Concerns," all of the Concerns have been categorized as Category III for seriousness except IH.6-1. Appendices B-1 and B-2 are provided as convenient reference tables. However, the user is cautioned to read the basis for each Concern, provided in Section III, in order to fully understand it. 


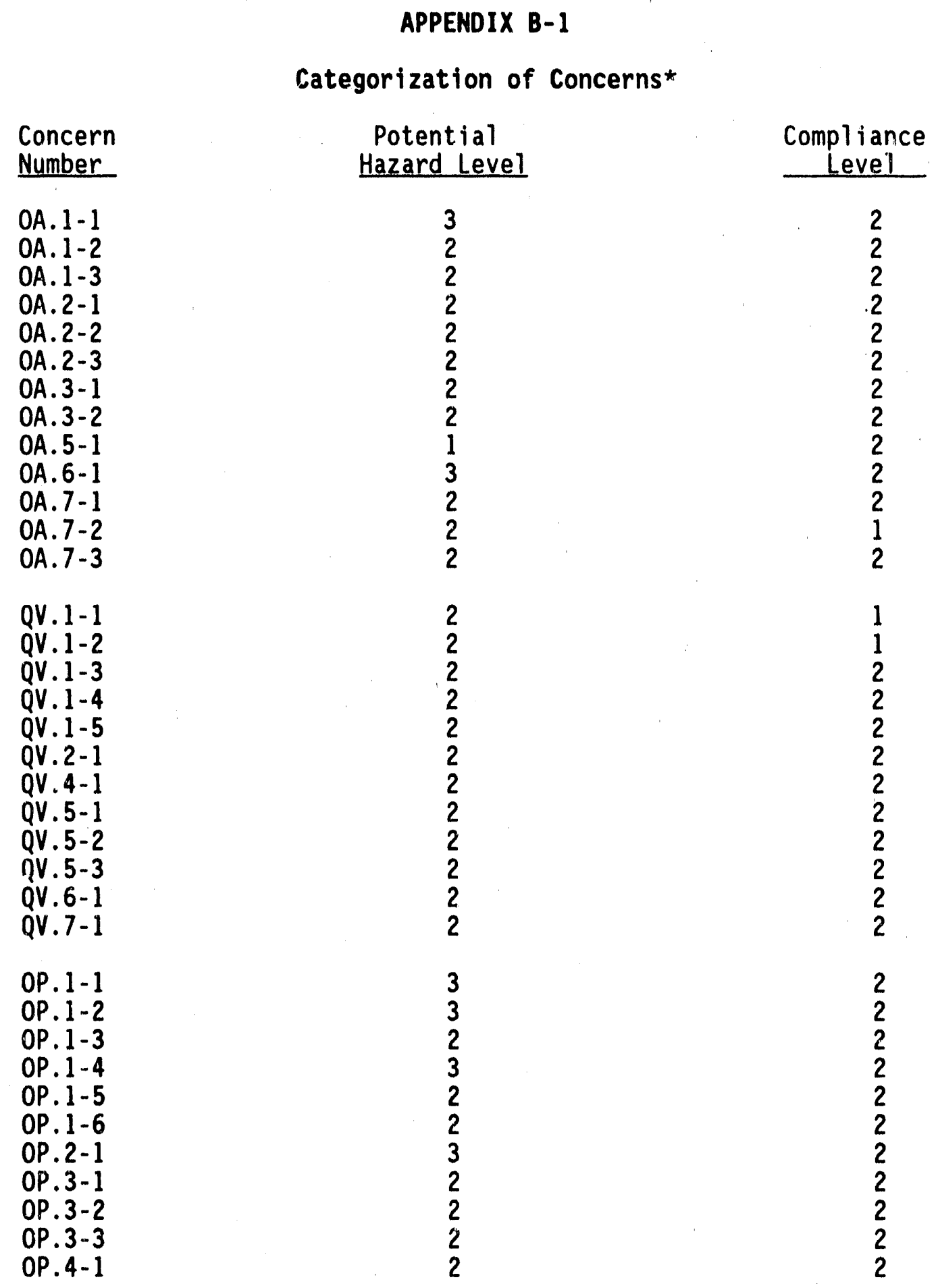

*This categorization includes the concerns from the BNL TSA, October 1989. 
Concern
Number

OP. 5-1

OP. 5-2

OP. 6-1

OP. 6-2

OP. 7-1

OP. 8-1

OP.9-1

OP. 10-1

MA. 1-1

MA.1-2

MA. 1-3

MA. 2-1

MA. 2-2

MA. 5-1

MA. 5-2

MA. 7-1

MA. 8-1

MA. 8-2

TC. . 1-1

TC. 1-2

TC. 2-1

TC. 3-1

TC. 4-1

TC. 4-2

TC. 5-1

TC. 9-1

AX. 5-1

EP. 1-1

EP. 2-1

EP. 3-1

EP. 5-1

EP. 5-2

EP. 6-1

TS. 1 - 1

TS. 2-1

TS. 2-2

TS. 2-3

TS. 2-4

TS. 3-1

TS. 3-2
APPENDIX B-1 (cont'd)

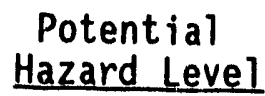

Compliance

Level

2
2
3
1
2
2
2
2

2

2

2

1

1

2

2

1

2

2

2

2

2

2

1

2

2

2

2

2

2

1

1

2

2

2

2
2
2
2
2
2

2
1
1
2
1
1

2
2
2
2
2
3
2

2
2
2
2
2
2
2

B-1-2 
APPENDIX B-1 (cont'd)

\section{Concern}

Number

TS. 3-3

TS. 4-1

TS. 4-2

TS. 4-3

TS. 8-1

CS. 1-1

CS.5-1

E/4. 2-1

EA. 4-1

SR. 1-1

SR. 7 - 1

FR. 4-1

FR. 5-1

RP. 3-1

RP. 3-2

RP. 3-3

RP. 3-4

.P. 3-5

RP. 3-6

RP. 3-7

RP. 3-8

RP. 4-1

RP. 5-1

RP. 7-1

RP. 8-1

RP. 9-1

RP.11-1

IH. 4-1

IH. 5-1

IH. $6-1$

IH. 6-2**

OS. 3-1

OS. 4-1

OS. 4-2*

OS. 4-3

OS. 5-1

OS. 5-2
Potential

Hazard Level

2
3
3
2
3

2

3
2

2

2
2

3

2

1

2

2

2

2

3

2

2

3

2
2
2
2

2
2
1
1
1
2
Compliance Leve]

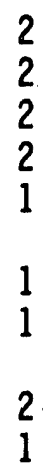

1

1

2

2

2

2

2

1

3

2

2

1

1

2

2
1
1
1

2
1
1
1
1
1

*This concern is a Category I.

**This concern is a Category II. All others are Category III.

B-1 - 3 
APPENDIX B-1 (cont'd)

Concern

Potential

Number

Hazard Level

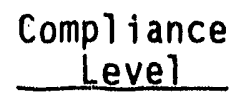

OS. 5-3

OS. 6-1

OS. 6-2

1
2

1

FP. 1-1

FP. 1-2

FP. 1-3

FP. 1-4

FP. 2-1

FP. 3-1

FP. 4-1

FP. 4-2

FP. 5-1

FP. 5-2

FP. 5-3

FP. 5-4

FP. 5-5

FP. 5-6

FP. 5-7.

FP. 5-8

FP. 7-1

FP. 7-2

FP. 7-3

FP. 7-4

FP. 7-5

FP. 7-6

FP. 7-7

FP. 7-8

FP. 7-9

FP. 7-10

FP. 7-11

FP. 7-12

FP. 7-13

FP. 7-14

FP. 7-15

FP. 7-16

MS. 2-1

MS. 4-1

MS. 5-1 


\section{APPENDIX B-1 (cont'd) \\ Potential \\ Hazard Level}

Concern

Number

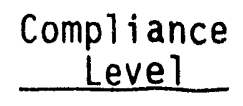

PT. 2-1

PT.3-1

PT. 4-1

PT. 5-1

PT. 6-1

PT.6-3

3
3
3
2
2
3

1

1

1

FS. 2-1

FS. 3-1

FS. $5-1$

FS. 6-1

FS. 6-2

2
2
2
2
2

2
3
3
1
2 


\title{
APPENDIX B-2
}

\author{
Tabulation of Concerns*
}

\section{A. ORGANIZATION AND ADMINISTRATION}

CONCERN: Lines of authority and responsibility cannot always be traced on (OA, 1-1) on existing organization charts, nor are organization charts $(\mathrm{H} 3 / \mathrm{C2})$ controlled or approved. (See al so Concern OP.1-1.)

CONCERN: Line safety responsibility was not clearly understood and (0A.1-2) practiced at Brookhaven National Laboratory. (Also see (H2/C2) Concerns OA.1-1, Appendix B; OP.1-1, Appendix B; and OP.1-3.)

CONCERN: Safety meetings are not regularly scheduled and do not fully (OA.1-3) promote safety at Brookhaven National Laboratory. $(\mathrm{H} 2 / \mathrm{C2})$

CONCERN: Administrative policies and controls are not in place to ensure the (0A.2-1) conditions that are necessary for a healthful and safe workplace. $(\mathrm{H} 2 / \mathrm{C} 2)$

CONCERN:

$(O A .2-2)$ $(\mathrm{H} 2 / \mathrm{C} 2)$

CONCERN: $(0 A .2-3)$ $(\mathrm{H} 2 / \mathrm{C} 2)$

CONCERN: $(0 A .3-1)$ $(\mathrm{H} 2 / \mathrm{C} 2)$
Laboratory-wide administrative policies and controls do not ensure that all elements of an effective safety program exist exist within each department and division. (Also see Concern 0A.2-1, Appendix B.)

A potential conflict of interest exists among those who have both independent safety review responsibilities and line safety responsibility or past safety responsibility for the program.

The BNL environment, safety, and health goals are neither definitive nor measurable and in many cases lack specific departmental action plans to accomplish the BNL-wide goals as well as the specific departmental goals. Safety goals are also not embraced or appreciated by al1 Laboratory management. (See also Concern OP.13.)

CONCERN: Measurable and definitive goals are not being developed and (OA.3-2) promulgated to all Laboratory employees. $(\mathrm{H} 2 / \mathrm{C} 2)$

CONCERN: (OA.5-1) $(\mathrm{H} 1 / \mathrm{C} 2)$

Interlock problems, including their use, misuse, and nonreporting, have not been evaluated, and the root cause of the problems root cause of the problems determined; nor has corrective action been taken to upgrade and enforce this primary system of personnel protection. (See also Concerns RP.3-4 and TS.4-1.)

*This tabulation includes the concerns from the BNL TSA, October 1989. 
CONCERN: Personnel programs do not ensure that specific jol descriptions and (OA.6-1). job qualifications are established for all positions that affect $(\mathrm{H} 3 / \mathrm{C} 2)$ safe and reliable operations.

CONCERN: Management is not ensuring control of vital safety and operating (OA.7-1) documents.

$(\mathrm{H} 2 / \mathrm{C} 2)$

CONCERN: The AGS and the 60-inch Cyclotron are not in compliance with

(OA.7-2) DOE 5481..1B, which requires an SAR for each DOE facility.

$(\mathrm{H} 2 / \mathrm{C} 1)$

CONCERN: The Brookhaven National Laboratory document control system does not (OA.7-3) ensure, as required by ANSI/ASME NQA-1, that documents important

$(\mathrm{H} 2 / \mathrm{C2})$ to the safe operation of a facility are available when needed and controlled.

\section{B. QUALITY VERIFICATION}

CONCERN: Documented and approved quality assurance plans are not all in place (QV.1-1) $(\mathrm{H} 2 / \mathrm{C} 1)$ at $B N L$ as required by the BNL Quality Assurance Manual and

CONCERN:

(QV.1-2)

$(\mathrm{H} 2 / \mathrm{Cl})$ DOE $5700.6 B$.

Independent verifications, surveillance, and audits of quality attainment within the departments, divisions, and projects are too few to enable the BNL Director and his line managers to review and evaluate the implementation of their quality assurance programs, as required by DOE $5700.6 \mathrm{~B}$.

CONCERN: The Quality Assurance Steering Committee functions and lines of

(QV.1-3)

$(\mathrm{H} 2 / \mathrm{C} 2)$ communication are not addressed in the Brookhaven National Laboratory Quality Assurance Manual.

CONCERN: Quality assurance audits at Brookhaven National Laboratory conducted (QV.1-4) by both the Quality Assurance Office and Designated Quality Assurance (H2/C2) Representatives do not cover all departments and divisions as required by Laboratory policy. (Al so see Concern QV.1-2, Appendix B.)

CONCERN: The Chicago Operations office had not conducted timely quality (QV.1-5) verification audits as required by DOE $5700.6 \mathrm{~B}$.

CONCERN: Brookhaven National Laboratory does not currently have a system in (QV.2-1) place for the evaluation and control of suppliers based on their $(\mathrm{H} 2 / \mathrm{C} 2)$ past performance.

CONCERN: The BNL policy for calibration of measuring and testing equipment (QV.4-1) is not implemented by all departments and divisions. $(\mathrm{H} 2 / \mathrm{C} 2)$ 
CONCERN: BNL management is not enforcing its basic policies for nonconformance (QV.5-1) issues.

$(\mathrm{H} 2 / \mathrm{C} 2)$

CONCERN: A formal system for the disposition of nonconforming materials has (QV.5-2) not been implemented by all Brookhaven National Laboratory

$(\mathrm{H} 2 / \mathrm{C2})$ departments and divisions.

CONCERN: Identification, control, and storage of safety-related hardware and (QV.5-3) materials are not being performed in accordance with ANSI/ASME $(\mathrm{H} 2 / \mathrm{C2}) \quad \mathrm{NQA}-1$ requirements.

CONCERN: Personnel requesting inspections and tests do not always provide (QV.6-1) acceptance instructions or procedures describing the effort to be $\left(\mathrm{H} 2 / \mathrm{CL}_{\mathrm{L}}\right)$ performed and the criteria for acceptance, as required by ANSI/ASME NQA-1.

CONCERN: Material identification requirements are not adequately provided in (QV.7-1) welding rod control procedures and practices.

$(\mathrm{H} 2 / \mathrm{C} 2)$

\section{OPERATIONS}

CONCERN: The responsibilities and authorities of each position in the (OP.1-1) organization are not uniquely defined in a formal document made $(H 3 / C 2)$ available to the staff at large. (See Concern OA.6-1.)

CONCERN: Measurable goal and performance indicators are not used at many (OP.1-2) facilities to effectively improve performance and safe operations. (H3/C2) (See Concern OA.3-1.)

CONCERN: Operations personnel do not clearly understand their authority and $(0 P .1-3)$ responsibility. (Also see concern $0 A .1-2$.

CONCERN: (OP.1-4) (H3/C2)

CONCERN: (OP.1-5) ( $\left.\mathrm{H} 2 / \mathrm{C}_{2}\right)$

CONCERN: (OP. 1-6) (H2/C2)

CONCERN: (OP. 2-1) (H3/C2)
Formal policy and guidelines from Department Chairpersoris and Division Heads do not exist for development, review, approval, and issuance of organization charts. (Also see Concern OA.1-2.)

Department Chairpersons and Division Heads are not effectively formulating and issuing policy for their organizations which is specific for their needs.

Use of the suggestive "should" in policy and guidance documents results in accountability for safety-related responsibilities not not being clearly established.

BNL, in general, does not have policy and procedures establishing the requirements for facility operations logs, their content, use, and review. 
CONCERN: (OP.3-1) ( $\mathrm{H} 2 / \mathrm{C2})$

CONCERN: (OP. 3-2) ( $\mathrm{H} 2 / \mathrm{C} 2)$.

CONCERN: (OP. 3-3) ( $\mathrm{H} 2 / \mathrm{C2})$

CONCERN: (OP. 4-1) ( $\mathrm{H} 2 / \mathrm{C2})$

CONCERN: (OP. 5-1) ( $\mathrm{H} 2 / \mathrm{C2})$

CONCERN: (OP. 5-2) ( $\mathrm{H} 2 / \mathrm{C} 2)$

CONCERN: (OP. 6-1) (H3/C2)

CONCERN: (OP. 6-2) $(\mathrm{H} 1 / \mathrm{Cl})$

CONCERN: (OP.7-1) ( $\mathrm{H} 2 / \mathrm{Cl})$

CONCERN: (OP. 8-1) ( $\mathrm{H} 2 / \mathrm{C2})$

CONCERN: (OP. 9-1) ( $\mathrm{H} 2 / \mathrm{C} 2$ )

CONCERN: (OP.10-1) (H2/C2)
In general, the BNL process for procedure preparation, approval, modification, distribution, and safety impact determination is inconsistent, not formaliz?d, and undocumented.

A policy controlling the posting and implementation of operating aids in the control rooms does not exist.

The operation of the NSLS and REF facilities is not in compliance with their Safety Analysis Reports.

A configuration control system did not exist requiring identification of safety-related components in the field and requiring formal review and approval beiore changes are made that may affect safe operation.

The control, use, and content of operating procedures for experiments are not sufficient to ensure that the experimental is provided a well-defined safe operating envelope.

Controls and procedures are not in place to ensure that access to the NSLS experiment floor area is restricted to authorized and trained users and escorted visitors.

Management has not established standards and directives providing a clear concise statement of acceptable operating states for facilities and experiments.

BNL Health and Safety Guide 1.5.1, "Lock-Out/Tag-Out Requirements" is not being enforced as required by DOE 5483.1A and 29 CFR 1910.147.

The housekeeping in some facilities is poor and is not in accordance with DOE 5483.1A, 29 CFR 1910.22, and generally accepted industrial practice. (See also Concerns OS.5-1 and FP.7-4.)

The depth and breadth of operator knowledge is not commensurate with acceptable industrial practices at facilities of comparable sophistication and complexity.

BNL has not developed and implemented coding convention standards (color, size, shape, position and nomenclature) for facility components and equipment.

The current shift turnover process does not assure effective and accurate transfer of essential information regarding the facility status between crews and interacting members of the same crew. 


\section{MAINTENANCE}

CONCERN: A uniform, BNL-wide maintenance program, consistent with the (MA.1-1) requirements of DOE 4330.4, industry standards, and gond practices $(\mathrm{H} 2 / \mathrm{Cl})$ is not provided by the current organizational structure.

CONCERN: The responsitility for the maintenance activity at NSLS is not (MA.1-2) defined.

$(\mathrm{H} 2 / \mathrm{C} 2)$

CONCERN: Formal or uniform maintenance programs are not consistently (MA.1-3) implemerited at the Alternating Gradient Synchrotron facility. $(\mathrm{H} 2 / \mathrm{C} 2)$

CONCERN: (MA.2-1) $(\mathrm{H} 2 / \mathrm{C} 2)$

CONCERN: (MA. 2 - 2) $(\mathrm{H} 2 / \mathrm{C} 2)$

CONCERN: (MA. 5-1) (H2/C?)

CONCERN: (MA. 5-2) ( $\mathrm{H} 2 / \mathrm{C} 2)$

CONCERN: (MA. 7-1) $(\mathrm{H} 2 / \mathrm{C} 1)$

CONCERN: (MA. 8-1) ( $\mathrm{H} 2 / \mathrm{C} 2)$

CONCERN: (MA. 8-2) $(\mathrm{H} 2 / \mathrm{C} 2)$
Many BNL facilities are crowded with equipment (which, in some cases, is unused) and may impact safe, effective operation, industry safety standards, and good operating practices.

Documentation of maintenance activities for programmatic equipment is incomplete, and procedures for work control are not sufficient to ensure safe and efficient maintenance.

Lack of consistent app"ication of safety requirements in maintenance shop areas promotes insafe conditions and contributes to the potential for accidents and injury.

A calibration and testing program which identifies instrumertation requiring periodic calibration and/or testing is not in place. (Also see Concern QV.4-1, Appendix B.)

Documentation of maintenance requirements, procedures and activities is incomplete and not sufficiently accurate to ensure safe and effective maintenance. This lack of documentation may affect the continuity of operations of one-of-a-kind and other special equipment should existing experienced personnel retire or transfer.

Documentation of maintenance data and information is not adequate to support a maintenance history program. (See also Concern TS.4-1.)

Maintenance procedures and documentation of maintenance activities for programmatic equipment frequently do not enable maintenance to be carried out in a controlled and safe manner. (Also see Concerns RP.3-5 and RP.3-7.) 


\section{E. TRAINING AND CERTIFICATION}

CONCERN: BNL has no lab-wide training policy or requirements for initial and (TC. $1-1)$ $(\mathrm{H} 2 / \mathrm{C} 2)$ ongoing qualification programs. (See also Concern 0A.6-1.)

CONCERN:

(TC.1-2)

$(\mathrm{H} 2 / \mathrm{C} 2)$

Training records of each individual's training participation and performance are not documented at BNL in several departments and divisions.

CONCERN:

(TC. $2-1)$

BNL does not have formalized lesson plans to ensure adequacy of $(\mathrm{H} 2 / \mathrm{C} 2)$ safety training.

CONCERN: (TC.3-1) $(\mathrm{H} 2 / \mathrm{C} 2)$

CONCERN: (TC. $4-1)$ $(\mathrm{H} 2 / \mathrm{Cl})$

CONCERN: (TC.4-2) $(\mathrm{H} 2 / \mathrm{Cl})$

CONCERN: (TC.5-1) $(\mathrm{H} 2 / \mathrm{C} 2)$

CONCERN:

(TC. 9-1)

$(\mathrm{H} 2 / \mathrm{C} 1)$
BNL has not developed and documented qualification standards and evaluation methods to adequately verify trainee competence in maintenance activities.

All radiatior, workers at Brookhaven National Laboratory have not been trained and certified to meet the requirements of DOE 5480.11.

Safety training and certification requirements for employee and visitor users are not in compliance with DOE 5480.11 at many Brookhaven National Laboratory facilities.

At most Brookhaven National Laboratory facilities, there is no maintenance training and qualification program to ensure safe and effective maintenance activities. (Also see Concern TC.3-1, Appendix B.)

Documentation of the health physics training program required to verify that technicians receive certified training in compliance with DOE 5480.11 is incomplete and not readily available.

\section{F. AUXILIARY SYSTEMS}

CONCERN: High-efficiency particulate air filters without pressure drop (AX.5-1) instrumentation cannot be monitored for clogging or penetration on $(\mathrm{H} 2 / \mathrm{C2})$ a continuous basis.

\section{G. EMERGENCY PREPAREDNESS}

CONCERN: The magnitude and consequences of emergencies involving

(EP.1-1) nonradioactive hazardous materials have not been identified, nor have $(\mathrm{H} 2 / \mathrm{C} 2)$ BNL emergency plans or emergency organization structures been well defined to respond to this type of emergency. (See also Concerns PT.5-4, PT.6-2, and FP.3-1.) 
CONCERN: Not all local emergency plans are being kept current in accordance (EP.2-1) with the requirements of the BNL Laboratory Emergency Response Plan. $(\mathrm{H} 2 / \mathrm{C} 1)$

CONCERN: Neither initial nor continuing training programs for most emergency (EP.3-1) response personnel have established formal qualification/requalifi$(\mathrm{H} 2 / \mathrm{C} 1)$ cation requirenents. (See also Concern TC.1-1.)

CONCERN: The BNL Emergency Operations Facility is not equipped to facilitate (EP.5-1) the control of all postulated emergencies.

$(\mathrm{H} 2 / \mathrm{C} 2)$

CONCERN: The radiation monitoring equipment designated for use during an (ㄷ. $5-2$ ) emergency response does not meet all of the requirements of $(\mathrm{H} 2 / \mathrm{Cl}) \quad$ ANSI N320-1979.

CONCERN: Emergency assessment and notification practices and procedures are (EP.6-1) not based on current DOE emeryency event classifications or $(\mathrm{H} 2 / \mathrm{Cl})$ protective action guides.

\section{H. TECHNICAL SUPPORT}

CONCERN: BNL has no formal system to ensure review of proposed actions by (TS.1-1) by interfacing organizations whose interests might be impacted.

$(\mathrm{H} 2 / \mathrm{C} 2)$

CONCERN: Engineering personnel who design facility modifications do not all (TS.2-1) have cognizance of or full access to document.s that define the safety $(\mathrm{H} 2 / \mathrm{C} 2)$ requirements for individual facilities.

CONCERN: There is no system of procedures for formal interchange of (TS.2-2) informat on between teclinical and operations/maintenance staff that $(H:, C 2)$ that ensures operation/maintenance practices and designs are consistent.

CONCERN: Operational safety limitations are not identified for most nonreactor (TS.2-3) facilities. (Also see Concern Ea.4-1.)

$(\mathrm{H} 2 / \mathrm{C} 2)$

CONCERN: In nonreactor areas, safety systems and devices are not fully (TS.2-4) $(\mathrm{H} 2 / \mathrm{C} 2)$ identified, and special testing or maintenance requirements are not stipulated for such equipment.

CONCERN: Many of the BNL organizations do not have written procedures (TS.3-1) $(\mathrm{H} 3 / \mathrm{C} 2)$ controlling design and review of modifications.

CONCERN: (TS.3-2) Safety Analysis Reports are not prepared before completion of a $(\mathrm{H} 2 / \mathrm{C} 2)$ facility design or of a facility modification. 
CONCERN: Brookhaven National Laboratory Occupancy Readiness Reviews do not (TS.3-3) satisfy the requirements for the more conventional Operational (H2/C2) Readiness Reviews.

CONCERN: There is no comprehensive program for systematic evaluation if (TS.4-1) equipment performance. (See also Concerns OA.5-1, MA.8-1, QV.1-2, $(\mathrm{H} 3 / \mathrm{C} 2)$ and QV.5-1.)

CONCERN: Not all performance testing and monitoring files are readily (TS.4-2) auditable by a third party for kerification of compliance with $(\mathrm{H} 3 / \mathrm{C2})$ requirements. (See also Concern QV.1-2.)

CONCERN: No formal sitewide system has been established for performance (TS.4-3) testing and monitoring of equipment within established safety para( $\mathrm{H} 2 / \mathrm{C} 2)$ meters and limits. (Also see Concern TS.4-1, Appendix B.)

CONCERN: The BNL Annual Site Environmental Report was not distributed on the (TS.8-1) schedule required by DOE 5400.1 . $(\mathrm{H} 3 / \mathrm{C} 1)$

\section{NUULEAR CRITICALITY SAFETY}

CONCERN: The criticality safety program is not independent of operations in (CS.1-1) compliance with ANS 8.1-1983 as required by DOE Orders. (Also see ( $\mathrm{H} 2 / \mathrm{C} 1)$ Concern OA.2-3.)

CONCERN: A criticality alarm system, nuclear accident dosimeters, and (CS.5-1) emergency procedures and drills have not been implemented to cover $(\mathrm{H} 2 / \mathrm{Cl})$ the fissile fuel storage areas at the High Flux Beam Reactor in compliance with DOE 5480.5.

\section{J. EXPERIMENTAL ACTIVITIES}

CONCERN: The charters for the department and division experiment safety review (EA.2-1) committees did not fully define the body, scope, and authority of $(\mathrm{H} 3 / \mathrm{C} 2)$ the committee.

CONCERN: The boundaries of safe operation were not developed for each (EA.4-1) experiment or class of experiments at the various departments and $(\mathrm{H} 2 / \mathrm{Cl})$ divisions at the Brookhaven National Laboratory, as required by DOE 5481.1B. (Also see Concern TS.2-3.)

\section{K. SITE/FACILITY SAFETY REVIEH}

CONCERN: The Ad Hoc Committee for the review and approval of table-top and (SR.1-1) planned larger (non-Radiation Effects Facility) experiments are not $(\mathrm{H} 2 / \mathrm{Cl})$ in compliance with DOE 5482.1B, Section 9.d. 
CONCERN: BNL is not in compliance with DOE 5482.1B in all programmatic areas (SR.7-1) reviewed in this TSA.

$(\mathrm{H} 2 / \mathrm{C} 1)$

CONCERN: Periodic facility safety reviews do not include a safety review of (FR.4-1) $(\mathrm{H} 2 / \mathrm{C} 1)$ all procedures and operat onal activities as required by by DOE 5482.1B.

CONCERN: Brookhaven National Laboratory does not perform a triennial

(FR.5-1) appraisal of the safety review system. (Also see Concern SR.7-1, $(\mathrm{H} 2 / \mathrm{Cl}) \quad$ Appendix E.)

\section{RADIOLOGICAL PROTECTION}

CONCERN: Implementation of some aspects, particularly radiation worker (RP.3-1) retraining, of DOE 5480.11 will not be accomplished by

(H3/C2) January 1, 1990, as specified in BNL's implementation plan. (See a) so Concern TC.2-1.)

CONCERN, BNL does not have uniform posting in radiation areas.

(RP.3-2)

$(\mathrm{H} 2 / \mathrm{C} 2)$

CONCERN:

(RP.3-3)

$(\mathrm{H} 2 / \mathrm{C} 2)$

In general, there are no formal, documented departmental radiation protection procedures which implement the guides in the BNL Safety Manual.

CONCERN:

(RP.3-4)

$(\mathrm{H} 1 / \mathrm{C} 2)$

Many of the interlock systems are not consistent with the BNL Safety Manual. (See also Concern OA.5-1.)

CONCERN:

(RP. 3-5)

Many radiation protection procedures developed and used by operations $(\mathrm{H} 2 / \mathrm{C} 2)$ personnel are outdated or do not apply accepted good practices. (Also see Concern MA.8-2.)

CONCERN:

(RP.3-6) $(\mathrm{H} 2 / \mathrm{C} 2)$

Procedures issued by the Safety and Environmental Protection Division are not being effectively tracked for review, revision, and approval.

CONCERN:

(RP.3-7)

$(\mathrm{H} 2 / \mathrm{C} 1)$

The existing Radiation Work Permit form lacks information required to ensure work is performed safety and does not ensure "as low as reasonably achievable."

CONCERN: Brookhaven National Laboratory does not have an effective program to (RP. 3-8) $(\mathrm{H} 2 / \mathrm{C} 3)$ control access to radiological areas.

CONCERN: (RP. 4-1) $(\mathrm{H} 2 / \mathrm{C} 2)$

External radiation exposure control is not adequate to minimize exposures or to quickly recognize that higher than normal exposure is being received by personnel. 
CONCERN: The commercial film badge service provided to BNL is not accredited (RP.5-1) under DOELAP.

$(\mathrm{H} 3 / \mathrm{C} 2)$

CONCERN: The Safety and Environmental Protection Division internal dosimetry (RP.7-1) $(\mathrm{H} 2 / \mathrm{Cl})$ program has not undergone an internal audit as required by

CONCERN: (RP.8-1) $(\mathrm{H} 2 / \mathrm{Cl})$ DOE 5482.1B.

CONCERN: Air monitoring systems do not ensure reliable estimates of air (RP.9-1) activity.

$(\mathrm{H} 3 / \mathrm{C} 2)$

CONCERN: BNL does not have a documented ALARA program.

(RP.11-1)

$(\mathrm{H} 3 / \mathrm{C} 2)$

Calibration of radiation protection instruments does not meet ANSI N323 as required by DOE 5480.4 .

\section{INDUSTRIAL HYGIENE}

CONCERN: Industrial hygiene data are not developed to allow lnng-term (IH.4-1) exposure estimates for many substances.

$(\mathrm{H} 2 / \mathrm{C} 2)$

CONCERN: BNL does not comply with the respiratory protection and laser safety (IH.5-1) standards required by DOE 5480.4. Internal audits have failed to $(\mathrm{H} 2 / \mathrm{Cl})$ identify these deficiencies.

CONCERN: The BNL hazard communications program, required by DOE 5480.4 and (IH.6-1) 5483.1A, has not been fully implemented.

$(\mathrm{H} 2 / \mathrm{Cl})$

CONCERN: Brookhaven National Laboratory is not in compliance with

(IH.6-2) 29 CFR 1910.1200 and unlikely to comply with deadlines established $(\mathrm{H} 2 / \mathrm{Cl})$ in 29 CFR 1910.1450.

(CAT II)

\section{N. OCCUPATIONAL SAFETY}

CONCERN: All pesticide hazards arising in the work place are not (OS.3-1) identified and controlled.

$(\mathrm{H} 2 / \mathrm{C} 2)$

CONCERN: The priority given to safety is not adequate to ensure that safety (OS.4-1) performance meets DOE expectations as required by DOE 5483.1A.

$(\mathrm{H} 2 / \mathrm{Cl})$ 
CONCERN: BNL is not controlling hazardous conditions at its construction (OS.4-2) activities and is not enforcing construction safety standards as $(\mathrm{H} 1 / \mathrm{C} 1)$ required by DOE 5480.4 and DOE 5480.9 .

(CAT I)

CONCERN:

(OS. 4-3)

$(\mathrm{H} 1 / \mathrm{Cl})$

CONCERN: (OS.5-1) $(\mathrm{H} 1 / \mathrm{C} 1)$

CONCERN: (OS.5-2) $(\mathrm{H} 2 / \mathrm{C} 1)$

CONCERN: (OS.5-3) $(\mathrm{H} 1 / \mathrm{Cl})$

CONCERN: (OS.6-1) $(\mathrm{H} 2 / \mathrm{C} 1)$

CONCERN: (OS.6-2) $(\mathrm{H} 2 / \mathrm{C} 1)$
BNL has not established a formal program to track the corrective actions identified during injury and illness recording, investigation, and reporting.

BNL is not consistently enforcing the use of personnel protective equipment as required by DOE $5483.1 \mathrm{~A}$.

The BNL Compressed Gas Cylinder Safety Policy and Procedures do not meet DOE 5480.4 requirements.

Egress or rescue capability is not provided for the catch basins as required by the Occupational Safety and Health Act, Section 5(a)(1).

BNL is not posting their injury and illness data as required by DOE 5483.1A.

BNL safety training program is not adequate as required by DOE 5483.1A.

\section{FIRE PROTECTION}

CONCERN: Not all of the fire protection functions required by DOE 5480.7 and (FP.1-1) BNL Safety Department operations procedures and safety directives are $(\mathrm{H} 1 / \mathrm{C} 2)$ being performed. (See also Concern OA.2-1.)

CONCERN: Fire protection deficiencies are not being corrected in a timely (FP.1-2) manner. (See Performance Objective FP.2, FP.3, and FP.7.) $(\mathrm{H} 1 / \mathrm{C} 2)$

CONCERN: (FP. 1-3) $(\mathrm{H} 2 / \mathrm{C} 1)$

CONCERN: (FP. 1-4) $(\mathrm{H} 2 / \mathrm{C} 2)$

CONCERN: (FP. 2-1) $(\mathrm{H} 1 / \mathrm{Cl})$
The Chicago Operations Office has not conducted Fire Protection Appraisals of Brookhaven National Laboratory facilities at the frequency required by DOE 5480.7 .

All requirements for testing frequency and documentation for fire protertion equipm ?nt are not clearly identified in Brookhaven Nat,orial Laboratory fire protection procedures.

BNL life safety provisions do not meet the minimum requirements of NFPA 101, The Life Safety Code, as required by DOE 5480.7-9.9(1). 
CONCERN:

(FP. 3-1)

$(\mathrm{H} 2 / \mathrm{C} 1)$

CONCERN:

(FP. 4-1)

( $\mathrm{H} 3 / \mathrm{Cl})$

CONCERN:

(FP. 4-2)

( $\mathrm{H} 2 / \mathrm{C2})$

CONCERN:

(FP. 5-1)

$(\mathrm{H} 3 / \mathrm{Cl})$

CONCERN:

(FP. 5-2)

( $\mathrm{H} 2 / \mathrm{C2})$

CONCERN:

(FP. 5-3)

(H2/C2)

CONCERN:

(FP. 5-4)

( $\mathrm{H} 2 / \mathrm{Cl})$

CONCERN:

(FP. 5-5)

( $\mathrm{H} 2 / \mathrm{Cl})$

CONCERN:

(FP. 5-6)

(H2/C2)

CONCERN:

(FP. 5-7)

(H2/C2)

CONCERN:

(FP. 5-8)

(H2/Cl)

COHCERN:

(FP.7-1)

(H3/C1)

No quantitative analysis has been performed to ensure that an offsite release of hazardous amounts of toxic or radioactive materials will not occur under maximum credible fire conditions as per DOE 5480.7-9.a.(3). (See also Concerns EP.1-1 and PT.5-1.)

BNL has not performed an analys is to verify that a credible fire loss could not impair an operation in a vital facility for a period greater than six months, as required by DOE 5480.7-9.b.

The transformer yard arrangement does not meet the criteria of Factory Mutual Data Sheet 5-4, Table III, for equipment and building separation.

BNL has not determined that a maximum credible fire may result in an unacceptable property loss as required by DOE 5480.7, Sections 9.c, 9.d, 10.b.(8), and 10.b.(11).

A fire involving either the Chemistry or Physics complex cooling towers may result in direct damage to the buildings in excess of the "improved risk" criteria of DOE 5480.7.

Combustible areas obstructed from sprinklers at the National Synchrotron Light Source and small combustible operations at the Alternating Gradient Synchrotron are not protected in accordance with Factory Mitual Data Sheet 2-8 for Highly Protected Risks.

Automatic Fire protection of critical records, off-site vital records storage, and the arrangement of equipment are not consistently provided for electronic data and computer apparatus as required by DOE 5480.7 and mandatory standards.

The maintenance of roof decks is inadequate to prevent damage to critical equipment and experiments and weakening to windstorm windstorm damage per DOE 5480.7 .

Cable tray arrangements do not meet the criteria of Factory Mutual Data Sheet 5-31, and the impact of a fire involving this material has not been recently analyzed.

The lack of fire walls, smoke barriers, or sealed vertical cut-offs poses a loss potential in excess of the improved risk criteria of DOE 5480.7 .

Brookhaven National Laboratory has not determined through formal and regularly scheduled analyses that a maximum credible fire will not result in an unacceptable property loss, as required by DOE 5480.7 .

Some sprinkler and halon systems at BNL do not completely conform to DOE $6430.1 A-1530-4.1$ and -5.25 requirements. 
CONCERN: The distribution of some portable fire extinguishers in several (FP.7-2) buildings is not in accordance with NFPA 10 and DOE 6430.1A-1530-7. $(\mathrm{H} 3 / \mathrm{C} 1)$

CONCERN:

(FP. 7-3) $(\mathrm{H} 2 / \mathrm{C2})$

COHCERN: (FP.7-4) $(\mathrm{H} 2 / \mathrm{C} 1)$

CONCERN: (FP.7-5) $(\mathrm{H} 2 / \mathrm{Cl})$

CONCERN: (FP.7-6) ( $\mathrm{H} 2 / \mathrm{Cl})$

CONCERN: (FP.7-7) ( $\mathrm{H} 2 / \mathrm{Cl})$

CONCERN: (FP. 7-8) ( $\mathrm{H} 2 / \mathrm{C} 1)$

CONCERN: (FP. 7-9) ( $\mathrm{H} 2 / \mathrm{C2})$

CONCERN: (FP.7-10) $(\mathrm{H} 2 / \mathrm{C} 1)$

CONCERN: (FP.7-11) (H2/C2)

CONCERN: (FP.7-12) ( $\mathrm{H} 2 / \mathrm{Cl})$

CONCERN: (FP.7-13) $(\mathrm{H} 2 / \mathrm{Cl})$

CONCERN: (FP.7 (H2/C2)
Housekeeping and the control of ordinary combustibles is not adequate in several buildings at BNL. (See also Concern 0S.5-2)

Flammable liquid hazards at BNL are not being controlled in accordance with DOE 5480.7-9a.(2)(b) and the requirements of NFPA 30.

During welding operations, site procedures for the protection of combustibles and use of fire watch personnel were not being followed, as required by NFPA 51B.

$B N_{L}$ is not implementing an effective fire barrier maintenance program as required by DOE 5480.7-10.b.(5) and 10.b.(7).

Materials with unusually high fire characteristics, notably expanded plastic duct insulation, exist in interior finish applications at BNL, in conflict with DOE 5480.7-9.a.(2)(a) and 6430.1A-0110-6.1. (See also Concern FP.1-1.)

Fire water main flows, water storage tanks, and emergency lights and signs are not tested or inspected at NFPA-specified frequencies.

Not all portable and modular buildings at BNL conform to the requirements of DOE/EV-0043, "Fire Protection for Portable Structures, "with respect to exposure distances and sprinkler protection.

Precautions for the storage and use of compressed gas cylinders are not in accordance with improved risk practices.

Automatic sprinkler systems at BNL are not always arranged and maintained according to improved risk as cutlined in the NFPA Fire Protection Handbook.

There is no diking around elevator hydraulic tanks and pumps per NFPA 30 Section 2-4.1.1 which can allow burning oil to spread to surrounding equipment.

Cable and wiring circuits are not fully maintained in accordance with NFPA 70 "National Electric Code".

The presence of combustibles in critical equipment or otherwise unprotected areas, such as at the Alternating Gradient Synchrotron, poses an avoidable fire risk. 
CONCERN: Tobacco smoking is an ignition source to transient combustibles in (FP.7-15) the Alternating Gradient Synchrotron, a largely unprotected and ( $\mathrm{H} 2 / \mathrm{C2})$ important facility.

CONCERN: Maintenance, cable support, and fire protection for the transformers (FP.7-16) ( $\mathrm{H} 2 / \mathrm{C} 2)$ near the be $2 m$ separator line of the Alternating Gradient Synchrotron is not in accordance with the manufacturer's instructions or Factory Mutual Data Sheet 5-4.

\section{P. MEDICAL SERVICES}

CONCERN: A formal tracking program does not exist in the Occupational (MS.2-1) Medical Clinic.

(H2/C2)

CONCERN: Policies, procedures, and practices of the Occupational Medical (MS.4-1) Clinic are not periodically reviewed and aucited as required by (H2/C2) good practices.

CONCERN: The Health Awareness and Wellness Program is not fully implemented (MS.5-1) for Brookhaven National Laboratory by the Occupational Medical $(\mathrm{H} 2 / \mathrm{CH}) \quad$ Clinic. 


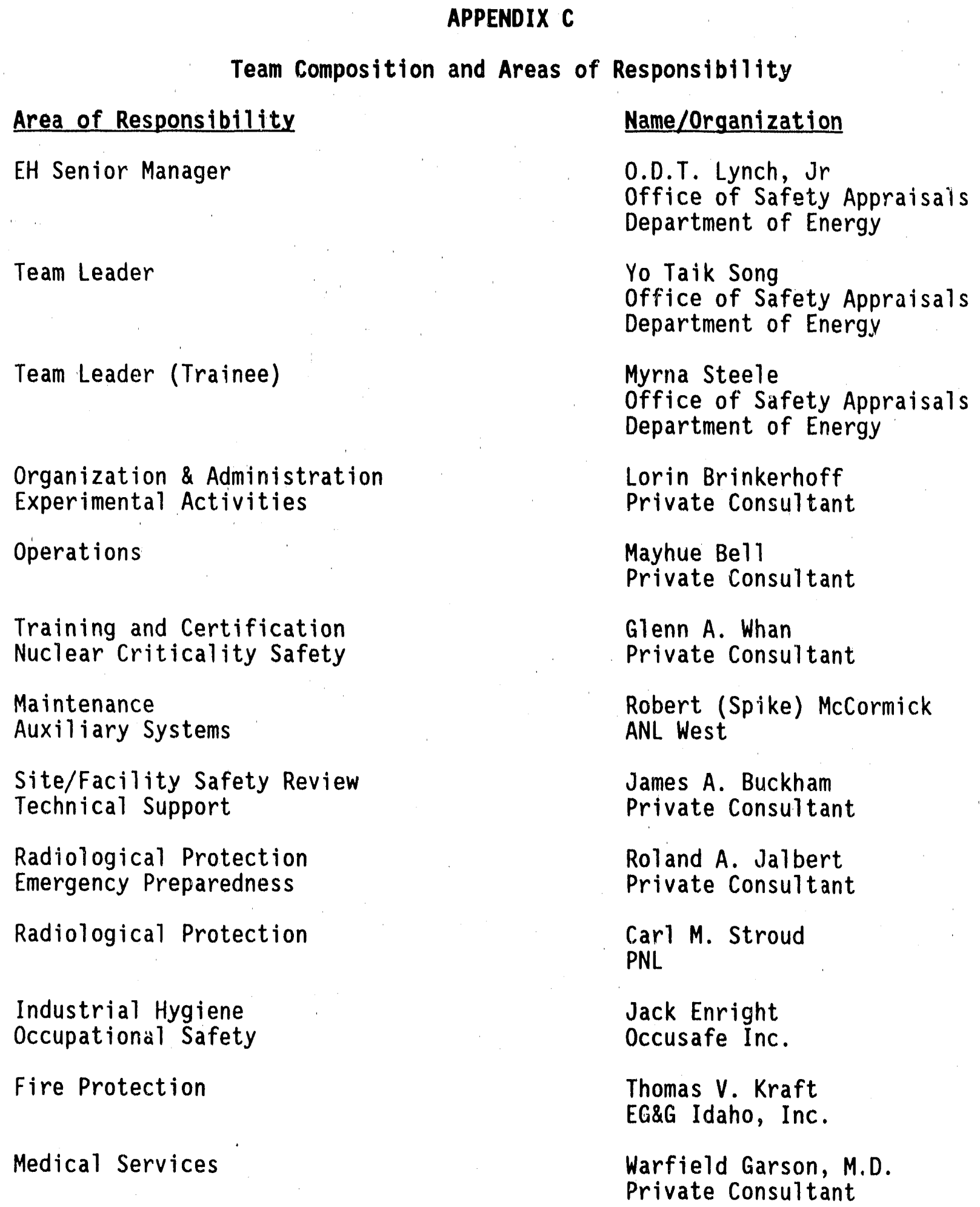


Area of Responsibility

Quality Verification

Report Quality

REPORT SUPPORT, OBSERVERS AND LIAISON:

Appraisal Specialists

Coordinators in Training

HQ/ER Liaison

EH Compliance

Field Office

Area Office
Name/Organization

Richard Glover Office of Quality Programs Department of Energy

Larry D. Warren

Private Consultant

Mary Meadows

Office of Safety Appraisals Department of Energy

Patricia Davidson

Office of Safety Appraisals Department of Energy

Robin Longerbeam

Office of Safety Appraisals

Department of Energy

Terry Blanton

Office of Quality Programs

Department of Energy

H.C. Field

ER/Office of Management

Department of Energy

Dae Y. Chung

Department of Energy

Just in Zamirowski

Chicago Operations office

Department of Energy

Michael A. Butler

Brookhaven Area Office

Department of Energy 


\section{APPENDIX D}

\section{Biographical Sketches of Team Members \\ Technical Safety Appraisa? \\ Brookhaven National Laboratory}

D-1 
NAME: $\quad 01$ iver D. T. Lynch, Jr.

AREA OF RESP: $\quad$ EH Senior Manager

ASSOCIATION: Office of Safety Appraisals, Headquarters, Department of Energy

EXPERIENCE: $\quad 26$ years

- Department of Energy, Germantown, Maryland

- Director, Safety Inspections Division, OSA

- U. S. Nuclear Regulatory Commission, Rockvilie, Maryland

- Radiation Measurements and Health Effects Section Chief

- Standardizatinn and Decommissioning Section Chief

- Safeguards and Non-Power Reactors Section Chief

- Radiation Protection Section Leader

- Senior Operating Reactor Project Manager

- Environmental Assessment Section Chief, TMI Program Office

- TMI Special Inquiry Group (Rogovin)

- Senior Environmental Project Manager

- International Atomic Energy Agency

- Technical Working Group Leader, Vienna, Austria

- Instructor, Cairo, Egypt

- General Dynamics, Electric Boat Division, Groton, Connecticut

- Chief, Radiological Control Health Engineering

- U. S. Atomic Energy Commission, Las Vegas, Nevada

- Radiological Specialist

- San Diego State University, San Diego, California

- Assistant Radiological Safety officer

EDUCATION: $\quad$ M.S., Nuclear Physics, San Diego State University

B.S., Applied Physics, San Diego State University

OTHER: Member, Health Physics Society

Member, American Forestry Association

Sigma Pi Sigma

Author, Textbooks and Training Manuals, Small

Craft Safety, Operations and Navigation

D-2 

NAME:
Yo Taik Song
AREA OF RESP: Team Leader
ASSOCIATION: Office of Safety Appraisals, Headquarters, Department of Energy
EXPERIENCE: $\quad 28$ years
- Team Leader - Office of Safety Appraisals, DOE
- Nuclear Engineering and Reactor Physics
- Research in Neutron and Photon Transport. Nuclear and Radiation, Safety for U. S. Navy Nuclear Weapons Program
- Teaching reactor physics, radiation transport and radiation shielding in universities
- Management of Nuclear Weapons Research, Development and Testing
- Appraisals and reviews of DOE reactor designs and operations
EDUCATION:
M.S. and Ph.D., Nuclear Engineering with minor in Mathematics and Chemical Engineering, University of Illinois, Urbana, I11.
B.S., Chemical Engineering
OTHER: Licensed Reactor Operator, Qualified Instructor for fall-out shelter design 
NAME: James C. Snel1

AREA OF RESP: Occupational Safety and Health Subteam Leader

ASSOCIATION: Office of Safety Appraisal, Headquarters

Department of Energy

EXPERIENCE: $\quad 27$ Years

- Department of Energy, Germantown, MD

- Team Leader for Technical Safety Appraisals of DOE facilities

- Policy review and revision to DOE Environmental Health and Safety Policies

- Participation in three Tiger Team/TSA reviews

- Department of Transportation, Washington, DC

- Safety engineer for regulatory review of Motor Vehicle Codes and Standards

- Department of Defense (Army), Alexandria, VA

- Inspector General, Team Leader responsible for technical engineering inspection teams and reviews of Defense Weapons Systems

- General Physics Corporation, Columbia, MD

- Manager of Licensing, responsible for nuclear power plant licensing concerns

- NUS Corporation, Gaithersburg, MD

- Manager of Licensing, responsible for review and compliance of 1 icensing activity for power plant clients

- Nuclear Regulatory/Atomic Energj Commission, Bethesda, MD

- Regulatory Project Manager to variety PWR's and BWR's responsible for Government acceptance and review of applications to construct and operate facilities

- U. S. Navy

- Communication Division officer responsible for both fleet and ship communication

EDUCATION: Graduate studies in Nuclear Engineering and Mechanical Design

B.S., Math and Physics, Lebanon Valley College

D-4 
NAME: Myrna Steele

AREA OF RESP: Team Leader (Trainee)

ASSOCIATION: $\quad$ Office of Safety Appraisals, Headquarters

Department of Energy

EXPERIENCE: $\quad 28$ years

- Department of Energy

- Nuclear Engineer, Technical Safety Appraisal Team Leader

- Nuclear Regulatory Commission/Atomic Energy Commission

- Deputy Director, Division of Technical Information

- Member, TMI Special Inquiry Group (Rogovin)

- Reactor Operations Project Manager, originator/writer of "Reactor Operating Experience Reports"

- Task Force that organized NRC from AEC

- Member, Rasmussen Report group (WASH-1400)

- Technical Assistant/Licensing for AEC Chairman

- Managing Editor, Reactor Technology journal

- National Aeronautics and Space Administration

- Licensing Officer and Startup Test Engineer for Materials Testing Reactor licensed by AEC

- Research physicist and experiment design engineer for space program

EDUCATION: Diploma, Federal Executive Institute, Charlottesville, VA

Law School, University of Toledo

Graduate courses in nuclear engineering and physics, University of Toledo (Ohio) and University of Tennessee

B.S., Physics and Mathematics, University of Kentucky

OTHER: Congressional Fellowship, USNRC/OPM

Member, American Nuclear Society

Reactor Operator

Member, National Contract Management Association

Member, Society for Information Management 
NAME:

Mayhue A. Bell

AREA OF RESP: Operations

ASSOCIATION: Private Consultant, EG\&G Idaho, Inc.

EXPERIENCE: $\quad 30$ years

- Department of Energy, Headquarters

- Managed the DOE Reactor Safety and Emergency Preparedness programs: Policy development and safety requirements, planning, coordinating and performing safety appraisals, individually and as team leader; covering organization and administration, management assessment, operations, maintenance, training and certification, technical support, experimental activities, facility safety review and quality assurance.

- Carolinas Virginia Nuclear Power Associates, Inc.

- General Manager: Responsible to sponsoring power companies (Duke, CP\&L, SCE\&G, Virginia Electric)

- Operating Director: Responsible for company operations, including technical support, health, plant testing, experimental research programs, training and certification, emergency preparedness, and piant operations through the plant Superintendent. Dual responsibilities of Training Director and Operating Director during initial staffing and plant startup phase.

- Nuclear Regulatory Commission

- Reactor Inspection Specialist: Responsible for performing inspections of licensed facilities during construction, plant testing and operation.

- Dupont, Savannah River Plant, Aiken, S.C.

- Senior Supervisor, Plant Operations: Shift Supervisor Reactor operations including operator training and qualification. Nuclear Engineer on loan to Homogeneous Reactor Experiment, Oak Ridge National Laboratory.

EDUCATION: Diploma, Nuclear Power Reactor Safety, Harwell, England

Diploma, Quality Assurance Nuclear Power Industry, NRC

Diploma, Federal Executive Institute, University 
of Virginia

Bachelor of Nuclear Engineering, with honors, North Carolina State University

OTHER:

U.S. Representative to IAEA - Served on panel of experts and editor, preparing manual on emergency preparedness, and on IAEA team responsible for training representatives from all Spanish speaking nations on emergency preparedness. 
NAME: $\quad$ Lorin C. Brinkerhoff

AREAS OF RESP: Organization and Administration and Experimental Activities ASSOCIATION: Private Consultant

EXPERIENCE: $\quad 36$ years

- Nuclear Safety Technical Consultant under contract with EG\&G, Idaho, Scientech, and ORAU

- Technical Safety Appraisal Team Leader, Office of Safety Appraisals, DOE

- Reactor and Nuclear Facility Safety Specialist, AEC/ERDA/DOE

- Senior Nuclear Engineer, Aerojet General Corporation, Nuclear Rocket Development Center, Nevada Test Site

- Manager, Nuclear Critical Facility, Lawrence Livermore Nationai Laboratory, Nevada Test Site

- Reactor Foreman, Phillips Petroleum Company, Idaho Test Site

- Graphite Research Analyst, Hanford Test Site, General Electric Company.

EDUCATION: $\quad$ B.S., Chemical Engineering, University of Utah

OTHER:

Past member of ANS-15 Standards Committee on

Research Reactor Safety

Past Member of ANSI N-16 Standards Committee on

Nuclear Criticality Safety

Listed in:

Who's who in the East

Who's Who in the World 


\author{
NAME: James A. Buckham \\ AREA OF RESP: Technical Support and Facility Safety Review \\ ASSOCIATION: $\quad$ Private Consultant \\ EXPERIENCE: $\quad 37$ years \\ - TSA Team Member \\ - Feed Materials Production Center, Y-12 Plant, Rocky \\ Flats Plant, West Valley Facility, Portsmouth Gaseous \\ Diffusion Plant, and Savannah River Laboratory TSAs. \\ - Oversight Team Leader \\ - To ensure safe, effective restart of Sequoyah Facility \\ - Allied-General Nuclear Services \\ - Executive VP and President with overall responsibilities \\ for the Barnwell Nuclear Fuels Plant \\ - Idaho National Engineering Laboratory \\ - Research and Development, Operations, and Management at \\ the Idaho Chemical Processing Plant \\ EDUCATION: $\quad$ Ph.D., Chemical Engineering, University of \\ Washington \\ M.S., Chemical Engineering, University of \\ Washington \\ B.S., Chemical Engineering, University of \\ Washington \\ OTHER: $\quad$ Member, Sigma $X_{i}$, Tau Beta $P_{i}$ \\ Fellow, American Institute of Chemical Engineers \\ Member, American Nuclear Society \\ Member, American Chemical Society \\ Instructor, University of Washington \\ Adjunct Professor, University of Idaho
}


NAME:

AREA OF RESP: Irdustrial Hygiene and Occupational Safety

ASSOCIATION:

EXPERIENCE:

EDUCATION:

OTHER:

John C. Enright

OCCUSAFE Inc., Wheeling, Illinois

18 Years

- oCCUSAFE, Inc. industrial hygiene and safety.

- General Motors Corporation Journal. metal model and pattern making.

M.B.A., Engineering, University of Dayton

B.S., Engineering, Purdue University
- Senior Consultant: Provides consulting services to program administration, and technical liaison with the academic, governmental, and labor communities in

- Held technical positions with automotive components manufacturing division and the corporate staff, and administrative responsibilities for major divisions. Presented technical papers at professional seminars within the automotive industry and national technical conferences. Assisted with peer review for papers publ ished in the American Industrial Hygiene Association

- Provided technical consultation and support to epidemiological studies of workers involved in wood and

- Participated as team leader in multi-disciplinary technical teams in resolving major occupational health and product health and safety questions and concerns.

Member, American Industrial Hygiene Association

Member, American Academy of Industrial Hygiene

Member, Michigan Industrial Hygiene Society

(Director, 1985-1987, President Elect, 1987-1988, President, 1988-1989)

Certified Industrial Hygienist

Certified Safety Professional 
NAME :

Warfield Garson, M.D.

AREA OF RESP: Medical Services

ASSOCIATION: Private Consultant

EXPERIENCE: $\quad 45$ Years

- Medical Director, Shippingport Nuclear Reactor Decommissioning Project DOE/General Electric Corp. Shippingport, PA.

- Medical Director, Bituminous Coal Research National Laboratory, University of Pittsburgh, Monroeville, PA.

- Medical Director, Centerville Clinic, Inc., Frederick Town, PA.

- Medical Director, Regular Corps, U.S.P.Y.S., Retired, Washington, DC.

- Private Consultant, Hanford Environmental Health Foundation Occupational Medical Program Appraisals of Portsmouth Gaseous Diffusion Plant, Portsmouth, Ohio and Mound Plant, Miamisburg, $\mathrm{OH}$.

- Private Consultant, Hanford Westinghouse Corp., Occupational Medical Program Appraisals of National Laboratary Sites.

- Clinical Professor of Occupational Health and Health Services Administration, Graduate School of Public Health, University of Pittsburgh.

- Attending Physician - Professor, Pulmonary Program Department of Medicine, School of Medicine, University of Pittsburgh and Veteran's Administration Medicine Center, Pittsburgh, PA.

EDUCATION: $\quad$ A.B., Bacteriology, University of California at Los Angeles

M.D., School of Medicine, University of Southern California

M.P.H., School of Hygiene and Public Health, The Johns Hopkins University

OTHER: Diplomat, American Board of Preventive Medicine Fellow, American College of Occupational Medicine Fellow, American College of Preventive Medicine Chairman, Governors Advisory Committee of Occupational Respiratory Disease. 
NAME:

N. Richard Glover

AREA OF RESP: Quality Verification

ASSOCIATION: Office of Quality Programs, Headquarters

Department of Energy

EXPERIENCE: $\quad 30$ Years

- Appraisal Performance Group Leader and Quality Assurance Engineer in Office of Quality Assurance, DOE

- Supervisory Operations Research Analyst in Operational and Environmental Safety Division, DOE

- Inspector, Office of Internal Review, ERDA

- Chief, Quality Assurance and Safety Branch, Rocky Flats Area Office, AEC/ERDA

- Materials \& Test Engineer, Quality Assurance Division, Albuquerque Operations office, AEC

- Fire Protection Engineer, Operational Safety Division, Albuquerque Operations office, AEC

- Fire Protection Engineer, Factory Insurance Association and Nuclear Energy Property Insi: ance Association

EDUCATION: $\quad$ M.P.A., Public Administration, University of New Mexico

B.S., Mechanical Engineering, University of Maine

OTHER: $\quad$ Certified Safety Professional

Member, American Society for Quality Control

Meniber, American Society of Safety Engineer

Member, Society of Fire Protection Engineers

Member, American Society of Mechanical Engineers 
NAME:

Joseph A. Hopkins. Jr.

AREA OF RESP: OSHA Compliance, Part Time

ASSOCIATION: DOE Headquarters - Office of Safety Appraisals

EXPERIENCE: $\quad 16$ years

- Department of Energy

- Occupational Safety Engineer, participated in tiger team and functional appraisals

- Department of Labor - OSHA

- Mechanical Engineer / National Technical Expert, responsible for the enforcement of OSHA standards in unprecedented cases of national interest

- U.S. Environmental Protection Agency

- Environmental Engineer, responsible for providing technical support for the enforcement of regulations promulgated under the Clean Air Act

- Bethlehem Steel Corporation

- Mechanical Engineer, responsible for developmental engineering of production equipment for a fully integrated steel mill, including prototype equipment for controlling environmental and workplace exposures to toxic substances

EDUCATION: $\quad$ B.S., Mechanical Engineering, University of Maryland

OTHER:

Member, American Society of Mechanical Engineers 
NAME:

Rol and A. Jalbert

AREAS OF RESP: Emergency Preparedness and Radiological Protection

ASSOCIATION: DOE Headquarters, Office of Safety Appraisal

EXPERIENCE: $\quad 32$ Years

- Los Alamos National Laboratory

- Field health physics involving accelerators, $x$-ray machines, portable radiation sources, in addition to instrument development, neutron shielding, radiological engineering, tritium handling safety.

- Member of "Tritium Systems Test Assembly" staff responsible for safety systems and for tritium contamination studies and tritium monitor research and development.

- DOE Safety Appraisals and Assessment.

- University of Alaska

- Assistant Professor of Physics

- General Electric Company, Richland, WA

- Member Health Physics Group

- Private Consultant:

- Technical safety appraisal, Savannah River Site

- American Atomics Corporation (Tucson, AZ) on tritium handling, safety, monitoring, dosimetry

- Quadrex Corporation (Richland, WA) on decommissioning radiochemistry laboratory

- Skyway Consulting, Inc. (Tucson, AZ) on tritium accident analysis

EDUCATION: M.S., Biophysics, Massachusetts Institute of Technology

B.S., Physics, Massachusetts Institute of Technology

OTHER:

Certified by American Board of Health Physics

Member, Panel of Examiners, American Board of Health Physics

Member, ANSI Committee that drafted Tritium

D-14 
Bioassay Standard

Member, Office of Fusion Energy, DOE, panel that reviewed Oak Ridge National Laboratory generic fusion safety technical basis document 
NAME :

AREA OF RESP:

ASSOCIATION:

EXPERIENCE:
Thomas V. Kraft

Fire frotection

$E G \& G$, Idaho

14 Years

- EG\&G Idaho, Fire Protection Engineer

- Responsible for Plan Review, Probable Maximum Loss Analysis, Fire Protection Impairment Handling Procedures Development, Training and Safety Audits for Power Reactors Program. Developed Test Reactor Area (TRA) Site Baseline Safety Study, Life Safety Analysis, Advance Test Reactor 10CFR $50 \mathrm{App}$. R. Study, and TRARisk Management Resource Manual. Currently involved in Site Wide Fire Protection and Alarm System Line Item Project Development.

- Crawford \& Company, Risk Control Consultant

- Develop and service wide range of property accounts, including plan review, risk hazard analysis, field surveys and training seminar development.

- CIGNA Loss Control Services (LCS), Senior Fire Protection and Utilities Specialist

- Services all property accounts including utilities and engineering risks. Coordinates major accounts, performs field and report audits. Engineering consultant for staff. Instructs seminars in house and risk management services for customers. Approves proposed protection system installations.

- LCS Fire Protection Specialist II, Serviced all property accounts, property inspections and coordinated service for major industry groups and conducted loss investigations. Developed loss control materials for distribution to insureds. Highly Protected Risk (HPR) property and engineering and loss control including plan review, training and administration of programs for a district office, handled impairments and developed training seminars for insureds.

- Factory Mutual Engineering Association, Fire Protection Consultant

- Serviced HPR properties providing surveys, water tests and loss incident investigations. 
EDUCATION:

OTHER:
B.S., General Engineering, Idaho State University

Society of Fire Protection Engineers National Fire Protection Association Certified Fire Protection Specialist American Society of Mechanical Engineers 
NAME:

AREA OF RESP: Maintenance and Auxiliary Systems

ASSOCIATION:

EXPERIENCE :

Robert P. McCormick

30 years
Argonne National Laboratory (West)

- Participated in the 221-H Cariyon TSA, Savannah River Site, 1986. Areas of responsibilities included Technical Support, Experimental Activities, and Facility Safety Review.

- Participated in the HFBR Reactor TSA, Brookhaven National Laboratory, 1987. Resporisible for Training and Certification.

- Participated in the HFBR Reactor TSA Followup, Brookhaven National Laboratory, 1989. Areas of responsibility included Training and Certification, Maintenance, and Operations.

- Participated in the FFTF Reactor TSA, Hanford, Washington, 1989. Responsible for Maintenance.

- Argonne National Laboratory

- Reactor Operator, EBR-I Reactor

- Reactor Operator, Treat Reactor

- Participated in construction and pre-operational checkout of Experimental Breeder Reactor II.

- Participated in initial EBR-II startup and operation as a member of the Critical Systems Maintenance Group and as a Reactor Operator.

- Shift Supervisor, EBR-II

- Staff Specialist EBR-II: Responsible for major electrical power distribution and experimental activities.

- Operations Analysis: Participated in development and implementation of Technical Specifications. Development of Technical Specifications Surveillance Program, and procedures.

- Manager, Training and Procedures: Responsible for development and implementation of procedures for experimental activities, operations, and maintenance.

D-18 
Development and implementation of the training programs for Operations, Maintenance, and Plant Chemistry.

EDUCATION: Two years at University of Idaho (Architecture) 
NAME: Jacqueline D. Rogers

AREA OF RESP: Industrial Hygiene and Safety

ASSOCIATION: Headquarters, Department of Energy

EXPERIENCE: $\quad 13$ years

- Senior Level Industrial Hygienist, Department of Energy, Germantown, MD

- Occupational Safety and Health Administration (OSHA), U.S. Department of Labor

- Directorate of Compliance Programs, Office of Health Compliance Assistance. Senior Level Industrial Hygienist. Responsible for developing compliance guidance documents for OSHA field staff for a wide range of health enforcement issues.

- Directorate of Field Operations. Industrial Hygienist. Project Coordinator for the OSHA Industrial Hygiene Technical Manual

- Directorate of Technical Support. Industrial Hygienist responsible for assisting in the deveiopment of chapters for the OSHA Field Operation Manual. Accompany senior level industrial hygienist on official OSHA compliance inspections.

EDUCATION: M.S., Physiology, University of Connecticut

B.S., Biology, Federal City College 


$\begin{array}{ll}\text { NAME: } & \text { James W. Slawski } \\ \text { AREA OF RESP: } & \text { Industrial Hygiene and Safety } \\ \text { ASSOCIATION: } & \text { Headquarters, Department of Energy } \\ \text { EXPERIENCE: } & 18 \text { years in occupational safety and health } \\ & \text { - Department of Energy - Industrial Hygiene } \\ & \text { - Department of Navy - Industrial Hygiene } \\ & \text { - Library of Congress - Safety and Occupational Health } \\ & \text { - Fireman's Fund American - Safety } \\ & \text { - Insurance Company of North America - Safety } \\ \text { EDUCATION: } & \text { M. S., Safety, University of Southern California } \\ \text { B. A., Economics, Claremont McKenna College } & \text { Certified Safety Professional }\end{array}$


NAME: Anthony Straquadine

AREA OF RESP: Quality Verification

ASSOCIATION: Los Alamos National Laboratory, Appraisal Group, OM-2

EXPERIENCE: $\quad 39$ Years

- ES\&H Appraisal Team Member, Appraisal Group, Los Alamos National Laboratory

- Quality Assurance Department Head, Zia Company

- ONWI Project, Quality. Assurance Field Office, Albuquerque, Battelle Memorial Institute

- Quality Assurance Engineer, Albuquerque Operations Office, DOE

- Quality Assurance Engineer, NASA Lewis Research Center

- Materials Engineer, TRW (formerly Thompson Products)

- Materials \& Process Engineer, Jack \& Heintz Company (Lear Sigler)

- Staff Metallurgist, Bingham Herbrand Forging Company

EDUCATION: $\quad$ B. Met. E., Metallurgical Engineer, Ohio State University

OTHER:

Member, American Welding Society (36 Years Life Member)

Participant in the formulation of original NASA

Quality Assurance Standards, NPC 200-1, 200-2, \& 200-3 


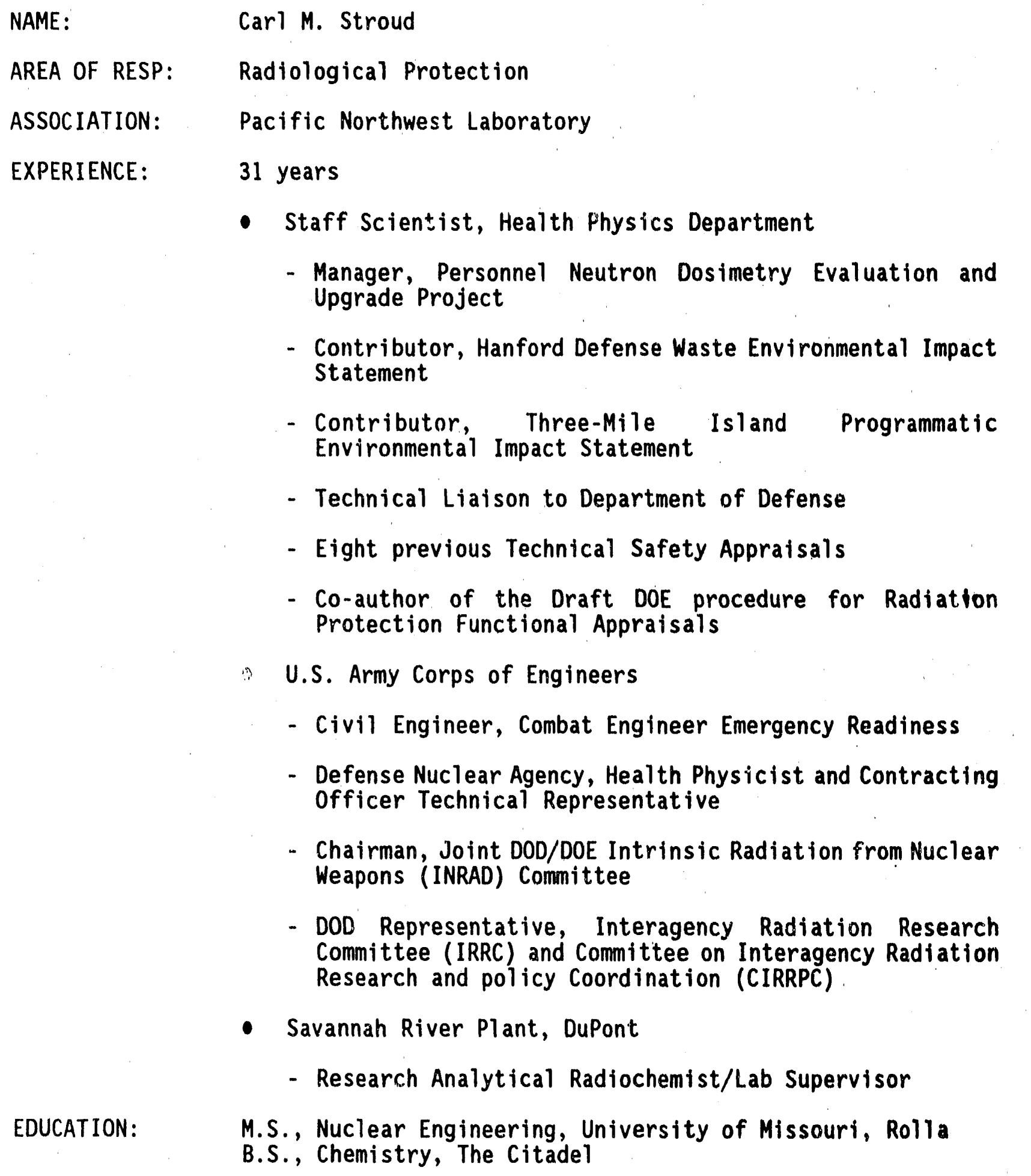




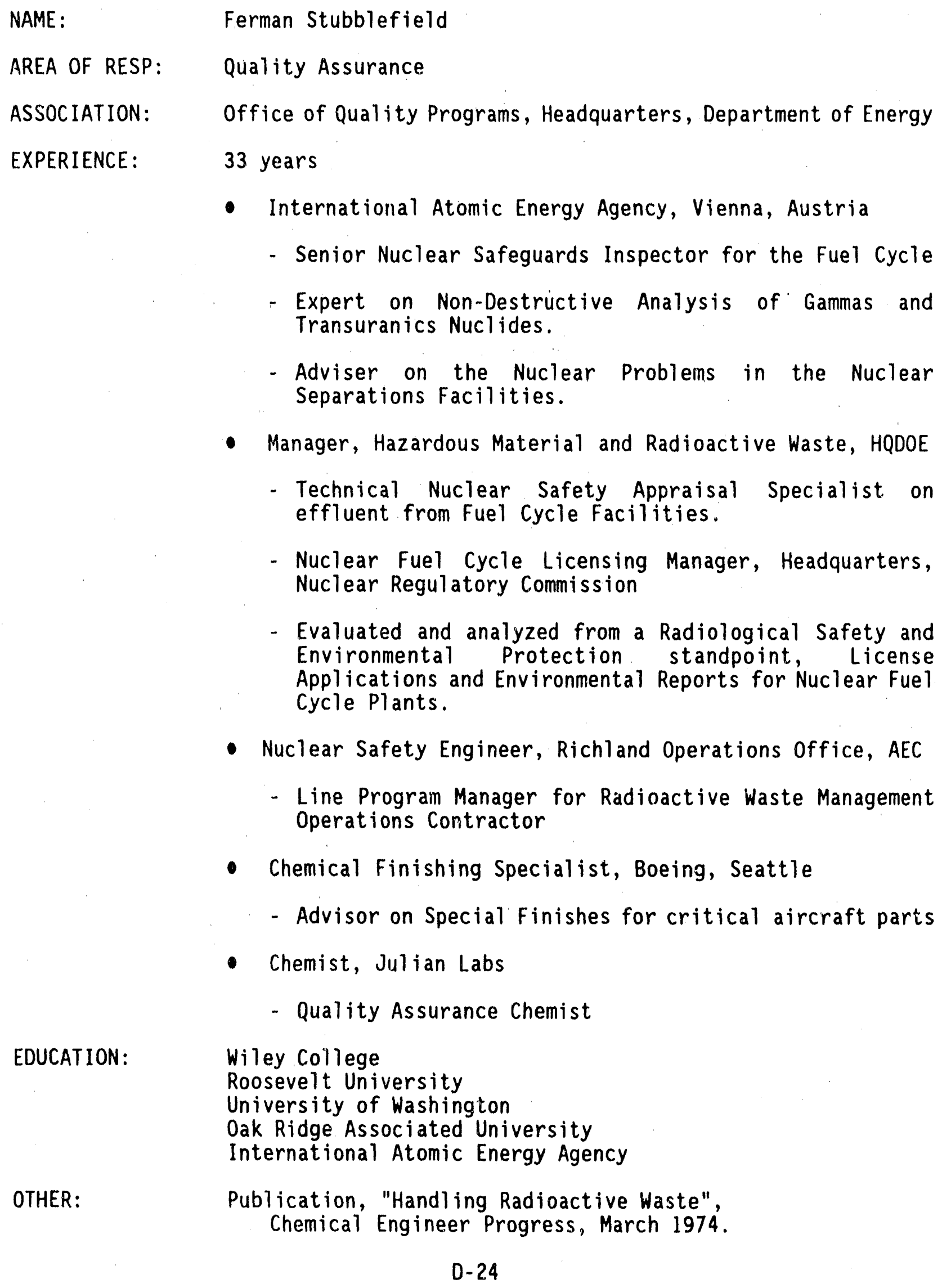

- Manager, Hazardous Material and Radioactive Waste, HQDOE

- Technical Nuclear Safety Appraisal Specialist on effluent from Fuel cycle Facilities.

- Nuclear Fuel Cycle Licensing Manager, Headquarters, Nuclear Regulatory Commission

- Evaluated and analyzed from a Radiological Safety and Environmental Protection standpoint, License Applications and Environmental Reports for Nuclear Fuel Cycle Plants.

- Nuclear Safety Engineer, Richland Operations Office, AEC

- Line Program Manager for Radioactive Waste Management Operations Contractor

- Chemical Finishing Specialist, Boeing, Seattle

- Advisor on Special Finishes for critical aircraft paris

- Chemist, Julian Labs

- Quality Assurance Chemist

EDUCATION: Wiley College Roosevelt University University of Washington Oak Ridge Associated University International Atomic Energy Agency

OTHER:

Publication, "Handling Radioactive Waste", Chemical Engineer Progress, March 1974. 
Member of the American Institute of Chemical

Engineers.

Member of DOE Speakers Bureau.

Past President of Toastmasters International. 
NAME:

AREA OF RESP: Industrial Hygiene and Safety

ASSOCIATION: Headquarters, Department of Energy

EXPERIENCE:

EDUCATION:

OTHERS:

John W. Teske

25 years Incorporated Wildlife Service Training Institute Administration University of Minnasota
- Occupational Health and Safety Program Management

- Chief, Occupational Safety and Health Branch and Senior Industrial Hygienist, U. S. Department of Agriculture

- Director, Industrial Hygiene Services, Versar

- Chief, Safety and Health Division, U. S. Fish and

- Instructor and Safety Engineer, University of Minnesota

- Occupational Health and Safety Compliance

- Senior Industrial Hygienist, Department of Energy

- Industrial Hygiene Program Leader, OSHA National

- Industrial Hygienist, Mining Safety and Health

Masters of Business Administration, George Mason University Graduate Studies Industrial Hygiene/Environmental Health,

B.S. Civil Engineering, University of Minnesota

Certified in Comprehensive Practice of Industrial Hygiene Registered Professional Safety Engineer, Cal ifornia Certified Safety Professional 
NAME: Larry D. Warren

AREA OF RESP: Report Quality

ASSOCIATION: Private Consultant

EXPERIENCE: $\quad 26$ Years

- Private Consultant

- Technical and management consulting to the Department of Energy and its contractors: Technical Safety Appraisals (TSAs), Tiger Team Assessments (TTAs), and management appraisals/reviews.

- U.S. Department of Energy, Germantown, MD

- Safety Programs Manager, Office of Weapons Safety and Operations, Deputy Assistant Secretary for Military Application, Defense Programs: Formulated safety and health policy and long-range plans for three national laboratories and five manufacturing facilities in the nuclear weapons complex. TSA coordinator/contact and Program Representative on 11 TSAs.

- Wilmington District, U.S. Army Corps of Engineers

- Deputy Commander: Managed/directed annual planning/execution of $\$ 60-70$ million in civil works projects, and \$9-15 million in military construction projects. Contracting office for construction and service contracts.

- Los Alamos National Laboratory

- Program Manager, Insertable Nuclear Component Technology Program and Corps Support Weapon System Concept Study; Design Engineer: Nuclear weapon components and subsystems.

- U.S. Army (Lieutenant Colone1, Retired)

- Various command, operations, and training assignments; and nuclear weapons research and development staff assignments.

EDUCATION: $\quad$ M.S., Nuclear Engineering, N. C. State University

B.S., Nuclear Engineering, N. C. State University

U.S. Army Command and General Staff College

OTHER: Member, Society of American Military Engineers 
NAME :

Glenn A. Whan

AREAS OF RESP: Training and Certification and Nuclear Criticality Safety ASSOCIATION: Emeritus Professor, Chemical and Nuclear Engineering University of Mexico

EXPERIENCE: $\quad 33$ years

- Participated in DOE Technical Safety Appraisals from 1986 to 1990 for: Oak Ridge Y-12 Plant, Portsmouth and Paducah Gaseous Diffusion Plants, Idaho Chemical Processing Plant, Hanford Plutonium Finishing Plant and PUREX Plant, Rocky. Flats Plant, West Valley Facility, and Savannah River Site.

- Professor and Department Chairman, Chemical and Nuclear Engineering Department, University of New Mexico, 1957-85

- International Atomic Energy Agency Technical Expert, Reactor Experimentation, 1966-67

- Los Alamos National Laboratory

- High Temperature Gas-Cooled Reactor Safety Analysis, 1974-75; Nondestructive Assay Measurements for Special Nuclear Materials, International Safeguards, 1983 to present

- Other Nuclear Safety Reviews

- DOE Independent Review Committee for Transuranic Waste (Chairman one year), 1980-84

- NRC Nuclear Criticality Safety Appraisal Team, Nuclear Fuel Services Corporation, Erwin, Tennessee, 1986

- DOE Readiness Review Team, Rockwell Hanford Operations, PUREX and PFP, Richland, Washington, 1986-88

- Nuclear Criticality Safety Analysis, Oak Ridge K-25 Gaseous Diffusion Plant Decommissioning Project, 1987-89

- EDS SAR Review, Criticality Safety, Lawrence Livermore National Laboratory, 1988

EDUCATION: Ph.D., Chemical Engineering, Carnegie-Mellon University

M.S., Chemical Engineering, Montana State University

B.S., Chemical Engineering, Indiana Institute of Technology 
OTHER:

Fellow of American Nuclear Soctety

Professional Engineer, Nuclear Engineering, State of New Mexico 

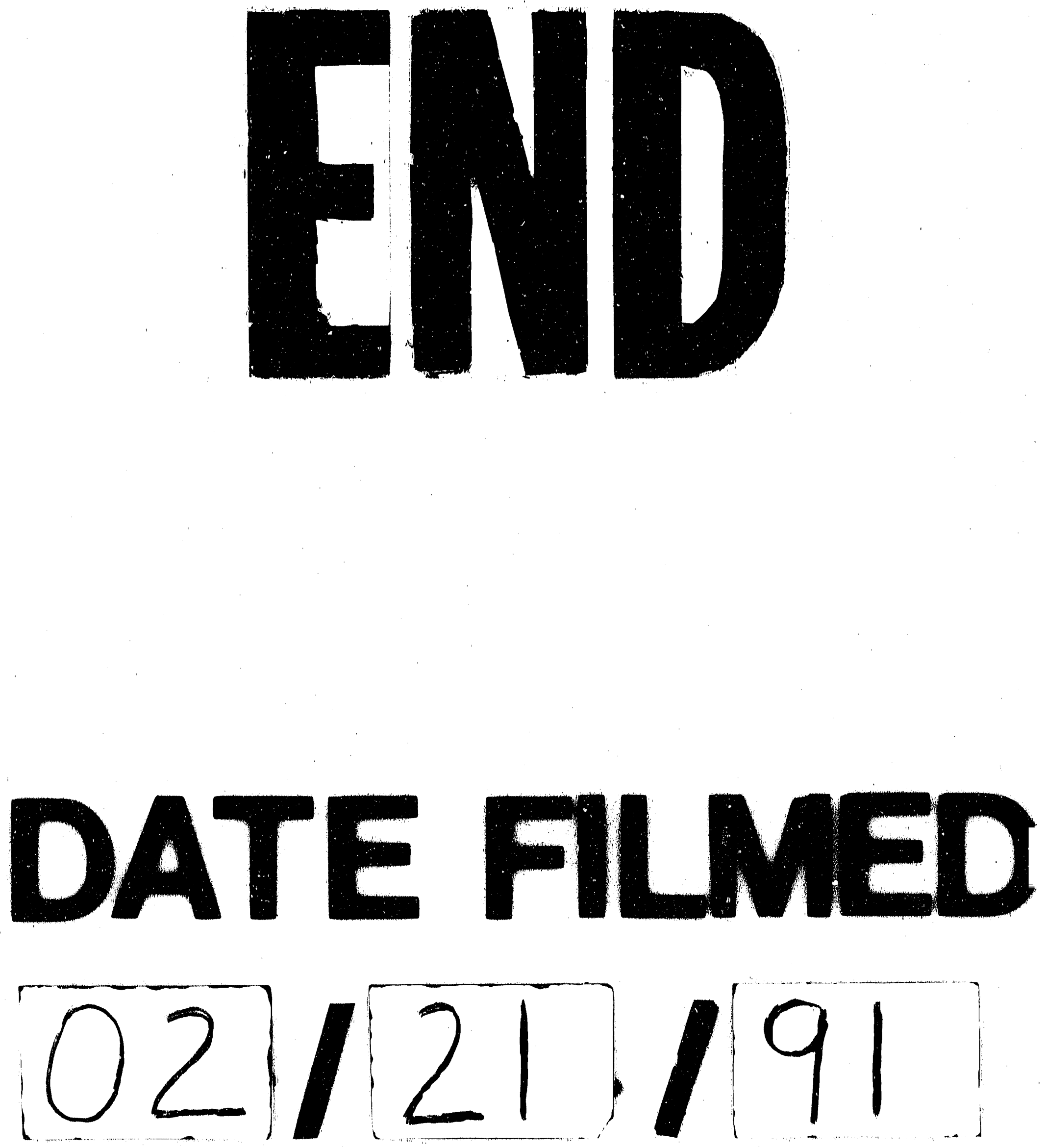
